Interação com Wikis por meio de

Mensageiros Instantâneos

Rafael Pereira dos Santos 


\title{
Interação com Wikis por meio de Mensageiros Instantâneos
}

\author{
Rafael Pereira dos Santos
}

Orientador: Profa. Dra. Renata Pontin de Mattos Fortes

Dissertação apresentada ao Instituto de Ciências Matemáticas e de Computação - ICMC/USP, como parte dos requisitos para obtenção do título de Mestre em Ciências de Computação e Matemática Computacional.

\author{
"VERSÃO REVISADA APÓS A DEFESA" \\ Data da Defesa: $\quad 19$ de Fevereiro de 2009 \\ Visto do Orientador:
}

USP - São Carlos

Fevereiro/2009 
"E conhecereis a verdade, e a verdade vos libertará" 
Dedicatória

Dedico esta dissertação à minha família e minha noiva 


\section{Agradecimentos}

Gostaria de agradecer primeiramente a minha orientadora Profa. Dra. Renata Pontin de Mattos Fortes, por sua dedicação e competência.

À minha família, que sempre me apoiou nos estudos e que possibilitou que eu conseguisse concluir mais essa etapa de minha caminhada acadêmica.

À minha lindinha, Sandra, por seu suporte e companheirismo durante boa parte de minha estadia em São Carlos e por ser tão especial na minha vida.

Aos companheiros da ABU São Carlos, eternos amigos.

À Capes, pelo auxílio financeiro.

E à Deus, em especial, por ser a base da minha vida e minha salvação. 
utilização da Internet cresceu amplamente nos últimos anos $A$ e tem propiciado o desenvolvimento de diversas ferramentas 1 de comunicação via web. Têm se destacado, de maneira especial, as ferramentas que possibilitam a disponibilização online de conteúdos diversos, criados pelos próprios usuários, como as wikis. O sucesso obtido pelas wikis deve-se, em grande parte, à pequena quantidade de esforço necessário para a edição das páginas, indicando que esta característica é muito apreciada pelos usuários. Visando tornar o processo de edição de wikis ainda mais ágil, este trabalho apresenta uma proposta de como os mensageiros instantâneos podem auxiliar nesta tarefa. Assim, uma nova nova forma de interação no processo de edição de wikis, por meio de Mensageiro Instantâneo, foi projetada e implementada. Essa forma de interação proposta altera a forma de interação com wikis convencional, no sentido de possibilitar que o autor do conteúdo a ser editado na wiki não necessite mudar de seu ambiente de comunicação, que atualmente tem sido muito utilizado, o de troca de mensagens por meio do mensageiro instantâneo. Além disso, esta pesquisa possibilitou a identificação de diversas vantagens e desvantagens da utilização de bots de mensageiros instantâneos, encontradas na literatura, bem como durante os experimentos e estudos de caso realizados. 
7 he Internet usage has grown significantly in recent years and has fomented the development of several communication tools via web. Tools that make available the various online contents created by the users, such as wikis should be especially highlighted. The success achieved by wikis is due in large extent to the small amount of effort required to edit pages. This is an indicator that this feature is very appreciated by users. In order to make the editing process of wikis even faster, this work presents a proposal of using integrated Instant Messaging tools features with wikis. Thus, a new means of interaction in the process of editing in wikis, via Instant Messenger, was designed and implemented. This proposed means of interaction augments the way of interaction with conventional wikis, by enabling authors to edit the wiki content without having to shift from his/her communication environment in use. This proposal is supported by the fact that Instant Messaging systems have been widely used and adopted. Moreover, this research provides evidences to help the identification of advantages and disadvantages of the use of bots in Instant Messaging, from the results of the experiments and case studies conducted. 
Abstract $\quad$ i

1 Introdução 1

1.1 Objetivo . . . . . . . . . . . . . . . . . . 2

1.2 Metodologia . . . . . . . . . . . . . . . . . 2

1.3 Organização do Trabalho . . . . . . . . . . . . . . . . . . . . . . 3

2 Sobre Wikis 5

2.1 Considerações Iniciais . . . . . . . . . . . . . . . . . . . . . . . . . . 5

2.2 Evolução das formas de publicação na web . . . . . . . . . . . . . . . . 5

2.3 Definições de wikis . . . . . . . . . . . . . . . . . . . . . . 8

2.4 Vantagens e Dificuldades em wikis . . . . . . . . . . . . . . . . . 10

2.5 Recursos presentes em wikis . . . . . . . . . . . . . . . . 13

2.6 Perfis de usuários de wikis . . . . . . . . . . . . . . . . . . . . 14

2.7 Usos de wikis . . . . . . . . . . . . . . . . . . . . . . . . . . 15

2.8 Considerações Finais ～. . . . . . . . . . . . . . . . . . . . . . . . . 19

3 Sobre Mensageiros Instantâneos $\quad 21$

3.1 Considerações Iniciais . . . . . . . . . . . . . . . . . . . . . . . . . 21

3.2 Mensageiros Instantâneos . . . . . . . . . . . . . . . . . . . 21

3.3 Bots . . . . . . . . . . . . . . . . . . 25

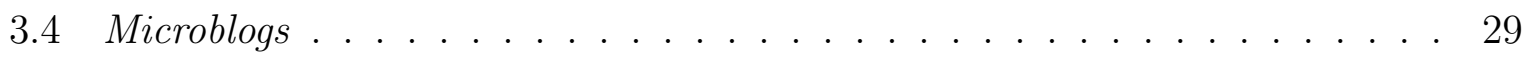

3.5 Considerações Finais . . . . . . . . . . . . . . . . . . . . 30

4 Um Sistema Interativo com wikis via Bots 33

4.1 Considerações Iniciais . . . . . . . . . . . . . . . . . . . . . . . . . . . . 33

4.2 Gerenciador de Bots . . . . . . . . . . . . . . . . . . 34

4.3 O Bot assistente.universal . . . . . . . . . . . . . . . . . 35

4.4 O Bot publicar.noticia . . . . . . . . . . . . . . . 37

4.5 O Bot robotwiki . . . . . . . . . . . . . . . . . . . 39

4.6 Considerações Finais . . . . . . . . . . . . . . . . . . . . . . . . . 42 
5 Avaliação dos Bots para Mensageiros Instantâneos $\quad 45$

5.1 Considerações Iniciais . . . . . . . . . . . . . . . . . . . . . . . . . . . . . . . . . . . . . . . . 45

5.2 Avaliação do Bot assistente.universal . . . . . . . . . . . . . . . 45

5.2.1 Avaliação por Questionário . . . . . . . . . . . . . . . . . 48

5.2.2 Avaliação por Estudo de Caso . . . . . . . . . . . . . . . . . . 50

5.3 Estudo de caso: Bot publicar.noticia . . . . . . . . . . . . . . . 54

5.4 Estudo de caso: Bot robot.wiki . . . . . . . . . . . . . . 56

5.5 Considerações Finais . . . . . . . . . . . . . . . . . . . . . . . . 59

6 Conclusões $\quad 65$

$\begin{array}{ll}\text { Referências } & 69\end{array}$

$\begin{array}{ll}\text { Apêndices } & 77\end{array}$

$\begin{array}{ll}\text { A Ferramentas de Publicação na Web: um estudo de caso } & 77\end{array}$

B Proposta de Taxonomia para Ferramentas de Comunicação na Web 83 


\section{Lista de Figuras}

2.1 Evolução das ferramentas de publicação na web . . . . . . . . . . . . . 6

3.1 Screenshot de um MI utilizando dois bots . . . . . . . . . . . . 26

4.1 Diagrama de atividades do gerenciador de bots . . . . . . . . . . . . 34

4.2 Diagrama de casos de uso do bot assistente.universal . . . . . . . . . . 36

4.3 Screenshot de utilização do bot assistente.universal . . . . . . . . . . . 36

4.4 Diagrama de atividades do bot assistente.universal . . . . . . . . . . . . . . 37

4.5 Diagrama de casos de uso do bot publicar.noticia . . . . . . . . . . . . 38

4.6 Diagrama de atividades do bot publicar.noticia . . . . . . . . . . . . . 39

4.7 Screenshots de utilização do bot publicar.noticia . . . . . . . . . . . . . 40

4.8 Diagrama de casos de uso do bot robot.wiki . . . . . . . . . . . . . . . . . . 40

4.9 Diagrama de atividades do bot robot.wiki . . . . . . . . . . . . . . . . 42

4.10 Screenshots de utilização do bot robot.wiki (I) . . . . . . . . . . . . . . 42

4.11 Screenshots de utilização do bot robot.wiki (II) . . . . . . . . . . . . . . 43

5.1 Concentração mensagens/usuário do bot assistente.universal . . . . . . . . 46

5.2 Clientes utilizados no acesso e interação com o bot assistente.universal . . . 47

5.3 Tipos de mensagens enviadas ao bot assistente.universal . . . . . . . . . . 47

5.4 Quantidade de tipos mensageiros utilizados por pessoa . . . . . . . . . 49

5.5 Quantidade estimada de buscas por dia . . . . . . . . . . . . . 52

5.6 Histograma Comparativo do Tempo de Busca . . . . . . . . . . . . . . . . 52

5.7 Relação entre experiência do usuário e tempo de busca . . . . . . . . . . . 54

5.8 Concentração mensagens/usuário do bot publicar.noticia . . . . . . . . . . 55

5.9 Tipos de mensagens enviadas ao bot publicar.noticia . . . . . . . . . . 55

5.10 Histograma de freqüência das postagens no bot publicar.noticia . . . . . . . 56

5.11 Concentração mensagens/usuário do bot robot.wiki . . . . . . . . . . . . 57

5.12 Clientes utilizados no bot robot.wiki . . . . . . . . . . . . . . 57

5.13 Tipos de mensagens enviadas ao bot robot.wiki . . . . . . . . . . 58

5.14 Histograma de freqüência das postagens no bot robot.wiki . . . . . . . . . 58

5.15 Tipos de comandos enviados ao bot robot.wiki . . . . . . . . . . . . . 59

A.1 Buscas pelo termos Internet ou web . . . . . . . . . . . . . 78

A.2 Popularidade das wikis . . . . . . . . . . . . . . . . . . 78 
A.3 Popularidade dos blogs . . . . . . . . . . . . . . . . . . . . . 79

A.4 Popularidade dos fotologs . . . . . . . . . . . . . . . . . . . . 79

A.5 Popularidade dos vlogs . . . . . . . . . . . . . . . . . . . 80

A.6 Popularidade dos podcasts . . . . . . . . . . . . . . . . . . 80

A.7 Comparação das cinco ferramentas analisadas . . . . . . . . . . . . . . 81

B.1 Taxonomia definida . . . . . . . . . . . . . . . . . . . . . 90 


\section{Lista de Tabelas}

2.1 Quantidade de artigos nas dez maiores Wikipédias - Dados obtidos em $25 / 01 / 2008 \ldots \ldots \ldots \ldots \ldots \ldots$

3.1 Proposta de classificação de bots para MIs . . . . . . . . . . . . . . . 27

B.1 Atributos da taxonomia de Long e Baecker . . . . . . . . . . . . . . . 85

B.2 Atributos da taxonomia de Wams e van Steen . . . . . . . . . . . . . 85

B.3 Atributos da taxonomia de Murnam . . . . . . . . . . . . . . . . . . 86

B.4 Atributos da taxonomia proposta . . . . . . . . . . . . . . 87

B.5 Origem dos atributos . . . . . . . . . . . . . . . . . 88 
A popularização dos computadores pessoais e das redes de computadores permitiu que a Internet ultrapassasse as barreiras das instituições acadêmicas e militares, e se expandisse para milhões de usuários domésticos, de forma globalizada. Durante os últimos anos, em especial, tem havido grande interesse por ferramentas nas quais usuários adicionam o conteúdo, isto é, o material disponibilizado nas páginas web é criado pelos próprios usuários e não por terceiros, como provedores de conteúdo. Como exemplos recentes de destaque temos o YouTube ${ }^{1}$, serviço de disponibilização de vídeos pela web, e a Wikipédia ${ }^{2}$, uma enciclopédia online mantida pelos próprios leitores, por meio de uma wiki.

As wikis são páginas web que podem ser editadas via browser por qualquer usuário que acesse a página [Leuf and Cunningham, 2001][Ebersbach et al., 2005], e têm obtido sucesso justamente por possibilitarem a concretização desse conceito. Observa-se que a agilidade no processo de edição é uma característica fundamental para que a colaboração em wikis ocorra de forma satisfatória, pois assim os usuários sentem-se motivados a participar.

Torna-se relevante, então, investigar aperfeiçoamentos sobre o modelo de interação existente, para que a utilização de wikis se torne cada vez mais ágil, auxiliando os usuários no processo de colaboração através de ferramentas web.

\footnotetext{
${ }^{1}$ http://www.youtube.com - último acesso em 31/07/2008

${ }^{2} \mathrm{http}: / /$ pt.wikipedia.org - último acesso em 31/07/2008
} 


\subsection{Objetivo}

Neste trabalho, o objetivo foi investigar a forma de interação em wikis por meio de mensageiros instantâneos, motivado pela busca de um paradigma de interação que aumentasse ainda mais a agilidade durante a edição das páginas. Assim, foram estudados os fundamentos das ferramentas de comunicação na Internet, e foi projetado e implementado um sistema que combinou propriedades de duas ferramentas de comunicação distintas: mensageiros instantâneos (MI) e wikis.

\subsection{Metodologia}

Para alcançar o objetivo deste trabalho, descrito na seção anterior, foram consideradas as seguintes etapas, as quais representaram esforços de pesquisa com resultados parciais do trabalho realizado:

1. um levantamento sobre os tipos de ferramentas de comunicação pela web;

2. estudo sobre os fundamentos de wikis;

3. projeto e desenvolvimento de bots ${ }^{3}$ para mensageiros instantâneos;

4. avaliação da interação em wikis por meio de bots para mensageiros instantâneos.

Inicialmente, na fase exploratória desta pesquisa, foi realizada uma revisão sistemática visando obter informações mais precisas e indícios na literatura sobre os diversos tipos de ferramentas de comunicação pela web. Como os resultados da pesquisa na literatura não possibilitaram evidenciar tendências ou fundamentos consolidados sobre o assunto, decidiu-se por elaborar uma proposta mais atualizada para uma classificação (Apêndice B) para esses tipos de ferramentas, considerando-se os poucos trabalhos encontrados. Essa fase foi relevante pois permitiu que os critérios e características distintas dessas ferramentas fossem estudados de maneira que o estado da arte sobre os avanços na web foi se delineando. Como resultado, os Capítulos 2 e 3 resumem esses estudos.

Após obter definições objetivas sobre wikis e mensageiros instantâneos, foi realizado um estudo mais aprofundado sobre as wikis, para compreensão de suas principais características. Seguiu-se então a etapa de estudo sobre bots para mensageiros instantâneos, visando o projeto e a implementação dos mesmos. Esse sistema interativo de bots, como agentes nos mensageiros instantâneos, se constituiu uma prova de conceito da proposta

\footnotetext{
${ }^{3}$ Neste trabalho adotamos a seguinte definição para bot, que originariamente vem do termo "robot": qualquer aplicação computacional que possua uma forma de interação que imite a humana
} 
de interação pesquisada e possibilitou experimentos para uma avaliação da proposta em diferentes contextos de uso.

\subsection{Organização do Trabalho}

Esta dissertação está organizada da seguinte maneira: no Capítulo 2 é apresentado um estudo detalhado sobre wikis, realizado a partir da literatura disponível, além de serem descritas implementações de wikis. No Capítulo 3 encontram-se os conceitos sobre mensageiros instantâneos e Bots, que foram pesquisados visando sua contribuição para viabilizar a proposta desenvolvida. No Capítulo 4 é apresentada a proposta que foi desenvolvida neste trabalho, descrevendo atividades realizadas, o projeto concebido e as principais características dos Bots implementados. O Capítulo 5 apresenta uma avaliação da nova forma de interação proposta, e os três bots implementados. Finalmente, o Capítulo 6 discute as conclusões obtidas com este trabalho, e indica trabalhos futuros.

Constam ainda neste documento dois apêndices: A ("Ferramentas de Publicação na Web: um estudo de caso") e B ("Proposta de Atualização de Taxonomia para Ferramentas de Comunicação na Web"), que se constituem resultados parciais dos estudos realizados durante o desenvolvimento desta pesquisa de mestrado, e foram importantes marcos para a consolidação das atividades realizadas. 



\subsection{Considerações Iniciais}

Pelo fato deste trabalho ter como um dos seus objetivos estudar as formas de interação disponibilizadas em ferramentas web, este capítulo inicia descrevendo os trabalhos encontrados na literatura e apresenta uma breve comparação das formas de publicação na web, sugerindo uma classificação em três gerações. Em seguida, este capítulo apresenta os conceitos fundamentais que caracterizam as wikis, definições, recursos, usos, perfis de usuários, além de vantagens e dificuldades em wikis. São também destacados exemplos de implementações de wikis: a Mediawiki, a TWiki e a QwikWeb, que foi uma wiki estudada e se mostrou relevante para esta pesquisa, pois propõe uma forma não convencional de interação durante o processo de disponibilização de conteúdo e colaboração via web.

\subsection{Evolução das formas de publicação na web}

De maneira geral, observa-se na literatura que existem classes distintas de ferramentas que permitem a publicação na web; três categorias (as quais podem ser denominadas como "gerações") podem ser notadas, principalmente em função de suas características e como elas foram sendo incorporadas na evolução destas ferramentas, evidenciada ao longo do tempo. 
A Figura 2.1 exibe uma linha do tempo, contendo uma possível divisão dos tipos de ferramentas utilizadas para publicação de conteúdos na web em três gerações ${ }^{1}$. Atualmente, os avanços dessas ferramentas continuam, mas tem-se observado uma tendência maior na disseminação das ferramentas de terceira geração.

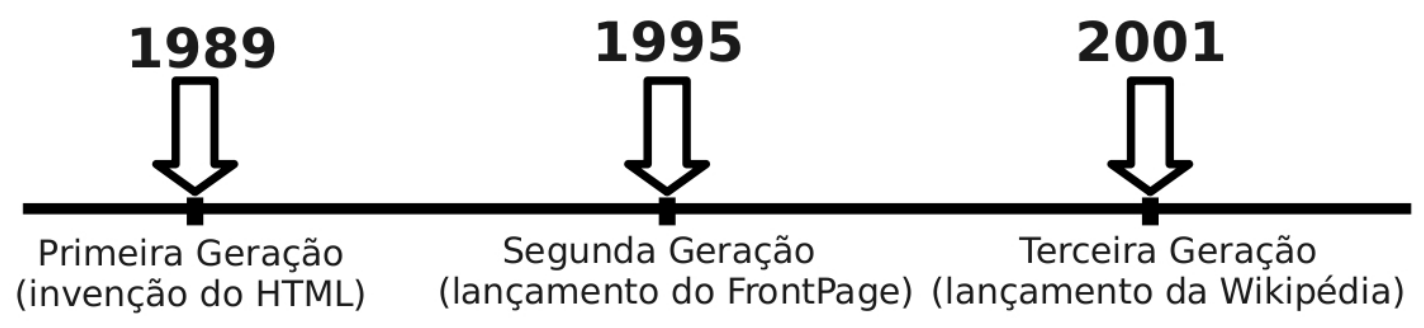

Figura 2.1: Evolução das ferramentas de publicação na web

Seguindo a proposta das gerações indicada na Figura 2.1, na primeira geração de ferramentas de publicação na web encontram-se os editores de texto simples, tais como: Vim $^{2}$, Kate $^{3}$ e Microsoft Notepad ${ }^{4}$. Em geral, são ferramentas básicas de edição, que permitem ao desenvolvedor adicionar código HTML em um arquivo texto, de maneira manual. Alguns desses editores, como Vim e Kate, possuem o recurso de highlight, cuja funcionalidade é destacar as tags HTML, colorindo o texto de acordo com sua sintaxe e contexto, facilitando assim a edição. Outro recurso interessante, também disponível em algumas dessas ferramentas, é a funcionalidade de "auto-completar", com a qual o sistema sugere ao usuário possíveis palavras para completar a tag ou atributo da tag que começou a ser digitado.

Essa primeira geração teve sua época de ampla utilização logo após a invenção do HTML (Hypertext Markup Language), por Timothy Berners-Lee em 1989 [Berners-Lee, 1989], [Berners-Lee and Cailliau, 1990]. Esse conjunto de ferramentas é utilizado até hoje por muitos desenvolvedores experientes que buscam simplicidade, porque permitem que se vá ao nível mais "baixo" de edição do hipertexto, mesmo usando uma ferramenta enxuta, como um simples editor de texto. Entretanto, para que o conteúdo dos arquivos editados seja apresentado nos browsers, requer a tarefa de que seja realizado upload dos arquivos a serem disponibilizados para o servidor, já que a edição é geralmente feita na máquina cliente.

A segunda geração de ferramentas de publicação na web surgiu devido à rápida expansão do número de usuários e de conteúdo na web, que gerou uma crescente demanda

\footnotetext{
${ }^{1}$ Embora a primeira wiki tenha surgido em 1995, elas começam a se popularizar globalmente somente após a criação da Nupedia (2000) e de sua sucessora, a Wikipédia (2001).

${ }^{2}$ http://www.vim.org - último acesso em 31/07/2008

${ }^{3}$ http://www.kate-editor.org - último acesso em 31/07/2008

${ }^{4}$ http://www.microsoft.com- último acesso em 31/07/2008
} 
pela construção de páginas hipertexto. O aumento da demanda, tanto por qualidade de design quanto por quantidade de páginas, impulsionou as grandes empresas de desenvolvimento de software a criar ferramentas para facilitar o desenvolvimento de páginas para web. Essas ferramentas, tais como: Microsoft FrontPage ${ }^{5}$ e Macromedia Dreamweaver ${ }^{6}$, propiciam transparência durante a criação de hipertextos, pois a interface é centrada no que ficará visível da página após ser publicada e não nas tags, que tornam-se invisíveis quando interpretadas pelo browser. Isso permite que desenvolvedores de nível intermediário ou até mesmo básico criem páginas para a web, mais facilmente, suprindo assim a demanda por criação de páginas existente no mercado. Vale observar que desenvolvedores mais experientes também utilizam ferramentas dessa geração, pois facilitam a criação do layout, além de, geralmente, possuírem uma interface paralela para a edição direta do código HTML, contendo todas as funcionalidades dos softwares da primeira geração.

Além disso, essas ferramentas da segunda geração tendem a ser WYSIWYG - What You See Is What You Get -, isto é, além de possuírem uma interface gráfica transparente para a edição do layout, procuram representar como a página será publicada, não havendo, portanto, a necessidade do desenvolvedor utilizar um software externo para visualização. A primeira ferramenta dessa categoria surgiu em 1995, quando a Microsoft comprou a empresa Vermeer Technologies ${ }^{7}$, que estava desenvolvendo o FrontPage. Atualmente, as ferramentas da segunda geração são amplamente usadas para o desenvolvimento de páginas web. Entretanto, assim como nas ferramentas de primeira geração, é necessário que o arquivo editado seja enviado para o servidor, para que seja possível sua publicação e visualização pelo browser nas máquinas clientes.

Finalmente, identificamos uma terceira geração de ferramentas de publicação na web: as ferramentas que são construídas sobre a própria web, ou seja, o software de edição também é uma página de Internet e por isso pode ser acessado via browser. Diferentemente das ferramentas de primeira e segunda geração, nunca há a necessidade de se realizar o upload da página, já que esta certamente já se encontra no servidor e é disponibilizada na máquina cliente para edição. As primeiras ferramentas dessa categoria foram os CMS e as wikis, que embora tenham surgido em 1995, começaram a tornar-se populares apenas após 2001, devido a melhoria dos recursos suportados pelos browsers, como aumento da largura de banda e a própria expansão da Internet. Esse aumento de popularidade pode ser notado na ampla utilização de ferramentas dessa categoria, como é o caso da Wikipédia. CMS são sistemas web para gerenciamento de conteúdo, geralmente através

\footnotetext{
${ }^{5} \mathrm{http://www.microsoft.com/frontpage} \mathrm{-} \mathrm{último} \mathrm{acesso} \mathrm{em} \mathrm{31/07/2008}$

${ }^{6} \mathrm{http}: / /$ www.macromedia.com/software/dreamweaver - último acesso em 31/07/2008

${ }^{7} \mathrm{http}: / /$ www.microsoft.com/presspass/press/1996/jan96/vrmeerpr.mspx - último acesso em $31 / 07 / 2008$
} 
de um SGBD, mas de forma transparente ao usuário, permitindo assim edição de páginas, pela utilização de templates pré-definidos. Exemplos populares dessas ferramentas são: plone $^{8}$, postnuke $^{9}$, phpnuke ${ }^{10}$, xoops ${ }^{11}$ e mambo $^{12}$. Mais exemplos podem ser encontrados em cmsmatrix.org ${ }^{13}$ onde há mais de 500 CMS avaliados. Os conceitos de wikis são detalhados na Seção 2.3.

Os avanços das ferramentas de terceira geração em relação aos softwares de primeira e segunda geração podem ser resumidos a partir das seguintes características:

Mobilidade: como a ferramenta de publicação também é uma página web, ela pode ser acessada, teoricamente ${ }^{14}$, de qualquer lugar do mundo, desde que haja conexão com a Internet e um browser[Leuf and Cunningham, 2001, p. 10]. Assim, usuários podem editar as páginas que publicam, sem terem que se deslocar até um computador que possua determinada ferramenta para acesso à edição da página.

Praticidade: não é necessário copiar nem instalar software algum para realizar a edição de uma determinada página web, bastando apenas possuir um browser, pois os sistemas operacionais mais utilizados atualmente já os incluem em sua distribuição.

Facilidade de Colaboração: por serem ferramentas utilizadas remotamente e com recursos de browsers comumente disponíveis, proporcionam um incentivo para que mais pessoas contribuam na edição de uma determinada página.

Como a ferramenta wiki é objeto de investigação deste trabalho, nas próximas seções são apresentados os fundamentos e conceitos que foram estudados.

\subsection{Definições de wikis}

Recentemente, os usuários da Internet têm sido estimulados a maior participação, tornando-se responsáveis pelo conteúdo disponibilizado na web, passando de agentes passivos para agentes ativos [Millard and Ross, 2006]. Esse novo comportamento torna-se evidente ao analisarmos o crescimento da popularidade de ferramentas nas quais os usuários adicionam o conteúdo, via web, como as wikis, blogs, fotologs, vlogs e podcasts. No Apêndice

\footnotetext{
${ }^{8}$ http://plone.org/

${ }^{9}$ http://www.postnuke.com/

${ }^{10}$ http://phpnuke.org/

${ }^{11}$ http://www.xoops.org/

12 http://www.mamboserver.com/

${ }^{13}$ http://www.cmsmatrix.org

${ }^{14}$ Desde que não existam restrições legais, como por exemplo a censura à Wikipédia chinesa em Out $/ 2005$
} 
A essas ferramentas são descritas e são apresentadas informações que, a partir de um levantamento realizado em $2006^{15}$, indicam o aumento da popularidade dessas ferramentas, através de gráficos, além de uma breve descrição das mesmas. Observando-se as tendências de popularidade dessas ferramentas, tornou-se necessário um estudo detalhado sobre a origem das wikis e os conceitos que definem esse tipo de ferramenta, visando analisar como suas formas de interação e tecnologias relacionadas evoluíram.

O sistema HyperCard [Hannay, 1992], embora offline, pode ser considerado como o precursor das wikis, devido a facilidade de uso e a utilização de conceitos como links, âncoras e nós, fundamentais em qualquer documento hipertexto. Foi o primeiro sistema hipermídia de sucesso, lançado pela Apple em 1987, tendo inspirado grande parte da web. O HyperCard já teve diversos usos como: sistema criador de slides, interface para jogos, ferramenta educacional, catálogo musical e ferramenta de prototipação.

Ward Cunnigham criou a primeira wiki, a Portland Pattern Repository ${ }^{16}$, em 1995, devido à experiência positiva obtida no uso do HyperCard [Leuf and Cunningham, 2001, p. 15]. Cunnigham [Leuf and Cunningham, 2001, p. 14] cunhou o termo "WikiWikiWeb" para a primeira wiki, devido à agilidade alcançada com o novo método de publicação de conteúdo na web (a palavra havaiana "wikiwiki"significa "rápido"). O termo wiki, na verdade, acabou surgindo como uma abreviação posterior da palavra original.

A definição de Cunnigham [Leuf and Cunningham, 2001, p. 14], traduzida por este autor, sobre wikis é:

"Uma wiki é uma coleção livremente expansivel de páginas web interligadas, um sistema hipertexto para armazenar e modificar informação - uma base de dados, na qual cada página é facilmente editável por qualquer usuário com um browser que utilize formulários."

Outra definição para wiki, fornecida por Ebersbach et. al [Ebersbach et al., 2005, p. 10], é:

"[...] um software web que permite que todos aqueles que visualizem a página possam alterar o conteúdo através da edição da página online em um browser"

Assim, é possível notar três requisitos em comum nas definições de wikis citadas:

(1.) As wikis devem ser páginas web.

(2.) As wikis devem poder ser editadas em um browser.

\footnotetext{
${ }^{15}$ Este levantamento foi atualizado no início de 2009.

${ }^{16}$ http://www.c2.com/
} 
(3.) As wikis devem poder ser editadas por qualquer usuário que veja a wiki.

Mesmo que certas wikis possam ter seu acesso restrito a um determinado grupo, ainda assim permitem que todos os visualizadores da página possam alterá-la [Ebersbach et al., 2005, p. 11]. Vale ressaltar que exceções podem ocorrer, como nos casos de vandalismo, que tornam necessárias medidas restritivas em relação a quem pode alterar a página.

A criação de novas páginas em wikis é realizada de maneira quase transparente e trivial ("inocente", segundo [Silva, 2005, p. 6]). As wikis são hiperdocumentos e, como tal, são compostos por nós e ligações. Cada nó (página) é identificado unicamente por um nome (wikiword), utilizando uma sintaxe especial, usualmente a CamelCase ${ }^{17}$. O conteúdo de cada nó, então, passa a conter âncoras para outros nós, a cada vez que uma wikiword é encontrada. Caso o nó não exista, o link apontará para a página que permitirá a criação do novo nó.

Em relação à formatação dos textos escritos em wikis, é importante ressaltar que geralmente não é requerido do usuário conhecimentos sobre tags HTML, bastando apenas saber algumas sintaxes correspondentes, que podem variar conforme a wiki [Ebersbach et al., 2005, p.16]. Por exemplo:

- para escrever um texto em negrito, ao invés de usar $\langle\mathrm{b}\rangle$ texto $\langle/ \mathrm{b}\rangle$, usa-se, por exemplo: "'texto"' na MediaWiki e *texto* na Twiki

- para escrever um texto em itálico, usa-se "texto"na MediaWiki, e _texto_ na Twiki, ao invés de $<i>$ texto $</ i>$.

Finalmente, observa-se que existem iniciativas para a padronização da sintaxe de formatação em wikis, para que os conteúdos de uma wiki possam ser exportados para outra sem a necessidade do processamento de alterações ou transformações, visando compatibilidade [Jugel and Schmidt, 2006, p. 34].

Após apresentarmos os principais conceitos de wikis, listamos a seguir diversas vantagens e dificuldades das wikis, encontradas na literatura.

\subsection{Vantagens e Dificuldades em wikis}

Na Seção 2.2, consideramos as wikis como ferramentas de terceira geração, segundo a proposta de classificação/evolução das formas de publicação na web. Dessa forma, as wikis são ferramentas que apresentam todas as características citadas: mobilidade, praticidade e facilidade de colaboração.

\footnotetext{
${ }^{17}$ Palavras com as iniciais em maiúsculas, sem espaços separando-as
} 
Além dessas características, as wikis, especificamente, possuem vantagens adicionais por buscarem a simplicidade e permitirem a edição aberta ${ }^{18}$, que são resumidas a seguir:

- Simplicidade para edição: editar uma wiki não pode requerer conhecimentos técnicos avançados, pois são construídas justamente para que isso não seja um obstáculo à colaboração [Ebersbach et al., 2005, p.13]. Caso haja erro de digitação em uma página, por exemplo, o usuário pode acessar um link na própria página para editá-la, sem ter a necessidade de saber o nome daquele determinado arquivo ou entender de estrutura de diretórios do Sistema de Arquivos utilizado no Sistema Operacional da Máquina servidora.

- Conteúdo de fontes diversificadas: pelo fato das wikis possuírem edição aberta, mais usuários sentem-se encorajados a colaborar, e dessa forma, há a disponibilização de conteúdo por pessoas de diversas áreas e conhecimentos diversificados. Em outras palavras, usuários das mais variadas formações adicionam conteúdo, tenham ou não conhecimento técnico [Leuf and Cunningham, 2001, p. 15]. Garante-se assim, de certa forma, a criação de conteúdo de maneira menos tendenciosa.

- Uso democrático: as wikis, por possuírem edição aberta, são uma excelente forma de apoio à implantação e manutenção da democracia [Leuf and Cunningham, 2001, p. 15], já que, como visto no item anterior, as informações tendem a ser mais imparciais. Além disso, permite que minorias possam se expressar de maneira relativamente equivalente às outras classes sociais, como pode ser notado na Anarchopedia $^{19}$, que utiliza a MediaWiki para divulgação dos ideais anarquistas. Na WipiPedia ${ }^{20}$ usuários podem definir termos relacionados a determinadas práticas sexuais. Já na Wikocracy ${ }^{21}$ os usuários são encorajados a alterar a constituição e outros textos referentes à lei dos Estados Unidos, conforme desejarem.

Por outro lado, alguns autores [Lio et al., 2005, p. 95][Davies, 2004, p. 20-21] relataram problemas encontrados no uso de wikis, principalmente durante o período de implantação da ferramenta. As principais dificuldades relatadas se referem às seguintes questões:

- Idioma: as wikis que apresentam informações em inglês e não possuem suporte a outros idiomas podem causar problemas para determinados usuários. Vale notar que esse não é um problema específico de wikis, podendo ocorrer com qualquer

\footnotetext{
${ }^{18}$ Open Editing: permissão de alteração da página por qualquer usuário

${ }^{19}$ http://eng.anarchopedia.org

${ }^{20}$ http://www.londonfetishscene.com/wipi/index.php/Main_Page

${ }^{21}$ http://wikocracy.com
} 
software. O caso foi relatado por usuários italianos, durante o uso da TWiki em 2004 [Lio et al., 2005, p. 95].

- Sintaxe: embora elaborada para ser mais didática que o HTML, a formatação em wikis também constitui uma dificuldade para determinados usuários, que não querem aprender mais uma sintaxe de formatação. Além disso, há sempre o risco de um texto ser formatado sem que o usuário deseje, por desconhecer os padrões utilizados e utilizá-los por outro motivo.

- Edição Aberta: diversos problemas foram encontrados em relação ao conceito de edição aberta e que, possivelmente, variam bastante dependendo do ambiente, isto é, o contexto cultural no qual a wiki é usada. A seguir, são descritos sentimentos negativos que determinados usuários podem desenvolver ao utilizarem uma ferramenta com edição aberta:

- Frustração por ter seu "próprio trabalho" alterado por outras pessoas. Neste caso, o usuário não entende que sua contribuição não apenas pode, mas deve ser alterada para que a qualidade do texto aumente.

- Hesitação em alterar o trabalho de outros por medo de ofender. Há relatos de que alguns usuários até enviam emails para seus superiores pedindo permissão para realizar as mudanças.

- Receio de ter seu trabalho criticado. Alguns autores apresentam auto-crítica elevada e acabam por manifestar medo de expor suas idéias ou conhecimentos para o público geral e receberem críticas para as quais não estão preparados.

- Relutância em desistir da autoria do trabalho. Muitos usuários inclusive adicionam sua assinatura no trecho escrito.

- Medo de vandalismos. Cabe ressaltar que este receio pode ser reduzido se o usuário conhecer os mecanismos de recuperação contra perdas existentes.

- Medo de se envolver em uma edit war ${ }^{22}$. Alguns autores se sentem provocados e começam a sistematicamente criar ciclos de edição 'faz-e-desfaz' com freqüência periódica.

Mesmo diante dessas dificuldades e, de certa forma desvantagens para uso das wikis, observa-se que as wikis se mostram como tecnologia promissora por atrair cada vez mais a interação dos usuários com a web. São ferramentas que priorizam a diversidade na criação de conteúdos, por usuários distintos, e propiciam recursos que estimulam a participação

\footnotetext{
${ }^{22}$ Em português, Guerra de Edição. Ocorre quando dois ou mais usuários revertem as edições de outro usuário, de forma sistemática. Fonte: http://en.wikipedia.org/wiki/Wikipedia:Edit_war
} 
ativa dos leitores e consumidores das informações. A seguir, são discutidos os recursos que comumente estão presentes como funcionalidades das wikis.

\subsection{Recursos presentes em wikis}

Para que uma wiki obtenha sucesso, isto é, seja fácil, rápida e a edição aberta possa ser bem conduzida, é necessário que determinadas características estejam presentes na implementação da wiki e que determinados conceitos estejam consolidados para sua adoção pelos usuários.

Assim, para uma wiki qualquer obter sucesso, segundo [Ebersbach et al., 2005, p. 19], as seguintes características devem estar presentes na sua implementação:

Edição: a grande maioria das páginas, senão todas, deve possuir de forma explícita a funcionalidade de edição. Dessa forma, o tempo investido para iniciar a tarefa torna-se bastante reduzido.

Links: como citado anteriormente, a criação das ligações entre os nós deve ser simplificada ao extremo. Pelo uso de CamelCase ou sintaxe semelhante, por exemplo, podem ser criadas novas páginas já linkadas à página original existente.

Histórico: sendo muito fácil alterar o conteúdo das páginas, é necessário que haja um histórico que armazene as últimas versões destas, para que possíveis vandalismos e outros problemas ligados à edição possam ser desfeitos rapidamente.

Últimas Modificações: também pelo motivo da edição aberta, é aconselhável que as wikis possuam uma página que armazene as últimas modificações realizadas, para que usuários possam verificar as novas contribuições dadas por outras pessoas. Uma watchlist, isto é, uma lista de quais páginas o usuário gostaria de observar, melhora ainda mais o acompanhamento das edições realizadas, pois contém apenas as páginas de interesse do usuário.

Página de Testes: ${ }^{23}$ para que usuários novatos, ou até mesmo experientes, possam aprender como as wikis funcionam ou testar novos recursos, deve ser disponibilizada uma página de testes. Também pode ser utilizada como ponto de partida para a criação de outras páginas, através do apontamento de links, já que, como visto, a citação da página sempre precede a criação da mesma.

\footnotetext{
${ }^{23}$ Em inglês é conhecida como SandBox ou PlayGround
} 
Funções de busca: para que as páginas possam ser acessadas rapidamente, é essencial que haja algum tipo de ferramenta de busca existente, principalmente nas wikis com muitas páginas armazenadas.

Para que realmente haja colaboração em wikis é necessário que exista um senso de comunidade online, e não apenas a implementação da ferramenta [Davies, 2004, p. 65-66]. Para tal, três conceitos-chave devem ser associados pelos usuários:

- Entendimento: para que a wiki obtenha sucesso, é necessário que os usuários entendam os aspectos sociais e técnicos relacionados com essa forma de colaboração, principalmente o conceito de autoria coletiva.

- Confiança: os usuários devem confiar na tecnologia, nos conteúdos disponibilizados nas wikis, na comunidade online e crer que a idéia como um todo dará certo.

- Valor: principalmente no uso corporativo, é necessário que os usuários percebam benefícios pessoais na utilização da wiki. Caso sintam-se apenas "tendo mais trabalho" durante o expediente, não irão valorizar a ferramenta e haverá grandes chances da implantação fracassar.

Pelo fato desta pesquisa estar envolvida com o desenvolvimento de wikis, é importante salientar o estudo sobre quais recursos devem estar presentes em uma wiki. Também é relevante obter indícios dos tipos de usuários que irão interagir com a wiki, pois isso poderá afetar a forma de sua implementação. Uma relação de perfis de usuários é apresentada a seguir.

\subsection{Perfis de usuários de wikis}

Segundo Jimmy Wales ${ }^{24}$ apud [Ebersbach et al., 2005, p. 25], fundador da Wikipédia, existem pelo menos seis perfis de usuários em wikis, que estão listados a seguir.

- Abelhas Operárias ${ }^{25}$ : usuários que colaboram criando diversos artigos para a wiki, seja por especialistas, seja por alguém com conhecimento mais genérico. São fundamentais para o sucesso da wiki, pois são responsáveis pela maioria do conhecimento adicionado.

- Marionetes ${ }^{26}$ : usuários que publicam informação utilizando mais de uma conta, para obter privacidade. Por exemplo: um professor pode, dessa forma, colaborar

\footnotetext{
${ }^{24}$ Também conhecido como Jimbo Wales

${ }^{25}$ Em inglês apenas bees

${ }^{26}$ Em inglês sock puppets
} 
com artigos "de respeito"e com a outra conta, a "conta marionete", adicionar contribuições em artigos que possam vir a manchar sua reputação. O uso de mais de uma conta também é utilizado por usuários que desejam manipular votações, visando obter mais votos.

- Juízes: usuários que preferem interagir no ambiente da wiki buscando a resolução de conflitos, sendo muito ativos em comitês e na proposta de votações.

- Encrenqueiros ${ }^{27}$ : usuários que buscam conflitos, gostam de discussões e envolvem-se frequentemente em flame wars $^{28}$.

- Vândalos: são um problema frequente devido à edição aberta, destruindo conteúdo segundo suas próprias vontades. Entretanto, em wikis com grande número de acessos esse problema tende a ser reduzido, pois outros usuários desfazem a edição inapropriada. Segundo estudo realizado pela IBM em 2004 [Viégas et al., 2004, p. 579], tentativas de vandalismo na Wikipédia são eliminadas em apenas três minutos (no caso de remoção completa do conteúdo do artigo); esse tempo cai para aproximadamente dois minutos se a página conter palavras obscenas ${ }^{29}$.

- Pessoas marginais à wiki: pessoas que continuam a desenvolver as wikis, como analistas ou programadores. Embora não estejam envolvidas diretamente com a colaboração de conteúdo, esses usuários acompanham a evolução do conteúdo e fazem eventuais intervenções técnicas quando necessário.

Apesar de não existirem trabalhos científicos que reportem quantificações desses tipos de usuários, é importante ter ciência de que, para novos desenvolvimentos de wikis, deve-se levar em conta possíveis funcionalidades que tratam as ações e intenções desses potenciais usuários.

Diante da abrangência de usos, a seguir são descritos exemplos encontrados na literatura, de utilização de wikis, bem como algumas implementações que foram importantes por direcionarem um referencial considerado na proposta desta pesquisa de mestrado.

\subsection{Usos de wikis}

Conforme Cunnigham [Leuf and Cunningham, 2001, p. 8,9], as wikis têm tido diversos usos, como: organização de informações pessoais; uso temporário em projetos específicos,

\footnotetext{
${ }^{27}$ Em inglês moths, mariposas

${ }^{28}$ Discussão acalorada entre participantes, com o uso de ataques pessoais e até palavrões.

${ }^{29}$ A palavra utilizada pelos pesquisadores da IBM, como exemplo de obscenidade foi fuck, por ter, segundo eles, uso desproporcional nos atos de vandalismo.
} 
como eventos; uso em grupos de interesse, isto é, discussões e colaborações em torno de um tema específico; uso acadêmico, como forma de complementar as aulas ou como apoio à projetos; uso corporativo, no qual empresas podem planejar, executar, documentar e acompanhar projetos.

Nesse último caso, as ferramentas convencionais de groupware têm sido substituídas por wikis, por estas serem mais amigáveis, tendo empresas como SAP, Motorola e British Telecommunications adotado essa nova abordagem [Ebersbach et al., 2005, p.11]. Além de serem mais amigáveis, as wikis custam menos, pois outras soluções, como Lotus Notes ${ }^{30}$ ou Microsoft Outlook ${ }^{31}$, requerem investimentos significativos em software, talvez em hardware e principalmente em treinamento de como utilizar as ferramentas [Leuf and Cunningham, 2001, p. 12]. Conforme pesquisa realizada [Majchrzak et al., 2006, p. 101], na qual foram entrevistados 168 usuários de wikis empresariais, há três benefícios principais no uso corporativo: trabalho realizado mais facilmente, maior organização dos processos da empresa e melhoria da reputação pessoal. O trabalho é realizado mais facilmente porque o conhecimento do funcionário está sempre mantido atualizado e pode ser facilmente recuperado e difundido. A maior organização dos processos ocorre pois a colaboração é incentivada, aumentando o reuso. A melhoria da reputação ocorre pois o funcionário que publica conteúdo na wiki da empresa ganha respeito de seus colegas de trabalho, aumentando seu status profissional e assim, sua reputação na companhia. Vale notar que a melhoria de reputação não foi confirmada pela grande maioria dos entrevistados, como foi nos itens anteriores.

Diversos projetos importantes de software livre têm adotado wikis, como $\mathrm{KDE}^{32}$ (K Desktop Environment), através da TikiWiki ${ }^{33}$ e GCC $^{34}$ (GNU Compiler Collection), utilizando a MoinMoinWiki ${ }^{35}$.

Com relação as implementações de wikis, podem ser citadas a MediaWiki, Twiki e a QwikWeb, que são detalhadas a seguir.

\section{MediaWiki e Wikipédia}

A expansão da utilização das wikis deve-se, sem dúvida, ao sucesso obtido pela Wikipédia, que após sete anos de existência, contabilizava em $2008^{36}$ aproximadamente 9,5 milhões de artigos, em 256 idiomas. A Tabela 2.1 contém o número de artigos existentes nas 10 maiores Wikipédias. Apenas para efeito comparativo, sabe-se que a Enciclopédia Britâ-

\footnotetext{
${ }^{30} \mathrm{http}: / /$ www-142.ibm.com/software/sw-lotus/products/product4.nsf/wdocs/noteshomepage

${ }^{31}$ http://office.microsoft.com/en-us/outlook/default.aspx

${ }^{32}$ http://wiki.kde.org

${ }^{33}$ http://tikiwiki.org

${ }^{34}$ http://gcc.gnu.org/wiki

${ }^{35}$ http://moinmoin.wikiwikiweb.de

${ }^{36}$ Fonte: http://meta.wikimedia.org/wiki/List_of_Wikipedias. Último acesso em 25/01/2008
} 


\begin{tabular}{|c|c|c|}
\hline \multicolumn{3}{|c|}{ Dez maiores Wikipédias } \\
\hline Posição & Idioma & Artigos \\
\hline 1 & Inglês & 2.188 .439 \\
\hline 2 & Alemão & 697.077 \\
\hline 3 & Francês & 611.962 \\
\hline 4 & Polonês & 463.141 \\
\hline 5 & Japonês & 460.113 \\
\hline 6 & Holandês & 402.237 \\
\hline 7 & Italiano & 400.643 \\
\hline 8 & Português & 355.344 \\
\hline 9 & Espanhol & 324.653 \\
\hline 10 & Sueco & 270.927 \\
\hline TOTAL & & 6.174 .536 \\
\hline
\end{tabular}

Tabela 2.1: Quantidade de artigos nas dez maiores Wikipédias - Dados obtidos em $25 / 01 / 2008$

nica possui 65 mil $\operatorname{artigos}^{37}$, contra aproximadamente 2,2 milhões da edição em inglês da Wikipédia. Vale notar que o tamanho e a confiabilidade dos artigos da wikipédia é objeto de discussão [Giles, 2005]. Embora a edição aberta permita vandalismos e a publicação de dados incorretos, a grande quantidade de usuários que revisam os artigos termina por torná-los confiáveis [Voss, 2005]. Uma métrica que pode ser utilizada para a determinação da qualidade de um artigo, ainda que de forma aproximada, é o número de edições que uma página recebeu ou o número de editores envolvidos [Lih, 2004]. Algumas iniciativas têm surgido visando construir uma enciclopédia semelhante à Wikipédia, mas que bloqueie a edição anônima e que cada artigo deva ser aprovado antes de ser publicado, buscando maior confiabilidade, como é o caso da Citizendium ${ }^{38}$ e da Scholarpedia ${ }^{39}$.

A Wikipédia utiliza como engine a MediaWiki ${ }^{40}$, um software livre que roda conforme o modelo cliente-servidor, através de páginas web dinâmicas, e tem como requisitos: um servidor web $\left(\right.$ Apache $e^{41}$ ou $\left.I I S^{42}\right)$ que interprete a linguagem $P H P^{43}$ e que comunique-se com um SGBD (MySQL $L^{44}$ ou PostgreSQL $\left.L^{45}\right)$.

A fundação Wikimedia ${ }^{46}$ é a organização responsável pela Wikipédia e seus projetos irmãos, que seguem listados a seguir:

\footnotetext{
${ }^{37}$ http://www.britannica.com. Último acesso em jan/07

${ }^{38}$ http://www.citizendium.org

${ }^{39}$ http://www.scholarpedia.org

${ }^{40}$ http://www.mediawiki.org

${ }^{41}$ http://httpd.apache.org

${ }^{42}$ http://www.microsoft.com/iis

${ }^{43}$ http://www.php.net

${ }^{44}$ http://www.mysql.org

${ }^{45}$ http://www.postgresql.org

${ }^{46}$ http://www.wikimedia.org
} 
- Wiktionary ${ }^{47}$ : visa a produção de um dicionário poliglota livre, com significados, etimologias e pronúncia.

- Wikiquote ${ }^{48}$ : objetiva a criação de um agrupamento de provérbios e citações de diversas personalidades.

- Wikibooks ${ }^{49}$ : visa o desenvolvimento e a livre disseminação de livros de conteúdo aberto.

- Wikisource ${ }^{50}$ : agrupamento de textos fiéis ao original, isto é, que não devem ser alterados pelos usuários, exceto para a correção de erros. Como exemplo do conteúdo disponibilizado, temos: hinos, poesias e diversos livros que podem ser copiados livremente.

- Wikinews ${ }^{51}$ : sistema de divulgação de notícias criadas pelos próprios leitores.

- Wikimedia Commons ${ }^{52}$ : coletânea de imagens, áudios e vídeos que podem ser utilizados de acordo com as licenças Creative Commons ${ }^{53}$.

- Wikispecies ${ }^{54}$ : organiza as formas de vida existentes de acordo com os padrões adotados na biologia, de forma taxonômica.

- Wikiversity ${ }^{55}$ : uma comunidade para a criação e uso de material relacionado a atividades de ensino, aprendizagem e pesquisa. Contém diversos cursos e disciplinas oferecidas.

\section{TWiki}

Desenvolvida desde 1998, a TWiki ${ }^{56}$ é uma wiki de grande destaque [Ebersbach et al., 2005, p. 147]. Foi criada para ser uma ferramenta corporativa da empresa TakeFive, por Peter Thoeny [Leuf and Cunningham, 2001, p. 374], mas atualmente é empregada em diversos lugares $^{57}$, como a Disney, Novel, Motorola, SAP, Texas Instrument e Yahoo. A TWiki é considerada uma excelente ferramenta para a documentação de projetos e a criação de artigos científicos [Raygan and Green, 2002, p. 141].

\footnotetext{
${ }^{47}$ http://www.wiktionary.org

${ }^{48}$ http://www.wikiquote.org

${ }^{49}$ http://wikibooks.org

${ }^{50}$ http://wikisource.org

${ }^{51}$ http://www.wikinews.org

${ }^{52}$ http://commons.wikimedia.org

${ }^{53}$ Os seis tipos de licença da versão 2.5 podem ser encontrados em http://creativecommons.org/licenses

${ }^{54}$ http://species.wikimedia.org

${ }^{55} \mathrm{http}: / /$ www.wikiversity.org

${ }^{56}$ http://twiki.org

${ }^{57}$ Fonte: http://twiki.org/cgi-bin/view/Main/TWikiSuccessStories
} 
Em relação à implementação, é importante ressaltar que a TWiki utiliza arquivos texto para armazenar as páginas, ao invés de um SGBD, que é o caso da MediaWiki [Ebersbach et al., 2005, p. 147]. Apesar da maior facilidade de instalação obtida, o uso de arquivos texto pode prejudicar operações de busca e armazenamento [Leuf and Cunningham, 2001, p. 22]. Outra diferença entre as duas implementações é a utilização da linguagem Perl ${ }^{58}$, ao invés da PHP.

\section{QwikWeb}

O trabalho de Eto et al. [Eto et al., 2005] estudou a combinação entre wikis e listas de email. O sistema desenvolvido, denominado QwikWeb, permite a edição de emails que já foram enviados, como se fossem wikis convencionais. Dessa forma, um usuário pode acessar uma determinada página web e alterar alguma informação incorreta que porventura tenha enviado por email para a lista de discussão. Além da interação entre wikis e listas de discussão, o sistema também pode utilizar emails como forma de comunicação usuário-computador, ou seja, as mensagens podem ter como destinatário final um software ao invés de uma pessoa. Nesse caso, os emails são enviados para gerenciar as listas de discussão, através das operações de criação de listas e adição ou remoção de usuários.

\subsection{Considerações Finais}

Como visto neste capítulo, uma wiki é qualquer ferramenta que possua as seguintes características: seja uma página web, editável em um browser e que possa ser alterada por todos aqueles que visualizem a página. As wikis possuem todas as vantagens das ferramentas de terceira geração, isto é, das ferramentas de publicação na web que funcionam sobre a própria web. Estas vantagens são: mobilidade, praticidade e facilidade de colaboração. Além disso, pelo fato de possuírem edição aberta, também têm como benefícios a simplicidade de publicação, conteúdo de fontes diversificadas e uso democrático. Vale notar que também existem diversas dificuldades encontradas no uso de wikis: necessidade de tradução, nova sintaxe a ser aprendida pelos usuários e problemas relacionados ao próprio conceito de edição aberta.

Para que uma página web possa ser utilizada como uma wiki, de forma satisfatória, é necessário que a implementação inclua: possibilidade de edição em cada página, uso de wikiwords, presença de histórico, lista de últimas modificações, páginas de testes e mecanismos de busca.

Existem atualmente diversas implementações de wikis, também conhecidas como wiki clones [Ebersbach et al., 2005, p. 17], sendo a MediaWiki e a Twiki exemplos de destaque.

\footnotetext{
${ }^{58}$ http://www.perl.com
} 


\section{CAPÍTULO 2. SOBRE WIKIS}

O site WikiMatrix ${ }^{59}$ contém uma relação com mais de 70 wikis que podem ser comparadas através de seus atributos. Uma relação ainda maior de clones, em torno de 140, pode ser encontrada no site da wiki original ${ }^{60}$.

Por fim, o sistema QwikWeb [Eto et al., 2005] foi proposto como meio de exploração de novas possibilidades de publicação na web, em especial, por meio do envio de emails. Dessa forma, QwikWeb se tornou uma ferramenta de referência bastante relevante para esta pesquisa, que investiga a interação em wikis por mensageiros instantâneos. No próximo capítulo, os conceitos e estudos sobre mensageiros instantâneos são apresentados.

\footnotetext{
${ }^{59}$ http://www.wikimatrix.org

${ }^{60}$ http://c2.com/cgi/wiki?WikiEngines
} 


\section{Sobre Mensageiros Instantâneos}

\subsection{Considerações Iniciais}

Por este trabalho estudar a interação em wikis por meio de mensageiros instantâneos, cabe agora apresentarmos os conceitos básicos dos mensageiros, além de seu histórico, exemplos relevantes, vantagens e desvantagens. Posteriormente, introduzimos o conceito de bot, e como foi possível aproveitarmos as interfaces de mensageiros instantâneos para enriquecermos a agilidade no processo de publicação de conteúdo em páginas web. Por fim, é apresentado o conceito de microblog, que é análogo à forma de publicação estudada nesta pesquisa, diferenciando-se apenas pelo fato de que na prosposta de pesquisa deste mestrado a ferramenta na qual os conteúdos são informados via bots foram as wikis, ao invés de blogs. As wikis, conforme apresentado no Capítulo 2 viabilizam mais características de incentivo à colaboração.

\subsection{Mensageiros Instantâneos}

Os mensageiros instantâneos (MIs ou comunicadores instantâneos) são ferramentas de comunicação que permitem a troca instantânea de mensagens de texto entre pessoas [Tran et al., 2007, p. 55] e devido a sua simplicidade e agilidade, se tornaram bastante populares [Isaacs et al., 2002, p. 179]. As implementações atuais permitem o uso de diversas mídias, como imagens, áudio e vídeo [Shin et al., 2007, p. 167], embora a forma 
mais popular de utilização seja o bate-papo, no qual curtas mensagens de texto são trocadas entre os usuários em tempo real [Team, 2002, p. 1]. Além disso, possibilitam a comunicação oportunista, isto é, permitem que um usuário decida conversar com outro aproveitando o momento em que este também se encontra online, sabendo que há grandes chances de obter uma resposta em curto período de tempo [Team, 2002, p. 2].

Uma característica relevante dos mensageiros instantâneos é que eles informam o estado atual dos usuários, tais como: conectado, desconectado, ocupado, disponivel, ausente, etc [Chung and Nam, 2007, p. 213]. Esta característica é importante pois fornece aos outros usuários uma informação em tempo real sobre as possibilidades de diálogo naquele momento. Além disso, diversas implementações permitem a definição de um trecho de texto que personaliza a situação atual que o usuário deseja que seja visível para todos os outros usuários, detalhando ainda mais o seu estado, como por exemplo "estou trabalhando..." ou "em casa". Também merece destaque a existência de uma lista de contatos (buddy list), que possibilita filtrar quem são os usuários que podem estabelecer diálogo com o usuário, além de poder organizá-los em categorias [Isaacs et al., 2002, p. 179].

Ainda com relação às características dos mensageiros instantâneos, é importante mencionar o estudo realizado durante o levantamento bibliográfico desta pesquisa de mestrado e que resultou na proposta de taxonomia elaborada a partir de outras três taxonomias previamente publicadas [Long and Baecker, 1997][Wams and van Steen, 2004][Murnan, 2006], que não contemplavam as ferramentas atuais ou estavam incompletas. A taxonomia elaborada (Apêndice B) contém 17 classes de ferramentas de comunicação, com seus atributos, definidos com base nas taxonomias estudadas e na avaliação das ferramentas atuais. A classe mensageiro instantâneo foi definida nessa taxonomia, com os seguintes pares atributo-valor:

- Comunicação-síncrona. Os participantes do diálogo precisam trocar mensagens durante o mesmo intervalo de tempo, isto é, estarem online simultaneamente.

- Estilo-unicast. Também conhecida como comunicação 1-1, destina-se ao diálogo privado entre apenas um emissor e um receptor.

- Mídias-texto. Essa é a principal mídia de comunicação utilizada, embora imagens, áudio e vídeo também estejam presentes em diversas implementações.

- Restrições-envio e recebimento. Indica que existe algum tipo de controle sobre quem pode enviar e quem pode ler as mensagens; uma autenticação geralmente é realizada, por meio de login e senha. 
- Retorno-esperado. Indica que o remetente da mensagem normalmente espera obter uma mensagem de resposta após cada envio (o que não ocorre com postagens em páginas web, por exemplo).

- Recebimento-não solicitado. Após o início do diálogo, o usuário não precisa solicitar o recebimento de novas mensagens, pois estas já são automaticamente enviadas.

- Editável-não. As mensagens que já foram enviadas para o destinatário não podem mais ser alteradas.

Na taxonomia proposta por Long e Baecker [Long and Baecker, 1997], que visa organizar as formas de comunicação pela Internet, encontramos diversas outras categorias que se assemelham aos mensageiros instantâneos, como é o caso de talk, IRC (Internet Relay Chat) e MUD (Multi-User Dungeon). O aplicativo talk, utilizado há mais de 20 anos em ambientes UNIX [Grinter and Palen, 2002, p. 21], realiza a troca de mensagens por caractere, isto é, a digitação de um usuário é exibida a outro praticamente em tempo real. Os IRCs têm como objetivo a realização de bate-papos organizados em canais, de acordo com o tema [Reid, 1991]. Já nos $M U D s$, os usuários navegam em um mundo virtual e se comunicam via texto, de acordo com a proximidade virtual, sendo que a descrição dos ambientes também deve ser realizada via texto [Fortim, 2006]. Por suas características, IRCs e $M U D s$ também podem ser considerados como precursores dos mensageiros instantâneos, embora não tenham como objetivo a comunicação 1-1 privada, mas sim a comunicação 1-n pública.

O primeiro mensageiro instantâneo amplamente utilizado foi o ICQ ${ }^{1}$, lançado em 1996 , pela empresa israelense Mirabilis [Rittinghouse and Ransome, 2005, p. 2]. Em seguida vieram os mensageiros instantâneos lançados pelas empresas AOL (AOL Instant Messenger), Microsoft (MSN Messenger) e Yahoo! (Yahoo!Messenger) [Rittinghouse and Ransome, 2005, p. 4]. Outros mensageiros instantâneos de destaque são o Skype e o Google Talk (Gtalk), lançados em $2003^{2}$ e $2005^{3}$, respectivamente.

Apesar do grande sucesso dos mensageiros instantâneos, foram encontradas na literatura algumas desvantagens e problemas relacionados, principalmente quando comparamos os mensageiros com emails. Chung e Nam [Chung and Nam, 2007, p. 213] citam as seguintes desvantagens:

- Aumento da pressão sobre os usuários, para que estes respondam imediatamente a mensagem;

\footnotetext{
${ }^{1}$ http://www.icq.com

${ }^{2}$ http://about.skype.com/

${ }^{3}$ http://en.wikipedia.org/wiki/Google_Talk
} 
- Falta de padronização entre todos os sistemas de mensagens instantâneas, impedindo a comunicação entre usuários de implementações diferentes (o que não ocorre com emails);

- Envio de resposta ao destinatário incorreto devido ao senso de urgência e administração de várias conversas simultâneas;

Outro problema, citado por Hodgetts e Jones, é o fato dos mensageiros instantâneos solicitarem a atenção dos usuários a cada nova mensagem recebida. Isso pode ocasionar perda de tempo, tanto no acesso e leitura da mensagem quanto no tempo necessário para que a mente volte a se concentrar na tarefa que estava sendo realizada. A sugestão deles é de que os mensageiros instantâneos fiquem desligados durante tarefas de muito planejamento ou concentração [Hodgetts and Jones, 2007, p. 824].

O estudo dos mensageiros instantâneos também inclui questões relativas à privacidade dos usuários [Patil and Kobsa, 2005], principalmente devido à disponibilização do estado do usuário para sua lista de contatos ou até mesmo em sites de redes de relacionamento pessoal, como o Orkut ${ }^{4}$.

Com relação à segurança, Rittinghouse e Ransome relatam "várias dificuldades técnicas, como ataques por buffer overflow no cliente, até riscos por uso inapropriado, como o vazamento de propriedade intelectual" [Rittinghouse and Ransome, 2005, p. 1]. Esse vazamento de informações pode ocorrer localmente (pela captura do registro da conversa na rede local) ou durante o tráfego das mensagens. Normalmente, as mensagens trocadas por mensageiros instantâneos trafegam pelos servidores das grandes empresas que gerenciam esses serviços [Flynn, 2004, p. 12]. Assim, é fácil perceber que a garantia de sigilo depende de como essas mensagens são manipuladas nessas empresas, que provavelmente operam sem qualquer fiscalização externa.

Outro desafio adicional na comunicação via mensageiros instantâneos é o tratamento de ambigüidades referentes ao sentido das mensagens trocadas entre os usuários, que se baseiam principalmente em texto. A proposta de Bodine e Pignol é incluir animações nos textos para destacar o significado da mensagem transmitida [Bodine and Pignol, 2003]. O uso de emoticons também auxilia na interpretação dos textos, porém, no caso de comunicações inter-culturais, ainda é possível haver ambiguidade, pois cada cultura poderá interpretar as imagens de um jeito diferente [Dix et al., 2003, p. 391], segundo Koda [Koda, 2007].

\footnotetext{
${ }^{4}$ Disponível em http://www.orkut.com
} 


\subsection{Bots}

Segundo Fryer, bot é uma abreviação de chatbot que é "um programa de computador destinado a simular uma conversa inteligente com um ou mais usuários humanos por meio de métodos textuais ou auditivos" [Fryer and Carpenter, 2006, p. 8]. Segundo a Ecration ${ }^{5}$, atualmente uma das principais desenvolvedoras de chatbots, um chatbot também poderá ser chamado de agente interativo, quando possuir técnicas de processamento de linguagem natural (NLP - Natural Language Processing), para simular a conversação humana. Apenas para exemplificar alguns chatbots, podemos citar ELIZA [Weizenbaum, 1966], ALICE [Wallace, 2002], SeteZoom e Ed ${ }^{6}$.

A definição do "The American Heritage Dictionary" para bot é que é um "software que simula o comportamento humano, consultando mecanismos de busca ou participando de salas de bate-papo ou discussões de IRC '[of The American Heritage Dictionaries, 2006]. Neste trabalho, entretanto, o termo será utilizado considerando apenas a simulação da forma de interação humana e não da forma de inteligência humana. Assim, o termo bot designa qualquer aplicação que interaja com usuários através de uma forma de comunicação que normalmente é usada entre humanos. Dessa forma, o termo bot não deve ser confundido com chatbot, tampouco como sinônimo de algum computador infectado por um programa nocivo, realizando tarefas como zumbi [Geer, 2005, p. 18][Holz, 2005, p. 76] ou mesmo como sinônimo de programas do tipo crawler [Cosley et al., 2007]

Com relação à interface de comunicação utilizada pelos bots, podemos citar diversos tipos, como: interação via salas de bate-papo [Fryer and Carpenter, 2006], interação por meio de ambientes virtuais, como jogos [Muñoz-Avila and Fisher, 2004, p. 1] [Golle and Ducheneaut, 2005, p. 1], interação por email (recebimento automático de emails em caso de erros, por exemplo) e interação por meio de mensageiros instantâneos [Chan et al., 2005]. Cabe agora ressaltar que, em todo o restante deste trabalho, o termo bot se restringe apenas a bots implementados em mensageiros instantâneos, que é a forma de interação estudada neste trabalho.

Para esclarecimento do conceito de bots para MI, a Figura 3.1 exemplifica a utilização de um MI com bots. O usuário Rafael está conectado no Gtalk e apenas quatro de seus amigos (contatos) estão online: "BOT: publicar.noticia", "BOT: robot.wiki", "Felip" e "Roberto". Neste caso, dois são usuários reais e dois são softwares com tarefas específicas. Para que o contato seja estabelecido com o outro usuário, basta iniciar um diálogo como se fosse falar com aquela pessoa online.

\footnotetext{
${ }^{5}$ Disponível em http://www.ecreation.nl

${ }^{6}$ Disponível em http://www.inbot.com.br
} 


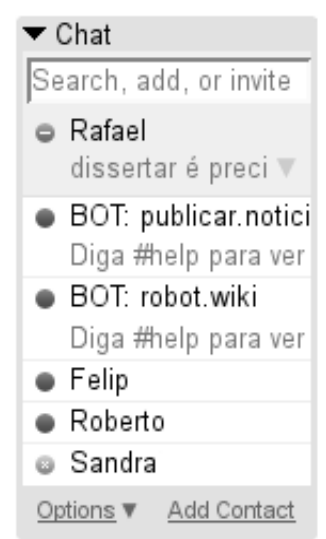

Figura 3.1: Screenshot de um MI utilizando dois bots

\section{Exemplos de Bots}

Em 2006 a cervejaria Bavária lançou o bot "Dado Spitze", cuja referência bibliográfica obtida édados@bavariapremium.com.br. O acesso a esse bot, através do MSN, permite que o usuário consulte informações sobre cervejas, futebol, restaurantes e eventos. Também em 2006, a Microsoft lançou, em fase beta, diversos serviços que enviam informações para o mensageiro instantâneo Windows Live Messenger ${ }^{7}$. O serviço é conhecido como MSN Alertas $^{8}$ e envia mensagens para os usuários automaticamente a cada período de tempo ou atualização na fonte dos dados. Exemplos de informações que podem ser obtidas por este serviço são manchetes de últimas notícias, dados sobre o trânsito, previsão do tempo, oportunidades de trabalho, atualizações de blogs e horóscopo.

Outros bots que se destacam são o encarta@conversagent.com (consulta à enciclopédia Encarta pelo MSN), IMified ${ }^{9}$ (gerenciador de anotações), Sleak ${ }^{10}$ (receptor e divulgador de informações sobre celebridades), GoogleMatic ${ }^{11}$ (realiza buscas no google), Anothr ${ }^{12}$ e Feed Crier $^{13}$ (recebimento de atualizações de conteúdos RSS).

Por fim, uma lista de 53 bots pode ser encontrada no site da competição de bots ${ }^{14}$ promovida pela Microsoft em 2006. Outras aplicações relevantes para bots, demonstradas na competição, foram: buscar o significado de palavras, traduzir palavras, resolver cálculos, enviar emails, realizar correção ortográfica, buscar letras de música, gerenciar agendas e anotar lembretes.

\footnotetext{
${ }^{7}$ http://messenger.live.com

${ }^{8}$ http://alertas.br.msn.com/

${ }^{9}$ http://imified.com

${ }^{10} \mathrm{http}: / /$ celeb.spleak.com

${ }^{11} \mathrm{http}: / /$ interconnected.org/googlematic

${ }^{12}$ http://anothr.com

${ }^{13}$ http://feedcrier.com

${ }^{14}$ http://www.robotinvaders.com
} 
Como proposta de inovação na utilização de bots, podemos citar o trabalho de Zambiasi e Rabelo [Zambiasi and Rabelo, 2007], que apresenta um modelo de utilização de bots em ambiente empresarial. Nesse ambiente, o bot se comunica com outros funcionários da empresa, fornecendo e solicitando informações como se fosse determinado usuário. Dessa forma, visa-se diminuir a carga de trabalho destinada ao funcionário representado.

Em outro trabalho relacionado com diferentes utilizações para bots, Chan et al. [Chan et al., 2005] cita quatro exemplos de possíveis aplicações para bots em mensageiros instantâneos: depuração colaborativa de software, na qual os desenvolvedores podem realizar tarefas de depuração como compilação e definição de breakpoints via mensageiro instantâneo; criação de um canal de comunicação entre um software e seus responsáveis, que transmite relatórios periódicos e alertas quando necessário; uso em computação distribuída; sistema de linha de comando acessado por mensageiro instantâneo.

\section{Classificação de Bots}

Partindo da definição adotada neste trabalho de que bot é "qualquer aplicação que interaja com usuários através de uma forma de comunicação que normalmente é usada entre humanos", podemos perceber que existem diversos tipos de bots, ao analisarmos a variedade de aplicações que existem. Podemos construir bots para diversas aplicações, como por exemplo para os mensageiros instantâneos, chats e até mesmo para ambientes de realidade virtual [Sourin, 2004]. Entretanto, como esta pesquisa visa a investigação de um projeto de bots para mensageiros instantâneos, foi proposta uma classificação que se restringe a este tipo de aplicação.

\begin{tabular}{||c|l||l|c||}
\hline \hline \multicolumn{2}{||c|}{$\begin{array}{c}\text { Classes de Bots para } \\
\text { Mensageiros Instantâneos }\end{array}$} & $\begin{array}{c}\text { Orientação da } \\
\text { Informação }\end{array}$ & $\begin{array}{c}\text { Iniciativa da } \\
\text { Interação }\end{array}$ \\
\hline \hline \multirow{2}{*}{ Publicação } & Passivo & Usuário $\rightarrow$ Bot & Usuário \\
\cline { 2 - 4 } & Ativo & Usuário $\rightarrow$ Bot & Bot \\
\hline \multirow{2}{*}{ Consulta } & Passivo & Bot $\rightarrow$ Usuário & Usuário \\
\cline { 2 - 4 } & Ativo & Bot $\rightarrow$ Usuário & Bot \\
\hline \hline
\end{tabular}

Tabela 3.1: Proposta de classificação de bots para MIs

A princípio, foi possível identificar quatro tipos de bots, conforme apresentado na Tabela 3.1: bot de publicação passivo, de publicação ativo, de consulta passivo e de consulta ativo, detalhados a seguir.

O primeiro critério usado nesta proposta de classificação utiliza a orientação da informação que é transmitida. Este critério de classificação permite que os bots sejam definidos como de publicação ou de consulta. Os bots de publicação são aqueles que recebem informações dos usuários e realizam alguma operação com ela, como a publicação em páginas web, manipulação de arquivos, etc. Vale notar que, mesmo que o bot envie mensagens 
para o usuário, informando o status das operações realizadas, sua função principal não é informar, mas sim armazenar alguma informação recebida (orientação usuário $\rightarrow$ bot). Já os bots de consulta são aqueles que enviam informações para o usuário, isto é, a informação que é relevante é enviada no sentido do bot para o usuário. Assim como no caso anterior, mesmo que o usuário também envie informações para o bot, como configurações, o objetivo final do bot é informar o usuário (orientação bot $\rightarrow$ usuário).

O segundo critério escolhido para classificar os bots foi a iniciativa de interação. Dessa maneira, podemos definir os bots para MI em ativos ou passivos. Nos bots ativos a informação é recebida ou enviada para o usuário por iniciativa do bot, ou seja, o bot "interrompe" o usuário, solicitando ou enviando alguma informação. No caso dos bots passivos as mensagens são recebidas ou enviadas para os usuários somente quando eles (os usuários) primeiro iniciam o diálogo.

A partir desta proposta de classificação, seguem exemplos práticos de cada um dos quatro tipos de bots:

1. Bot de publicação passivo: uma aplicação que disponibilize em uma página web em qual cidade se encontra cada vendedor de uma empresa. O vendedor acessa o bot cada vez que muda de cidade para atualizar sua localização. Neste caso o bot deve ser passivo já que o evento que gera a atualização da informação (mudança de cidade) parte do usuário.

2. Bot de publicação ativo: um sistema de gerenciamento de listas de email que solicite ao usuário moderador que aprove ou rejeite novos membros sempre que alguém deseje fazer parte da lista. Como o evento que dispara a solicitação de aprovação/rejeição é de "conhecimento" inicial do bot e não do usuário, o bot deve ser ativo para maximizar a agilidade no processo de avaliação de novos membros. Essa combinação de características (bot de publicação que é ativo) pode ser posteriormente estudada para levantamento de suas vantagens e desvantagens. Pode-se estimar que o fato do usuário precisar estar online e que ele será interrompido para fornecer informações são algumas de suas desvantagens.

3. Bot de consulta passivo: um sistema no qual o usuário consulte as últimas notícias de um site, sempre que desejar. O bot "Dado Spitze", apresentado na Seção 3.3, poderia ser classificado como um bot deste tipo, já que permite que o usuário consulte diversas informações, também por iniciativa do usuário.

4. Bot de consulta ativo: um sistema que informe o usuário periodicamente a previsão do tempo. O bot MSN Alertas, apresentado na Seção 3.3, seria um bot de consulta ativo, pois envia informações relevantes para o usuário automaticamente. 
É interessante notar que, dependendo da característica do bot, ele poderá ser de consulta e de publicação ao mesmo tempo, já que informações relevantes trafegam tanto na orientação bot $\rightarrow$ usuário, quanto na orientação usuário $\rightarrow$ bot. Um exemplo desse tipo de bot poderia ser um sistema de armazenamento e recuperação de números de telefone: quando o usuário armazena alguma informação, o bot está sendo utilizado como bot de publicação passivo mas quando algum número é consultado, o bot desempenha o papel de bot de consulta passivo. Assim, esse bot teria ambas as classificações, podendo ser denominado como bot de consulta e publicação passivo.

Os três bots implementados pelo autor deste trabalho, que são detalhados no Capítulo 4, também poderiam ser classificados de acordo com os tipos propostos. O bot assistente.universal seria um bot de consulta passivo pois realiza consultas a um dicionário e os bots robot.wiki e publicar.noticia, bots de publicação passivos, pois realizam, respectivamente, a edição de wikis e a publicação de últimas notícias em uma página web.

\subsection{Microblogs}

O termo microblog ainda está em fase de consolidação, pois designa um conjunto de ferramentas recentes, que começaram a ficar populares no final de 2006. Por meio desses sistemas é possível publicar conteúdo em páginas web através de bots para mensageiros instantâneos e outros métodos rápidos, como mensagens de celular (SMS). Também enviam mensagens no sentido bot $\rightarrow$ usuário, sendo, dessa forma, um sistema que utiliza bots de consulta e publicação, ativos ou passivos (dependendo da implementação), conforme proposta de classificação apresentada na Tabela 3.1. Sinônimos encontrados para o termo são miniblog [McFedries, 2007] e tumblelog ${ }^{15}$.

Uma das principais utilizações atuais dos microblogs é tornar pública a tarefa que determinado usuário está realizando, disponibilizando-a em uma página web e enviando-a para aqueles que desejam seguir o cotidiano deste usuário. Vale notar que a atualização da tarefa é realizada pelo usuário, sendo ele o responsável por administrar o quanto sua privacidade está sendo exposta por este sistema. Diversos jornalistas também utilizam a ferramenta como meio de divulgação de notícias em tempo real, para os usuários que decidirem seguir as atualizações. Para que as mensagens possam ser lidas facilmente nos mensageiros instantâneos, elas devem utilizar apenas texto e serem curtas, tendo no máximo 140 caracteres (valor adotado pelos principais sites ${ }^{16}$ ).

É importante ressaltar que, o fato da publicação por mensageiros instantâneos ter tamanho restrito e apenas um campo, para entrada de dados, dificulta alguns aspectos da

\footnotetext{
${ }^{15}$ http://pt.wikipedia.org/wiki/Tumblelog

${ }^{16}$ http://en.wikipedia.org/wiki/Micro-blogging
} 
publicação. O pequeno espaço para a adição de textos faz com que muitas vezes o mesmo deva ser reescrito, aumentando o trabalho. Já a falta de campos diminui a carga semântica da mensagem, isto é, existem poucos ou nenhum campo disponível para metadados.

Uma forma de amenizar este problema é através da utilização de vários ciclos de pergunta-resposta, isto é, para que a inserção de uma postagem realmente ocorra, mais de uma mensagem deve ser enviada para o bot. Uma outra alternativa, estudada por dos Santos e Fortes [dos Santos and Fortes, 2006], é a extração automática metadados [Pansanato and Fortes, 2005], baseando-se no conteúdo da mensagem enviada. Assim, comparando as palavras contidas no corpo da mensagem com uma ontologia pré-definida é possível determinar, com certa precisão, algum metadado, como por exemplo qual o assunto da mensagem.

Um dos primeiros exemplos de microblog conhecidos é o BloggerBot ${ }^{17}$, de 2001. Nele, é possível adicionar postagens a uma página web através de um bot implementado no AIM (AOL Instant Messenger). Em 2006, foram lançados dois representantes atuais do microblogging que são bastante populares: o Jaiku ${ }^{18}$ e o Twitter ${ }^{19}$. Segundo [McFedries, 2007], essas ferramentas tem disseminado uma nova cultura de estar "sempre" conectado, mesmo que virtualmente.

A pesquisa de [Burke, 2004] utilizou um microblog para que os alunos de determinada matéria mantivessem um diário online sobre o que aprendem no decorrer das aulas. Por meio de um mensageiro instantâneo os alunos atualizavam seus diários e o professor verificava essas anotações em uma página web. Dentre os trabalhos relacionados encontrados, este foi o que mais se aproximou desta pesquisa (em especial do bot robot.wiki, detalhado no próximo capítulo), pois ambas utilizam bots para mensageiros instantâneos como forma de publicação em páginas web.

\subsection{Considerações Finais}

Este capítulo apresentou as principais características dos mensageiros instantâneos, além do histórico de utilização da ferramenta, bem como vantagens e desvantagens existentes. A seguir, foram descritos os bots para mensageiros instantâneos, foco desta pesquisa, sendo apresentadas as definições, histórico dos bots, exemplos e uma proposta de classificação elaborada pelo autor deste trabalho. Por fim, foram incluídas informações sobre microblogs, que também podem utilizar bots para mensageiros instantâneos como forma de interação.

\footnotetext{
${ }^{17} \mathrm{http}: / /$ www.fibiger.org/bloggerbot

${ }^{18} \mathrm{http}: / /$ jaiku.com

${ }^{19} \mathrm{http}: / /$ twitter.com
} 


\section{CAPÍTULO 3. SOBRE MENSAGEIROS INSTANTÂNEOS}

Os estudos bibliográficos realizados, apresentados nos Capítulos 2 e 3, foram base para a investigação da forma de interação com wikis por meio de MIs, proposta deste mestrado. Os conceitos de mensageiros instantâneos e bots foram referência e representam os trabalhos relacionados mais próximos e que inspiraram o desenvolvimento desta pesquisa, o qual é descrito nos próximos capítulos. Em especial, os trabalhos relacionados que se destacam são os microblogs e o diário editado via bot implementado durante a pesquisa realizada por Burke [Burke, 2004], descritos neste capítulo, e a Qwikiweb [Eto et al., 2005], apresentada no capítulo anterior. A proposta desenvolvida durante este mestrado combina características desses trabalhos relacionados, além de evidenciar um estudo mais detalhado a partir da proposta de classificação apresentada na Seção 3.3. 



\section{Um Sistema Interativo com wikis via}

\subsection{Considerações Iniciais}

A partir dos estudos sobre wikis (Capítulo 2) e bots para mensageiros instantâneos (Capítulo 3), neste capítulo é descrito o modelo de interação proposto: a utilização de bots para mensageiros instantâneos para realizar tarefas em páginas web, especificamente em wikis. São apresentadas as funcionalidades projetadas nos três bots implementados neste trabalho: assistente.universal, publicar.noticia e robot.wiki. Os bots foram desenvolvidos na seguinte ordem cronológica: primeiro foi desenvolvido o bot assistente.universal, para possibilitar a familiarização com os aspectos tecnológicos envolvidos na implementação de bots. Além disso, foi possível obter um conhecimento inicial sobre bots de consulta, já que é uma instância dessa categoria. O segundo bot criado foi o publicar.noticia, implementado para maior conhecimento de bots de publicação. Por fim, foi implementado o terceiro bot, denominado robot.wiki, também um bot de consulta, mas que visa a colaboração em uma wiki e que é a proposta alvo deste trabalho. 


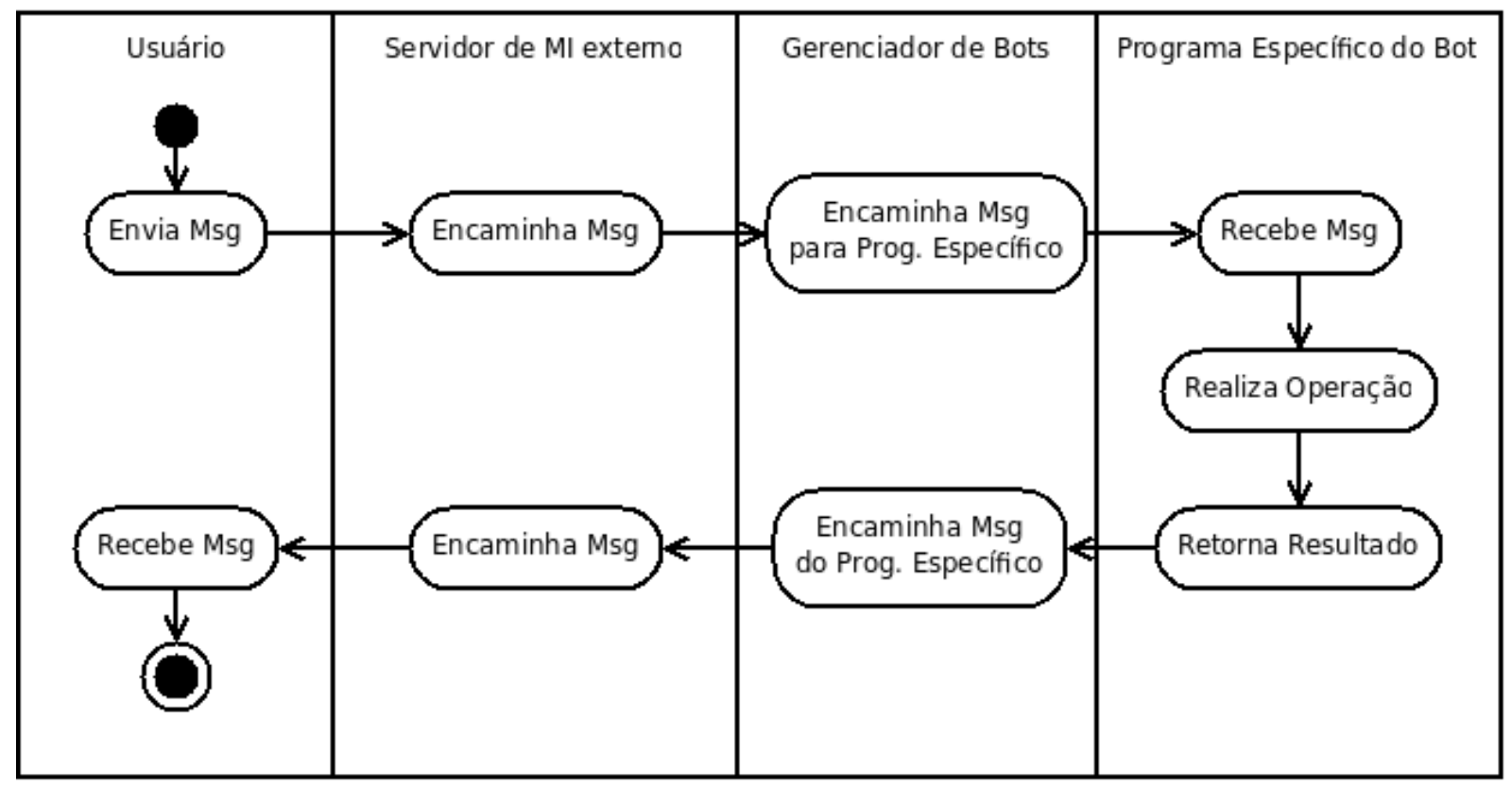

Figura 4.1: Diagrama de atividades do gerenciador de bots

\subsection{Gerenciador de Bots}

Para o desenvolvimento dos bots foi utilizado um gerenciador de bots também desenvolvido pelo autor deste trabalho. Seu projeto foi concebido de acordo com o diagrama de atividades da Figura 4.1. Este gerenciador, implementado em Java, tem a função de autenticar os bots nos servidores e mantê-los em constante execução, evitando que fiquem desconectados. Além disso, manipula as mensagens enviadas e recebidas pelos bots, encaminhando para o software final que irá realizar as tarefas específicas de cada bot. Ele também centraliza o registro das trocas de mensagens ocorridas, unificando o sistema de log (registro de cada informação trocada entre usuário e bot). O conceito de webservices [Snell et al., 2001] foi utilizado para encaminhamento das mensagens recebidas pelo gerenciador de bots para os softwares específicos de cada bot. No caso dos três bots implementados, todos foram desenvolvidos em PHP, acessados por URLs. Assim, as mensagens são recebidas pelo gerenciador e a partir dele são enviadas para as páginas PHP correspondentes. O caminho inverso também ocorre: após processar a mensagem, a página PHP retorna para o gerenciador o resultado da operação e esta é encaminhada para o usuário final através do MI.

O núcleo do gerenciador de bots nada mais é do que um software cliente para o mensageiro instantâneo Google Talk. Tal mensageiro foi escolhido pois, além de sua popula- 
ridade, é um MI compatível com padrões abertos, utilizando o protocolo Extensible Messaging and Presence Protocol (XMPP, também conhecido como Jabber) [Wright and Moore, 2003] para autenticação, troca de mensagens e sinalização de presença, facilitando assim a implementação. Foi utilizada uma API Java chamada Smack ${ }^{1}$, que encapsula toda a complexidade referente a criação de novos pacotes XML segundo o padrão, fornecendo os métodos necessários, como a autenticação e o envio e recebimento de mensagens pelo mensageiro.

\subsection{O Bot assistente.universal}

O bot assistente.universal foi o primeiro a ser projetado e implementado pelo autor deste trabalho, tendo por objetivo inicial adquirir o conhecimento para a construção de bots. Dois experimentos foram realizados para análise da viabilidade da utilização de bots por usuários em tarefas do dia-a-dia.

O conceito por trás da criação deste bot (assistente.universal) é a disponibilização de um contato no MI que auxilie o usuário nas mais variadas tarefas ${ }^{2}$, se configurando como um assistente disponível sempre que necessário. Entretanto, por ter sido desenvolvido apenas como prova de conceito, as únicas funcionalidades presentes no bot são retornar o significado de palavras (dicionário) e retornar o cardápio do dia que será servido no refeitório da USP São Carlos. O bot assistente.universal, segundo classificação proposta na Seção 3.3 desta dissertação, se caracteriza por ser um bot de consulta passivo.

Como funcionalidades secundárias, tem-se a opção de obter a lista de dicionários consultados pelo bot e a possibilidade de se alterar o idioma das buscas. O conjunto de funcionalidades do bot encontra-se representada no diagrama de casos de uso da Figura 4.2 .

A seguir é apresentada a lista de comandos suportados pelo bot, acrescida de uma breve descrição do que é realizado:

- bandex: retorna o cardápio do dia;

- fonte: exibe a lista de dicionários consultados;

- idioma: permite a alteração do idioma;

- help: exibe ajuda, explicando os comandos disponíveis;

- priv: exibe política de privacidade;

\footnotetext{
${ }^{1}$ A API pode ser encontrada em http://www.igniterealtime.org. Último acesso em 20/01/08

${ }^{2}$ Por isso foi batizado de assistente.universal
} 


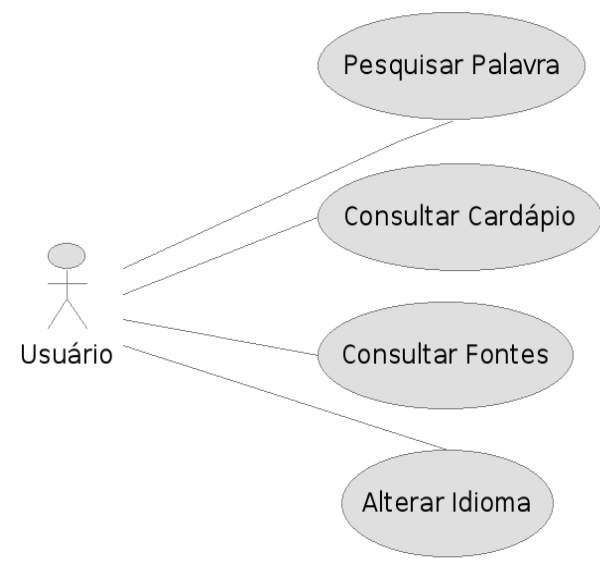

Figura 4.2: Diagrama de casos de uso do bot assistente.universal

- sobre: exibe informações sobre o bot;

- (qualquer outra palavra): realiza a busca nos dicionários online;

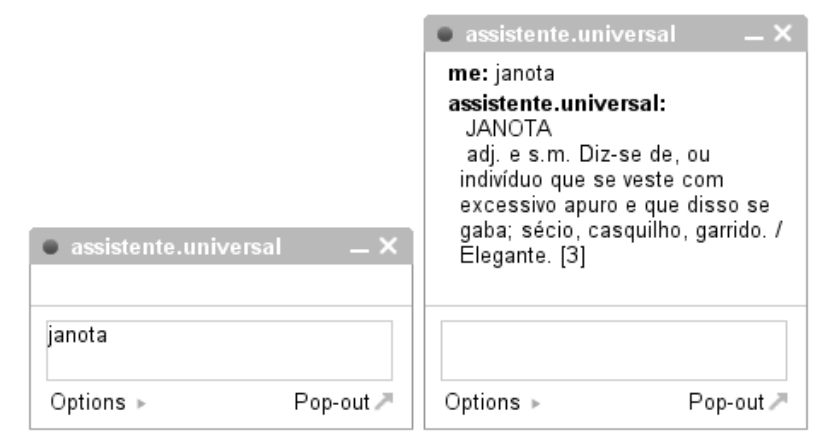

Figura 4.3: Screenshot de utilização do bot assistente.universal

A Figura 4.3 apresenta screenshots que exemplificam o uso do bot. À esquerda da figura está a interface onde o usuário digita para o bot a palavra para a qual procura por uma definição. À direita, encontra-se o resultado obtido, retornado pelos web services acionados pelo bot, e que é apresentado ao usuário.

Conforme mencionado anteriormente, os bots implementados utilizam um gerenciador de bots como camada intermediária para reduzir a complexidade de implantação e manutenção dos bots. Assim, nas descrições de implementações de cada bot será omitida a presença do gerenciador.

A Figura 4.4 mostra o funcionamento do bot, por meio do diagrama de atividades. Inicialmente o usuário digita a palavra desejada ("Informa Palavra") e, ao enviá-la, solicita automaticamente uma busca por definição dessa palavra. Os servidores de mensagens instantâneas encarregam-se de entregar a mensagem do usuário para o bot. Assim que a mensagem é recebida pelo bot ("Recebe Palavra"), uma consulta é realizada a um web service que disponibilize o serviço de retorno de definições de palavras ("Consulta Base 


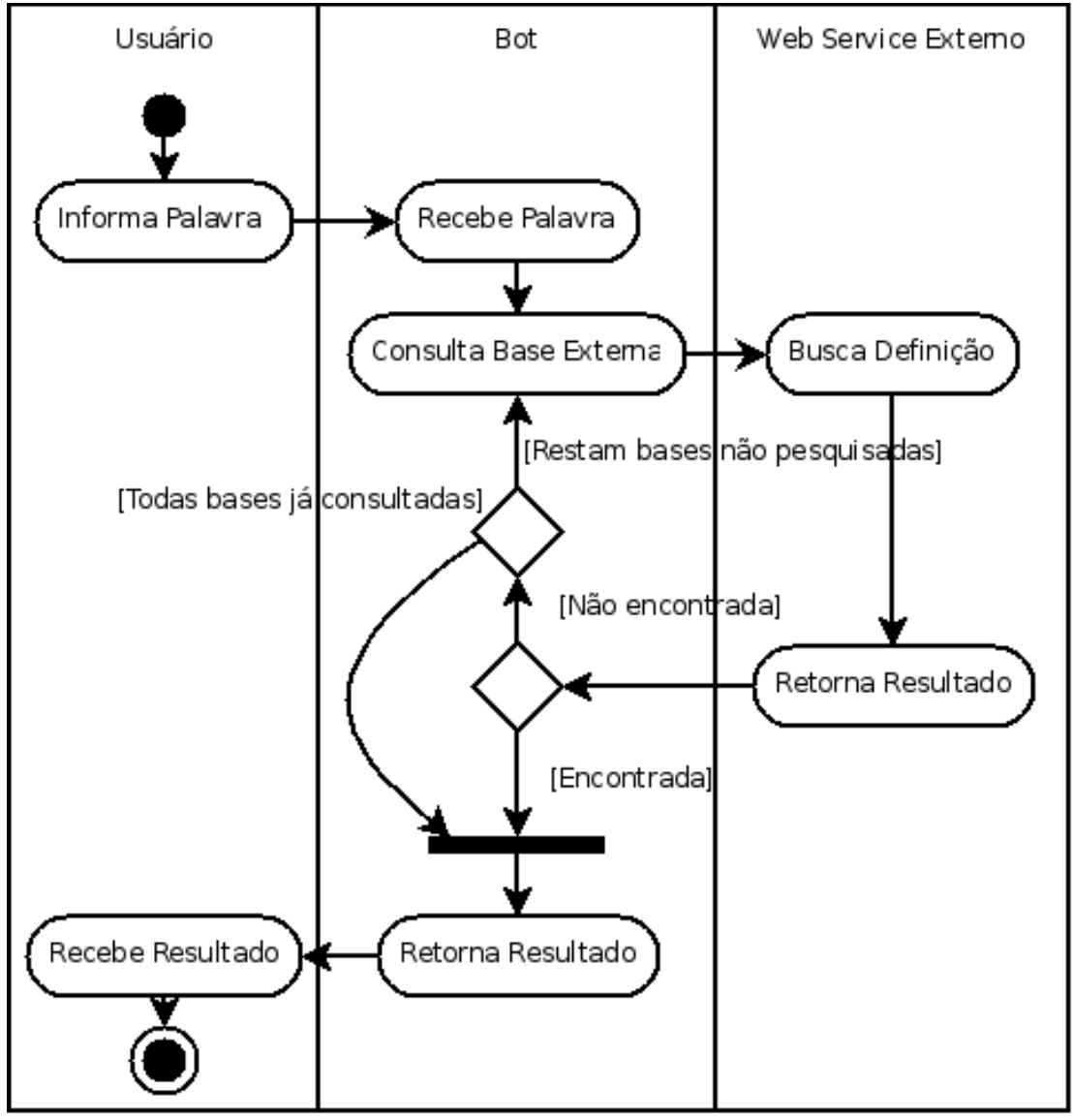

Figura 4.4: Diagrama de atividades do bot assistente.universal

Externa"). Caso o web service consultado não encontre o significado da palavra, outro web service é acessado. Assim que uma definição é encontrada, é retornada ao usuário pelo bot ("Retorna Resultado"). O usuário também é informado caso nenhuma definição tenha sido encontrada na lista de web services cadastrados. Vale notar que esta lista atualmente é composta de três sites: google ${ }^{3}$, priberam $^{4}$ e kinghost ${ }^{5}$ e que a busca dos valores não ocorre por meio de SOAP[Snell et al., 2001] ou qualquer outro protocolo, mas por simples consulta à página e extração da informação relevante de seu conteúdo, para que a implementação do bot fosse agilizada.

\subsection{O Bot publicar.noticia}

Após a criação do bot assistente.universal, o segundo bot projetado pôde ser implementado: o publicar.noticia, para obtenção de experiência com bots de publicação ${ }^{6}$. Este bot

\footnotetext{
${ }^{3}$ http://www.google.com, utilizando o comando "define:". Último acesso em 27/01/08.

${ }^{4} \mathrm{http}: / /$ www.priberam.pt. Último acesso em 27/01/08.

${ }^{5}$ http://www.kinghost.com.br/dicionario. Último acesso em 27/01/08.

${ }^{6}$ Trata-se de um bot de publicação (passivo) e também de consulta (passivo), pois permite que sejam consultadas as últimas notícias por meio do bot.
} 
foi utilizado de forma integrada ao site IEA-Difusão ${ }^{7}$, uns dos veículos de divulgação de jornalismo científico do Instituto de Estudos Avançados da USP/São Carlos. A avaliação ocorreu por meio de entrevistas com os jornalistas que utilizaram o bot, além da análise do registro das mensagens enviadas, pela observação do arquivo de log.

O objetivo principal deste bot, como o próprio nome sugere, é a publicação de notícias em um site, especificamente na seção de últimas notícias (notícias mais recentes). Como ações secundárias, podemos citar a exclusão de notícias e a listagem das últimas entradas de informação a serem publicadas via bot no sistema.A relação de casos de uso do bot encontra-se no diagrama da Figura 4.5.

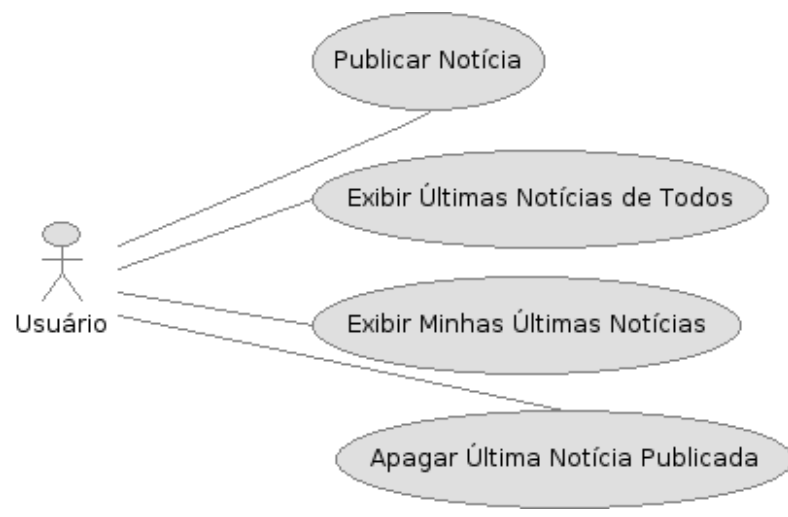

Figura 4.5: Diagrama de casos de uso do bot publicar.noticia

A lista dos comandos definidos para interação com o bot é apresentada a seguir:

- \#help: exibe ajuda, apresentando os demais comandos disponíveis;

- \#list: exibe as últimas notícias informadas e submetidas via bot pelo usuário;

- \#show: exibe as últimas notícias de todos;

- \#undo: exclui a última notícia publicada pelo usuário;

- (qualquer outra palavra): inicia processo de publicação de nova notícia;

Após a experiência inicial com o primeiro bot (assistente.universal), foi adicionado o prefixo $\#^{8}$ aos comandos do sistema, para diferenciá-los das mensagens referentes à publicação de nova notícia. Assim, caso o usuário digite algum comando incorretamente, é exibida a mensagem "comando não encontrado", ao invés de ter início um novo processo de publicação, automaticamente.

\footnotetext{
${ }^{7}$ http://www.ieadifusao.com.br. Último acesso em 27/01/08

${ }^{8}$ A escolha do caractere "/" (barra) seria mais adequada, já que diversos bots seguem este padrão para indicar comandos. Infelizmente esse fato só foi percebido após a criação e divulgação os bots.
} 
Outra característica específica deste bot é que a operação de publicação de nova mensagem não é atômica, já que são necessários vários passos para que uma nova entrada seja adicionada ao sistema. O diagrama da Figura 4.6 contém os três passos necessários para que uma nova mensagem seja publicada: informe da manchete, informe da URL e informe da fonte. Apenas quando estas três informações são recebidas pelo bot, uma nova entrada é gerada no sistema e a notícia é efetivamente publicada.

Vale ressaltar que, a qualquer momento, o usuário pode cancelar a publicação, enviando "\#undo" para o bot. Com relação à implementação, um vetor de estados foi adicionado ao sistema, para que ficasse armazenado em qual dos três passos está cada usuário (estado atual).

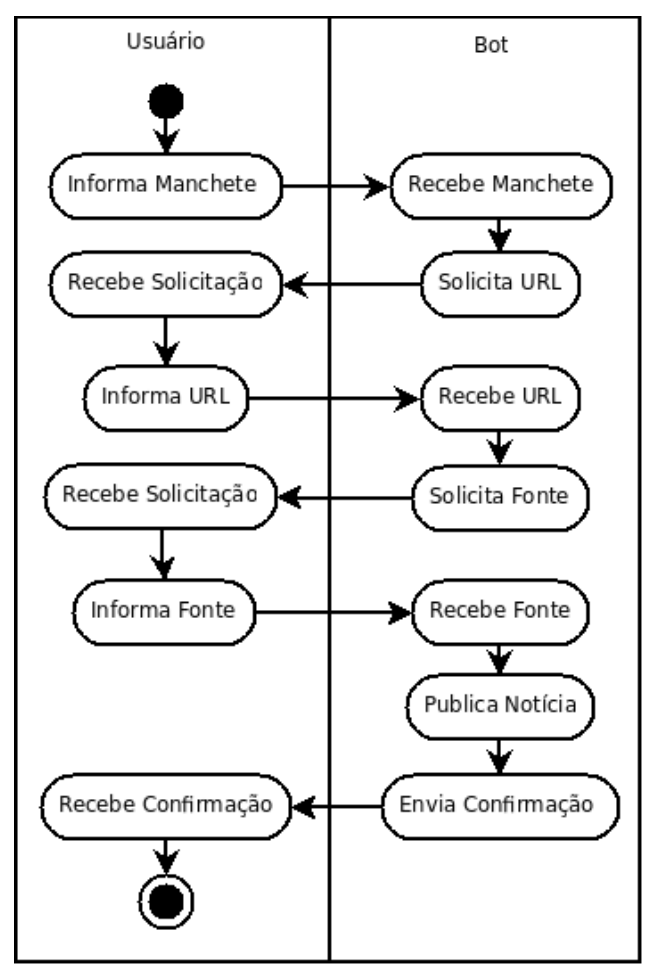

Figura 4.6: Diagrama de atividades do bot publicar.noticia

A Figura 4.7 contém screenshots que demonstram a utilização do bot: após informar os três dados solicitados é realizada a alteração na seção de últimas notícias do site.

\subsection{O Bot robot.wiki}

O terceiro bot desenvolvido foi denominado robot.wiki e é mais semelhante ao bot publicar.noticia pois ambos são bots de publicação ${ }^{9}$, porém se diferencia por habilitar a edição

\footnotetext{
${ }^{9}$ Após a adição da funcionalidade de ler as mensagens dos usuários pelo bot, tornou-se também um bot de consulta (passivo), segundo a proposta de classificação do autor.
} 


\section{CAPÍTULO 4. UM SISTEMA INTERATIVO COM WIKIS VIA BOTS}

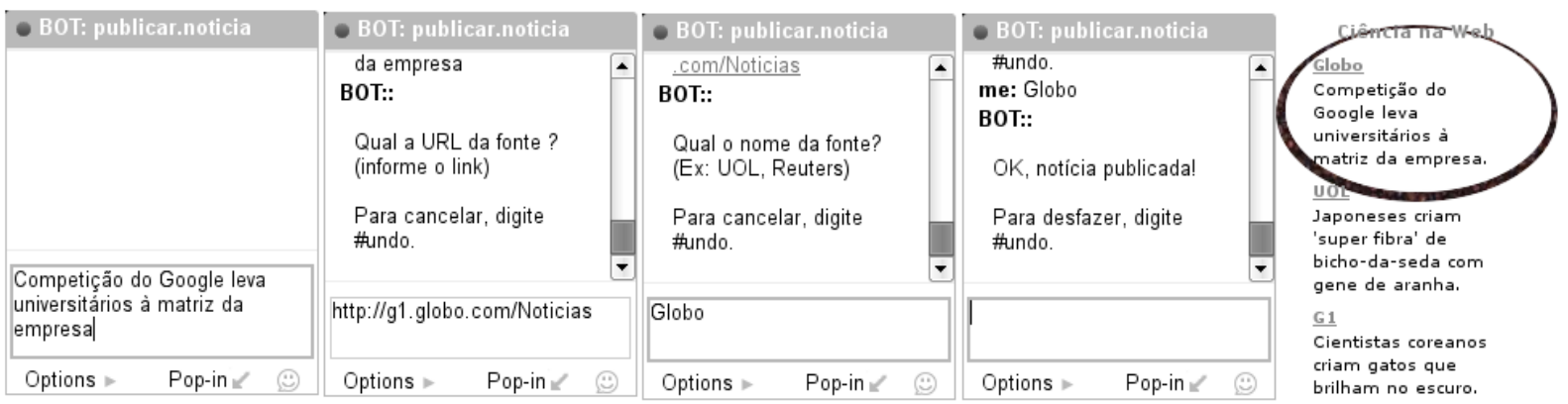

Figura 4.7: Screenshots de utilização do bot publicar.noticia

da informação publicada, caracterizando-se como uma página editável via web por qualquer usuário, ou seja, fundamentando-se no princípio de wiki. Para que um usuário possa colaborar com o conteúdo da página, basta adicionar o bot em seu mensageiro instantâneo e começar a inserir informações ou alterar mensagens já existentes.

O bot robot.wiki tem por objetivo ser um mural de recados, para que usuários possam postar mensagens de texto em uma página web de forma ágil. Foi utilizado por parte do grupo de pesquisa do Laboratório Intermídia do ICMC/USP como forma de acompanhamento das atividades dos membros pelo orientador. A principal funcionalidade do bot é permitir a inserção de mensagens em uma determinada página web, além de possuir os comandos básicos referentes ao gerenciamento das entradas: exibição, edição e remoção. Além disso, exibe estatísticas sobre as mensagens. Os casos de uso deste bot encontram-se representados no diagrama da Figura 4.8.

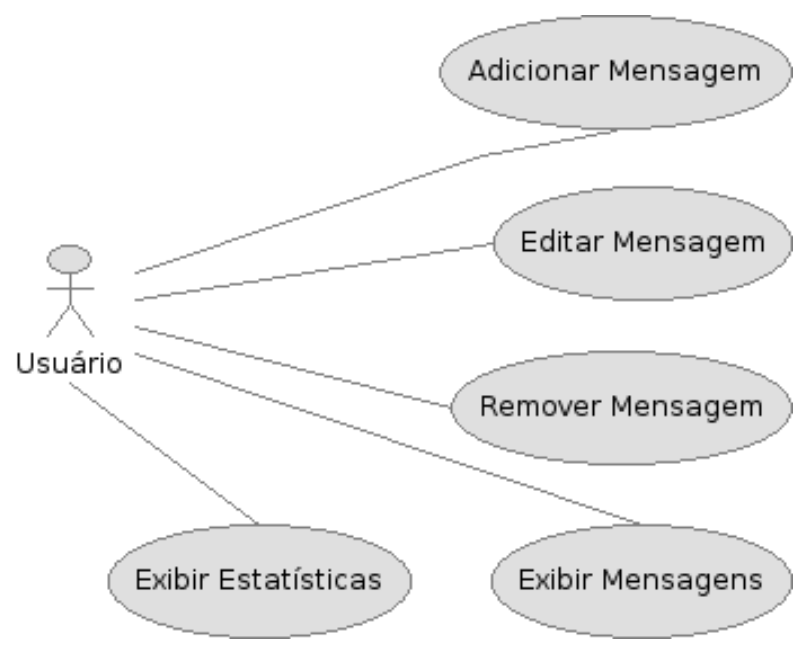

Figura 4.8: Diagrama de casos de uso do bot robot.wiki

A lista de comandos ${ }^{10}$ definidos para interação com o bot é a seguinte:

- \#all: lista últimas mensagens de todos os usuários;

\footnotetext{
${ }^{10}$ Alguns comandos são análogos aos utilizados em terminais de sistemas Unix/Linux, como rm e ls.
} 
- \#edit: exibe menu de opções para editar mensagens;

- \#help: exibe ajuda, apresentando os comandos disponíveis;

- \#ls [usuário]: lista as mensagens do usuário especificado;

- \#rm: exibe a relação de mensagens que podem ser removidas;

- \#stat: exibe estatísticas;

- \#undo: apaga a última mensagem enviada pelo usuário;

- (qualquer outra palavra): adiciona nova mensagem ao site;

O bot robot.wiki possui os seguintes comandos para operações não-atômicas: \# edit e \#rm. Nessas operações, o comando retorna um menu contendo todas a mensagens e um número correspondente. Ao informar o número, o usuário então pode apagar ou editar a mensagem identificada por aquele número.

Um outro diferencial presente no robot.wiki é a presença do parâmetro opcional usuário no comando \#ls, que possibilita a consulta com o envio de apenas uma mensagem. Nesse caso, é possível utilizar parâmetros pois o usuário consegue lembrar o nome de determinada pessoa, o que é praticamente inviável com relação às mensagens, isto é, é muito difícil do usuário lembrar qual o número de uma mensagem.

Para realizar a principal funcionalidade deste bot, que é a publicação de mensagens, pretendeu-se deixar a interação o mais simples quanto possível. Assim, ela pode ser verificada no diagrama da Figura 4.9. Por ser uma operação de apenas um passo, o bot simplesmente recebe a mensagem do usuário, a publica na página web correspondente e envia uma mensagem informando o status da operação.

Os screenshots da Figura 4.10 demonstram um exemplo da utilização do bot. Inicialmente, na tela mais à esquerda, o usuário digita a mensagem desejada e a envia para o bot. Após ser recebida pelo bot, a página web tem seu conteúdo modificado e uma mensagem de sucesso é retornada para o usuário. Uma diferença com relação aos outros bots é a utilização de emoticons nas mensagens de status, para tornar a interface mais amigável. Assim, caso uma operação ocorra com sucesso é retornado "Mensagem Publicada :)" e caso ocorra erro o usuário recebe "Erro! :(". Vale lembrar que o cliente de MI utilizado converte os símbolos dos emoticons para as figuras correspondentes, evitando que usuários que desconheçam emoticons não entendam parte da mensagem.

Uma característica relevante deste bot é que além de aproveitar a autenticação já realizada pelo usuário no MI também obtém automaticamente outras informações do usuário . Cada usuário registrado no MI utilizado tem a possibilidade de adicionar seu nome e uma foto nos servidores do Gtalk (além de outras informações). O protocolo Jabber permite 


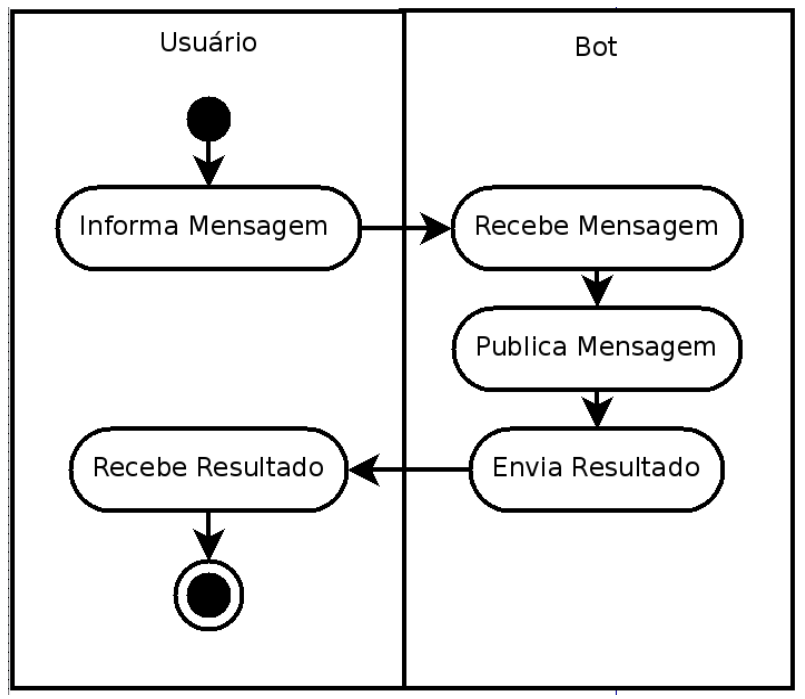

Figura 4.9: Diagrama de atividades do bot robot.wiki
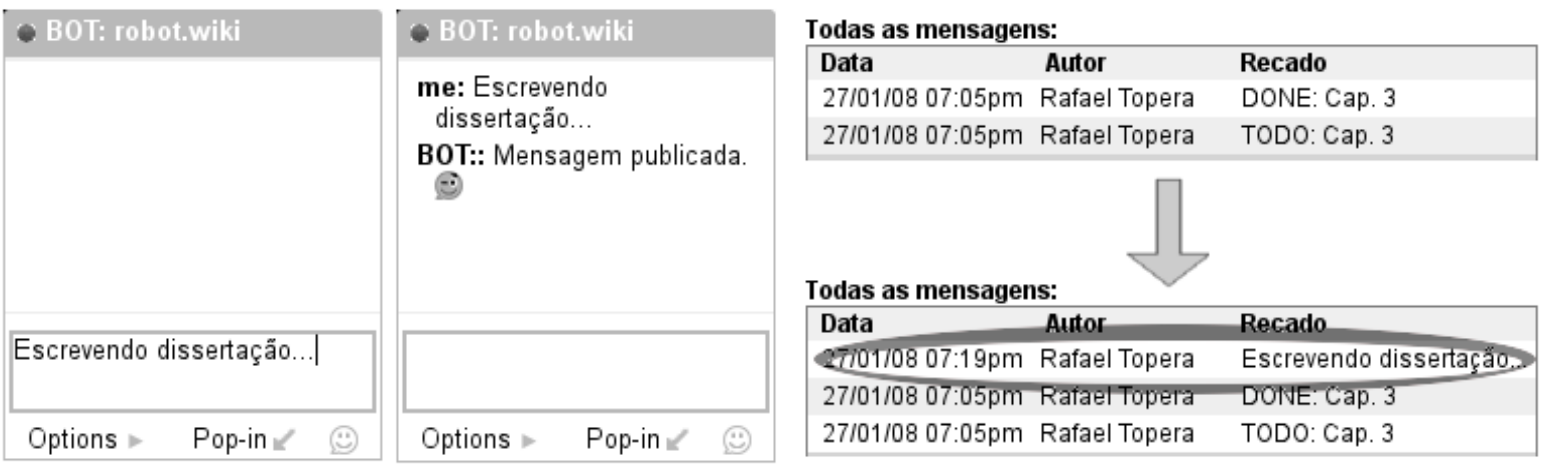

Figura 4.10: Screenshots de utilização do bot robot.wiki (I)

que estes dados sejam obtidos através do envio de pacotes específicos para consulta de dados. Assim, percebe-se uma vantagem da utilização de bots: não há necessidade do usuário informar novamente seus dados, pois estes serão obtidos automaticamente pelo bot. No caso do robot.wiki, são obtidos os nomes e as fotos dos usuários automaticamente $^{11}$ e posteriormente disponibilizados na página web que funciona como mural de recados, como mostra o screenshot da Figura 4.11.

\subsection{Considerações Finais}

Neste capítulo foram apresentados os três bots que foram projetados e implementados (assistente.universal, publicar.noticia e robot.wiki). Eles serviram como prova de conceito

\footnotetext{
${ }^{11} \mathrm{Na}$ verdade isso ocorria apenas na implementação inicial, realizada completamente em PHP. Após a migração do núcleo do sistema para Java, a busca automática de fotos deixou de funcionar porque a API Smack ainda não possui essa funcionalidade. É importante frisar que a migração do PHP para Java ocorreu porque a API em PHP ainda é muito instável e tornava o bot offline diversas vezes.
} 


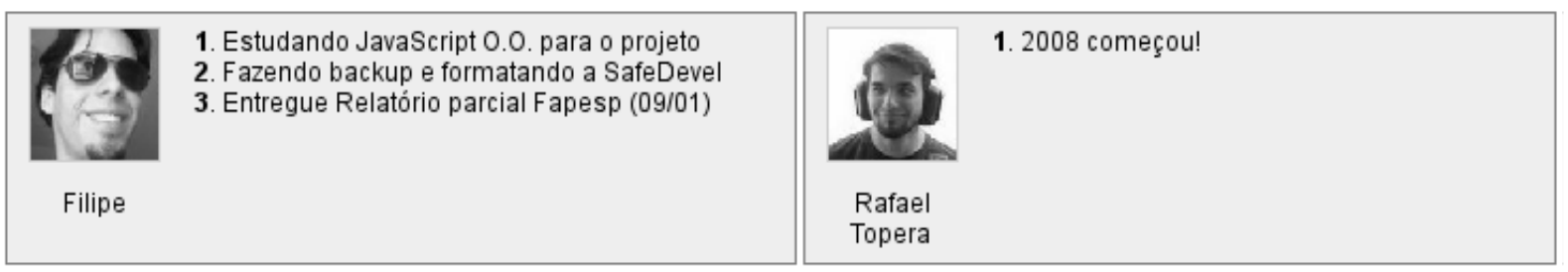

Figura 4.11: Screenshots de utilização do bot robot.wiki (II)

para que a investigação sobre a forma de interação proposta fosse experimentada. Além disso, foi destacado o gerenciador de bots, que propicia uma generalização para a criação e gerenciamento de bots. Para cada bot foram descritas suas funcionalidades, comandos definidos e screenshots de utilização, visando ressaltar as características gerais e específicas dos três bots. No próximo capítulo, estão relatados os resultados das experiências realizadas com usuários reais utilizando os bots. 



\section{Avaliação dos Bots para Mensageiros}

Instantâneos

\subsection{Considerações Iniciais}

No contexto da proposta de combinação de bots com mensageiros instantâneos para interação com wikis, os bots projetados, conforme descrito no capítulo anterior, foram alvo de experiências de uso por usuários em cenários reais. Segue-se neste capítulo um relato de como os bots foram avaliados durante o período de utilização. Por fim, são apresentadas as vantagens e desvantagens observadas e analisadas a partir da forma de interação proposta pelo autor deste trabalho.

\subsection{Avaliação do Bot assistente.universal}

O bot assistente.universal foi implementado para ser utilizado livremente por qualquer usuário da Internet, sendo inicialmente divulgado entre os estudantes da USP São Carlos. Foram registradas todas as mensagens enviadas para o bot nos últimos quatro meses de utilização $^{1}$, sendo constatado que 132 pessoas o utilizaram pelo menos uma vez, enviando um total de 2808 mensagens (quantidade aproximada de mensagens por usuário: mínimo=1, máximo=149, média=21 e moda=6).

\footnotetext{
${ }^{1}$ De $01 / 10 / 07$ a $01 / 02 / 08$
} 


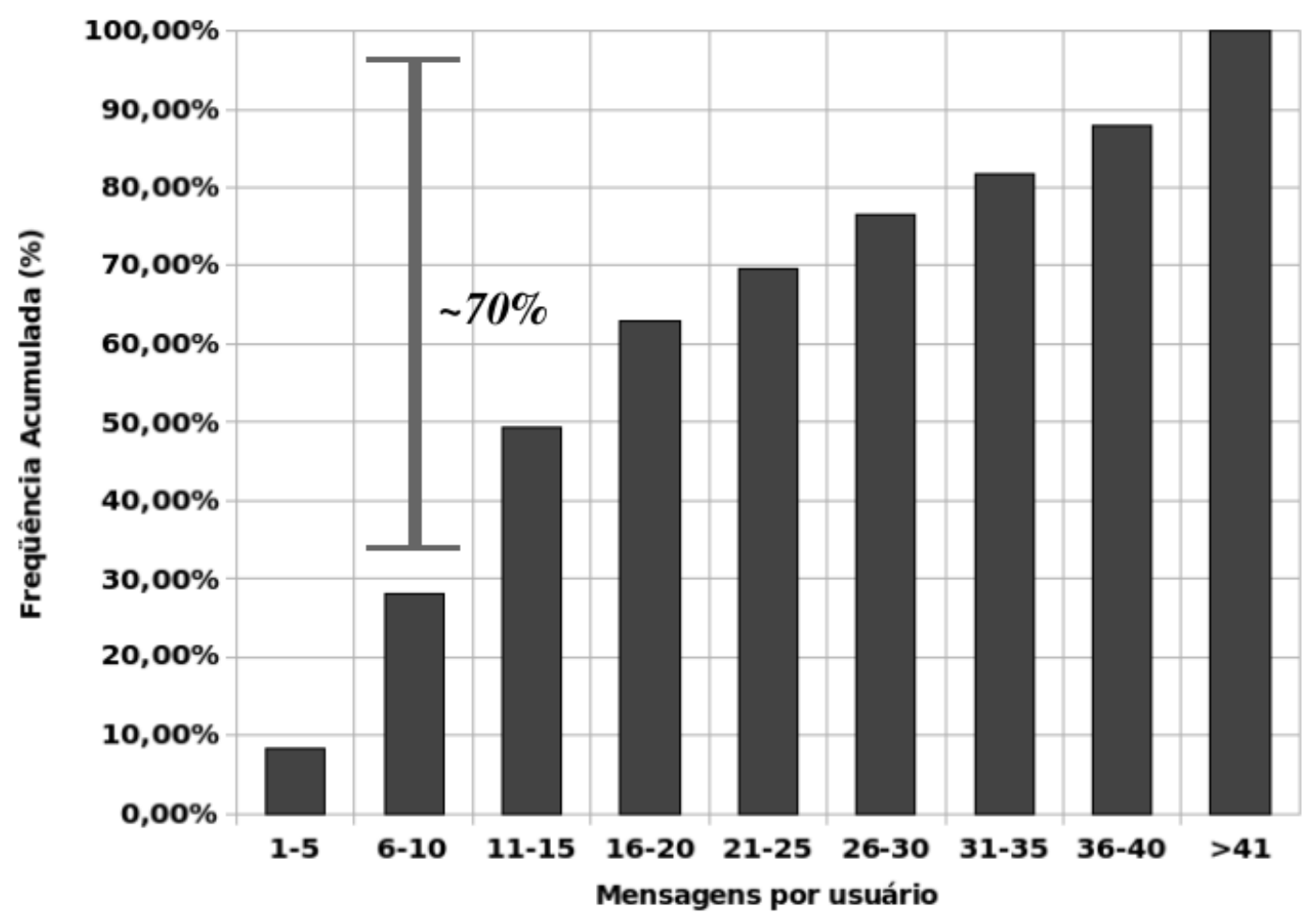

Figura 5.1: Concentração mensagens/usuário do bot assistente.universal

No histograma acumulado da Figura 5.1, pode-se notar que o bot teve uma baixa taxa de rejeição, já que aproximadamente apenas $8 \%$ dos usuários enviaram menos do que 5 mensagens, ao passo que quase $70 \%$ utilizou a ferramenta pelo menos 10 vezes.

Os usuários utilizaram 6 aplicativos (programas clientes de MI) diferentes ${ }^{2}$ para acessar o bot assistente.universal: Gmail ${ }^{3}, \mathrm{Gtalk}^{4}$, Pidgin $/ \mathrm{Gaim}^{5}, \mathrm{Meebo}^{6}$, Miranda ${ }^{7}$ e TalkGadget $^{8}$. Como mostra a Figura 5.2, temos que a grande maioria (aproximadamente 82\%) dos acessos ocorreu pelo cliente Gmail, mostrando uma preferência dos usuários por este modo de acesso ao bot durante o período de sua disponibilização. Entretanto, ainda há cerca de 1/5 dos usuários acessando a partir de clientes diversos, o que sugere aos desenvolvedores criarem bots que possam ser acessados de forma padronizada. É importante dar especial atenção à formatação das mensagens e na utilização de emoticons em bots, já que cada cliente poderá interpretar as marcações de forma diferenciada. Ao constatar esse fato, as formatações de texto foram restringidas apenas aos usuários do Gmail, pois

\footnotetext{
${ }^{2}$ Foram descartadas variações de versão dentro do mesmo cliente.

${ }^{3}$ Versão embutida no Gmail, acessada via browser.

${ }^{4}$ Versão que deve ser instalada no Sistema Operacional do usuário

${ }^{5}$ http://www.pidgin.im

${ }^{6}$ http://www.meebo.com

${ }^{7}$ http://www.miranda-im.org

${ }^{8}$ http://www.google.com/talk
} 


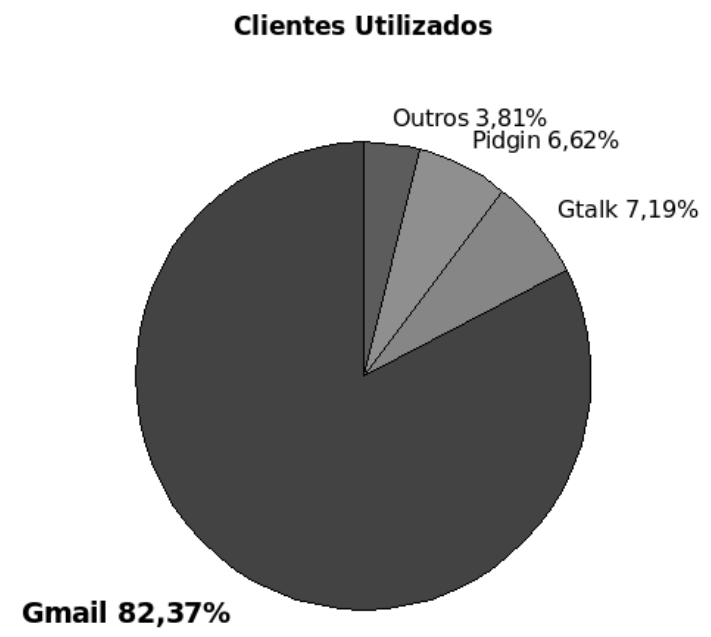

Figura 5.2: Clientes utilizados no acesso e interação com o bot assistente.universal

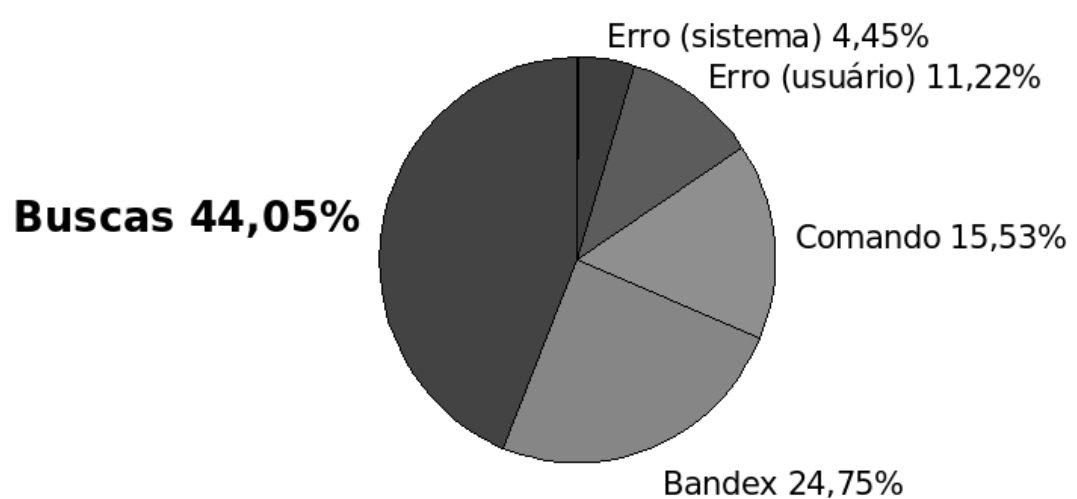

Figura 5.3: Tipos de mensagens enviadas ao bot assistente.universal

diversos usuários estavam recebendo mensagens "poluídas" com caracteres de formatação que não foram interpretados pelo software cliente.

Com relação ao conteúdo das mensagens enviadas, na Figura 5.3 é apresentado o gráfico mostrando os tipos de comandos mais utilizados no período e observa-se que aproximadamente metade das mensagens enviadas ao bot teve por objetivo buscar palavras no dicionário, e que 1/4 das mensagens foram enviadas para consulta do cardápio do dia (pelo comando "bandex"). Esse fato possibilita evidenciar que os usuários realmente apreciaram a busca pelo cardápio, pois, mesmo esta não sendo a função principal idealizada para o bot, acabou tornando-se muito utilizada. Cerca de $15 \%$ das mensagens foram referentes a outros comandos, como exibição da tela de ajuda (41\% dos comandos), mudança de idioma ( $26 \%$ dos comandos) e consultas gerais ( $33 \%$ dos comandos), pelos comandos sobre, fonte e priv. 
Com relação aos "erros", cometidos por parte dos usuários (11,22\% das mensagens), temos que diversos enviaram linguagem natural, sendo que a maior parte dos usuários o fizeram para testar ou se divertir com o sistema (7,4\% de todas as mensagens enviadas), como pode-se notar no conteúdo das mensagens. Além disso, foram registradas 107 (3,8\% do total) mensagens que correspondem a comandos inválidos. Os erros do sistema correspondem ao envio de mensagens vazias $^{9}$ do bot para o usuário e totalizam a 125 (4,45\% do total) mensagens.

Além da análise do log, foram realizados uma pesquisa por meio de questionário e um estudo de caso com usuários para a avaliação do bot, que seguem documentados nas próximas seções.

\subsubsection{Avaliação por Questionário}

Um questionário foi elaborado e enviado por email para as 132 pessoas que utilizaram o bot assistente.universal. Foram recebidas 69 respostas (52\% responderam). As perguntas elaboradas foram:

1. Você já tinha utilizado algum bot de mensageiro instantâneo antes?

2. Quais dos mensageiros instantâneos abaixo você usa normalmente? (opções: $M S N$, Gtalk, ICQ, AIM, Outro)

3. Como ficou sabendo do bot? (opções: pelo próprio criador do bot, uma pessoa me falou, pelo orkut, não lembro/outro)

4. Aonde você mora atualmente?

5. O que mais gostou e o que menos gostou no bot?

6. Dê uma nota para o bot quanto à:

- Utilidade (1: extremamente inútil, 5: extremamente útil)

- Facilidade de Uso (1: extremamente difícil, 5: extremamente fácil)

A partir da análise das respostas, foi possível obter seguinte taxa de utilização dos mensageiros instantâneos no dia-a-dia dos usuários que responderam ao questionário: MSN (88,4\%), Gtalk (81,1\%), ICQ (14,5\%), Outros (5,8\%) e AIM (0,0\%). Vale notar que grande parte dos usuários normalmente utiliza mais do que um tipo de mensageiro

\footnotetext{
${ }^{9}$ Esta falha existente no bot, de causa ainda indefinida, fazia com que o bot enviasse mensagens sem conteúdo para qualquer usuário que havia se comunicado com o bot anteriormente, após certo período de tempo
} 
instantâneo $(78,2 \%)$, conforme mostra a Figura 5.4. Outro fato relevante é que três pessoas não utilizam mensageiros instantâneos com frequiência, mas mesmo assim decidiram utilizar o bot.

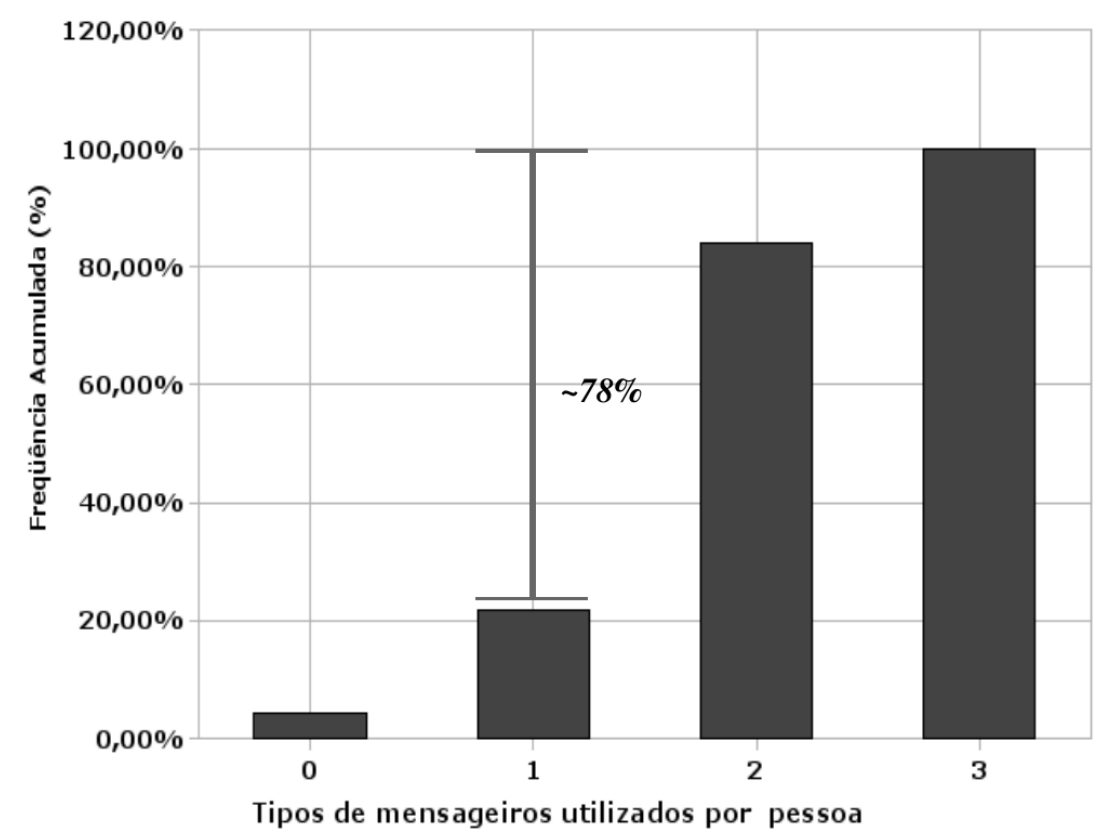

Figura 5.4: Quantidade de tipos mensageiros utilizados por pessoa

Com relação à propagação da utilização do bot, tem-se que $17(24,6 \%)$ pessoas ficaram sabendo do bot através do próprio autor deste trabalho, $48(69,6 \%)$ pessoas ficaram sabendo por terceiros, nenhuma pessoa soube pelo Orkut e $4(5,6 \%)$ por outras formas, como listas de email. Com relação à distribuição geográfica, tem-se que a maioria $(79,7 \%)$ das pessoas que utilizaram são residentes em São Carlos/SP, cidade aonde encontra-se a universidade na qual foi realizada esta pesquisa. Todos as pessoas que responderam a pesquisa eram brasileiros.

Também pode-se constatar que a ferramenta foi considerada útil pelos usuários, obtendo nota média igual a $\mathbf{3 , 8 3}$, sendo verificado também que não há diferença significativa $^{10}$ entre as respostas informadas por quem conheceu o bot por meio do seu criador ou não, comprovando-se a imparcialidade das respostas.

Com relação à facilidade de uso, o bot obteve nota média 4,55; dados também imparciais $^{11}$ que revelam que a ferramenta é considerada fácil ou extremamente fácil pelos usuários. É importante ressaltar que os bots foram considerados mais fáceis do que úteis (variação de aproximadamente 16\%), isto é, a qualidade que mais se destaca é sua facilidade e não sua utilidade, embora ambos os atributos tenham obtido notas altas. Outro

\footnotetext{
${ }^{10}$ Média da utilidade do bot: 3,82 (quem conhece), 3,83 (quem não conhece)

${ }^{11}$ Média da facilidade do bot: 4,59 (quem conhece), 4,54 (quem não conhece)
} 
dado relevante é que 56 pessoas $(81,1 \%)$ nunca haviam utilizado bots anteriormente, indicando que o tempo necessário para aprendizado é, de fato, pequeno, tendo em vista a gradação alta obtida na nota relativa à facilidade de uso.

Por fim, foram examinadas as respostas qualitativas dos usuários, como elogios, críticas e sugestões. As principais qualidades destacadas foram a praticidade/comodidade (14 menções) e agilidade (12 menções). Já as principais críticas foram com relação ao truncamento das respostas ( 8 menções) e respostas incorretas (4 menções). As principais sugestões recebidas foram a adição de novos recursos no bot (5 menções) e a adição de inteligência para processamento de linguagem natural (4 menções).

\subsubsection{Avaliação por Estudo de Caso}

\section{Descrição}

O estudo de caso realizado consistiu na comparação do tempo gasto pelos usuários para encontrar a definição de determinadas palavras utilizando dois métodos diferentes, que nominalmente foram bot e google. No primeiro método os usuários deveriam buscar o significado das palavras utilizando apenas o bot. Já no segundo, os usuários estariam livres para buscar o significado das palavras, começando no site do Google Brasileiro ${ }^{12}$. Ao final da realização do experimento de uso dos dois métodos, foi aplicado um pequeno questionário para obtenção da impressão dos usuários sobre o bot.

Cada participante tinha a tarefa de buscar o significado de oito palavras pré-definidas, utilizando de forma alternada, os métodos bot e google. A utilização dos métodos alternadamente foi controlada durante o estudo de caso. As palavras definidas foram capataz, janota, veronal, besigue, embira, pangolim, xilose e mortalha.

Elas foram escolhidas utilizando os seguintes critérios:

- Serem palavras incomuns à maioria das pessoas - para tornar o experimento mais próximo do uso real, isto é, da busca em dicionários.

- Terem três sílabas e não possuir caracteres especiais como acentos, hífens ou cedilha - para reduzir a variação do tempo gasto com digitação.

- Serem testadas previamente, isto é, as definições das palavras dever ser encontradas pelo bot e estar entre os dez primeiros resultados do Google, quando buscadas sem nenhum parâmetro extra.

O tempo gasto na busca das duas primeiras palavras para cada usuário foi descartado na análise final, servindo apenas como treinamento para o experimento. A ordem de

\footnotetext{
${ }^{12} \mathrm{http}$ ///www.google.com.br. Último acesso em 28/01/08
} 
exibição das palavras para cada usuário foi variável, sendo utilizadas oito sequências diferentes.

A cada uma das oito palavras foi associado um cronômetro em JavaScript que era acionado assim que a palavra era exibida ao usuário, sob solicitação deste. O usuário, então, parava o cronômetro assim que julgava ter recebido a definição da palavra, tanto no bot, quanto na busca pelo Google. Vale notar que, na busca pelo método google, os usuários eram livres para navegar em qualquer site da Internet em busca do significado da palavra, embora o significado já aparecesse na primeira tela de resultados retornados pelo buscador ${ }^{13}$. Quando a busca ultrapassava 30 segundos, o cronômetro era interrompido, mesmo que a definição da palavra não tivesse sido encontrada, indicando que o usuário atingiu o tempo limite máximo permitido para cada busca.

Participaram do experimento 30 alunos (27 homens e 3 mulheres) de cursos de graduação relacionados à computação, da Universidade de São Paulo, campus São Carlos, que foram convidados nos laboratórios de ensino e pequisa de forma aleatória pelo condutor do experimento. O experimento aconteceu em diversos computadores, utilizando o sistema operacional Linux ou Windows e os navegadores utilizados foram Microsoft Internet Explorer ou Mozilla Firefox, escolhidos pelos usuários. No navegador foram abertas três abas que ficaram dispostas uma ao lado da outra, contendo as seguintes páginas, no início do experimento:

- Página do experimento contendo as palavras a serem pesquisadas pelos usuários

- Página com Gmail e Google Talk habilitado, para interação com o bot implementado

- Página inicial do Google

O experimento teve início com a leitura em voz alta do termo de consentimento, seguindo-se as explicações sobre como utilizar os dois métodos de busca, utilizando duas das oito palavras como exemplo. Após as instruções iniciais, os usuários realizaram a busca pelos significados das seis palavras restantes. Foram interrompidos pelo condutor do experimento quando se confundiam, ao utilizar o método incorreto para a busca, por exemplo, buscando no bot uma palavra que deveria ser buscada no Google. Os usuários também eram alertados quando alcançavam o tempo máximo de 30 segundos para cada busca. Ao final do experimento, os usuários responderam voluntariamente a três questões sobre as impressões gerais que tiveram do bot. 


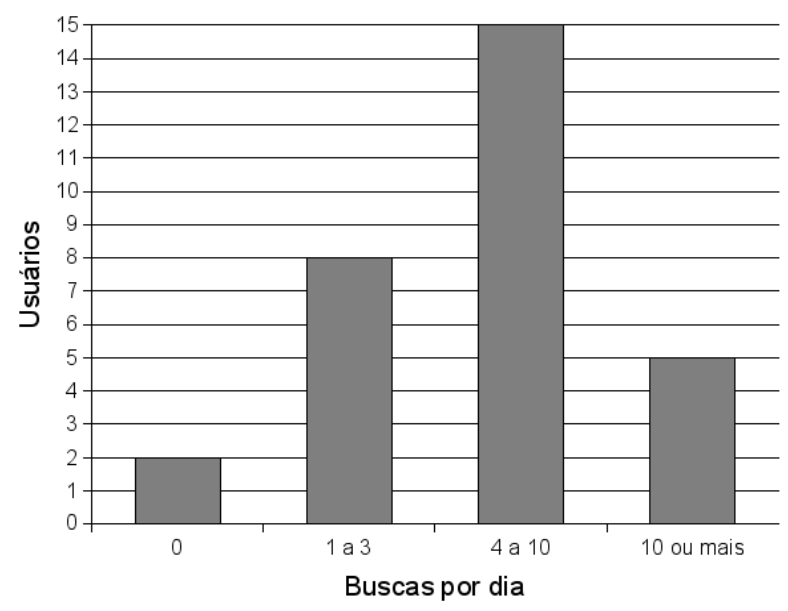

Figura 5.5: Quantidade estimada de buscas por dia

\section{Resultados}

A Figura 5.5 exibe a quantidade de buscas que cada usuário informou que julga realizar por dia no buscador Google. Vale notar que $94 \%$ dos participantes do experimento informaram utilizar o buscador pelo menos uma vez ao dia, sendo que aproximadamente $66 \%$ do total utilizam pelo menos 4 vezes. Tal informação indica certa familiaridade dos participantes com a ferramenta utilizada como comparação no experimento.

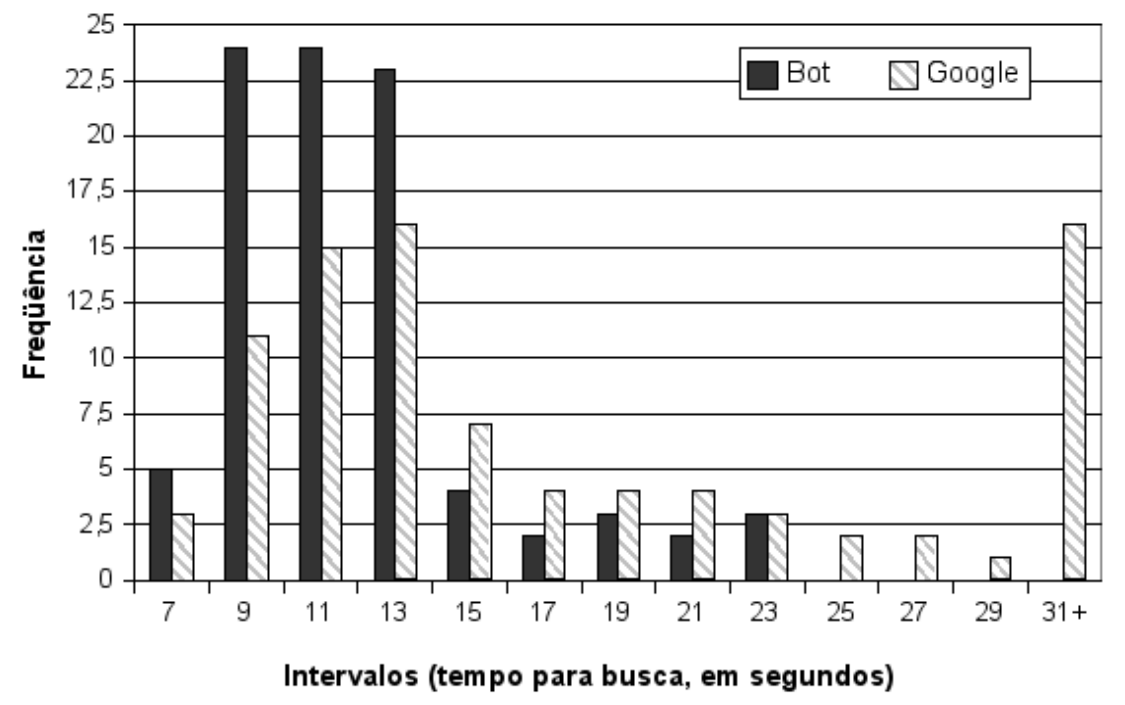

Figura 5.6: Histograma Comparativo do Tempo de Busca

Foi realizado um tratamento inicial dos dados referentes às buscas, sendo descartadas 2 das 180 realizadas $(1,1 \%)$ pelo fato do usuário informar que havia encontrado a definição da palavra sem ao menos ter iniciado a busca. Vale notar que 16 das 90 (17,7\%) buscas pelo método google ultrapassaram o tempo máximo permitido pelo condutor do experimento

\footnotetext{
${ }^{13}$ Todas as palavras foram testadas previamente para que isso acontecesse.
} 
e foram interrompidas, sendo atribuído o valor de 30 segundos, o que explica o pico encontrado na classe de 31 segundos do histograma da Figura 5.6.

Os tempos das buscas realizadas pelo método bot mantiveram-se relativamente próximos, ao passo que os tempos das buscas pelo método google mostraram-se mais dispersos. Em ambos os métodos, porém, houve uma predominância das buscas com duração entre 9 e 13 segundos. O tempo médio das buscas por bot e google foi de aproximadamente 10,9 e 16,4 segundos, respectivamente, sendo importante ressaltar que a média por google é de fato maior, já que as buscas mais demoradas foram interrompidas.

Vale notar que o tempo para as buscas variou não apenas pela ferramenta utilizada, isto é, pelo método bot ou google, mas também pela forma como os usuários interagiam como o computador, devido à experiência de cada um. Cabe ainda destacar as seguintes observações:

- Alguns usuários leram a palavra informada e a digitaram novamente ao passo que outros utilizam atalhos como Ctrl+A (selecionar tudo) e Ctrl+C (copiar), reduzindo o tempo necessário para a busca.

- Alguns poucos usuários utilizaram o argumento define no buscador Google, visando delimitar a busca. Porém o uso do argumento aumentou o tempo de buscas pelo método google, já que em 6 das 8 palavras pesquisadas nenhum resultado foi retornado.

- Diversos usuários demoraram para perceber ou sequer perceberam que foi retornada uma página contendo a definição da palavra pesquisada.

A Figura 5.7 mostra a relação existente entre maior utilização do Google e menor tempo gasto com buscas durante o experimento realizado. Conforme esperado, ambos os métodos de busca foram realizados em menor tempo quanto maior a experiência do usuário com buscas, exceto por aqueles que informaram utilizar mais de dez vezes por dia. Isso se deve, provavelmente, ao fato de usuários experientes utilizarem o parâmetro define.

Os usuários foram questionados sobre a velocidade do bot em relação ao Google, dando notas entre 5 (muito melhor) e 1 (muito pior). O bot obteve a nota $\mathbf{3 , 9 7}$, fornecendo indícios de que os usuários tiveram conhecimento de que as buscas estavam sendo realizadas de maneira mais eficiente com ele. Também foram questionados sobre a utilidade da ferramenta, podendo avaliar com notas de 5 (extremamente útil) a 1 (extremamente inútil). A nota final obtida foi de $\mathbf{4 , 3}$, fornecendo evidências de que os usuários se interessariam em utilizar bots desse tipo no dia-a-dia para aumentar sua produtividade.

Alguns usuários observaram que a busca via bot tem a vantagem de ser especializada, isto é, tem uma única função, ao passo que a busca via Google retorna diversos resultados 


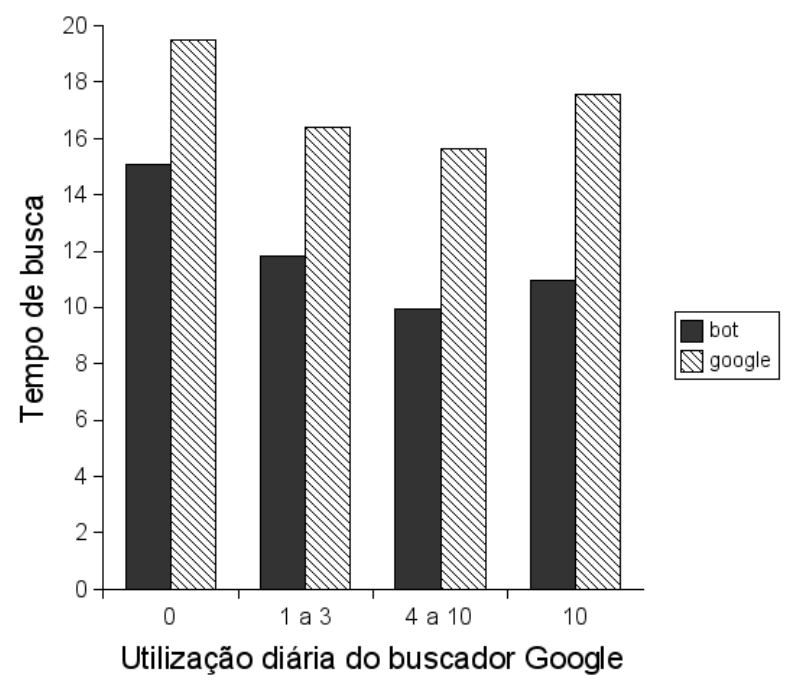

Figura 5.7: Relação entre experiência do usuário e tempo de busca

irrelevantes para quem apenas necessita de um dicionário online. Outros destacaram a vantagem da interação via bot ocorrer por meio de um mensageiro instantâneo, sendo desnecessário abrir outro aplicativo ou página web, para aqueles que já utilizam o Google Talk no dia-a-dia. Outros usuários destacaram desvantagens, salientando que mesmo a busca pelo bot sendo mais objetiva e rápida, a busca via método google retorna informações mais completas, já que a interface de exibição é uma página web e não apenas texto.

Finalmente, para atender os objetivos desta pesquisa, o estudo de caso proporcionou um cenário real, o qual foi bastante útil para observações dos comportamentos de usuários que, mesmo já atuando em computação, reagem de diferentes maneiras diante da inovação que lhe são apresentadas.

\subsection{Estudo de caso: Bot publicar.noticia}

O bot publicar.noticia foi utilizado por cinco jornalistas do Instituto de Estudos Avançados da USP São Carlos, durante o segundo semestre de 2007 e início de 2008, sendo a análise do log dos últimos quatro meses ${ }^{14}$ a forma de avaliação utilizada.

Ao analisar o log do bot, constatamos que o mesmo recebeu 204 mensagens enviadas pelos cinco jornalistas, sendo que uma pessoa foi responsável por grande parte das mensagens enviadas $(42 \%)$ e outra pouco o utilizou (2\%), como mostra a Figura 5.8. Todas as mensagens recebidas pelo bot foram envidas pelo cliente do Gtalk embutido no Gmail, indicando forte preferência dos jornalistas participantes por este software.

Conforme esperado, as mensagens referentes à publicação de novas notícias dividiram-se em partes praticamente iguais: $32 \%, 31 \%$ e $31 \%$ do total, respectivas a cada um dos passos

\footnotetext{
${ }^{14}$ De $01 / 10 / 07$ a $01 / 02 / 08$
} 


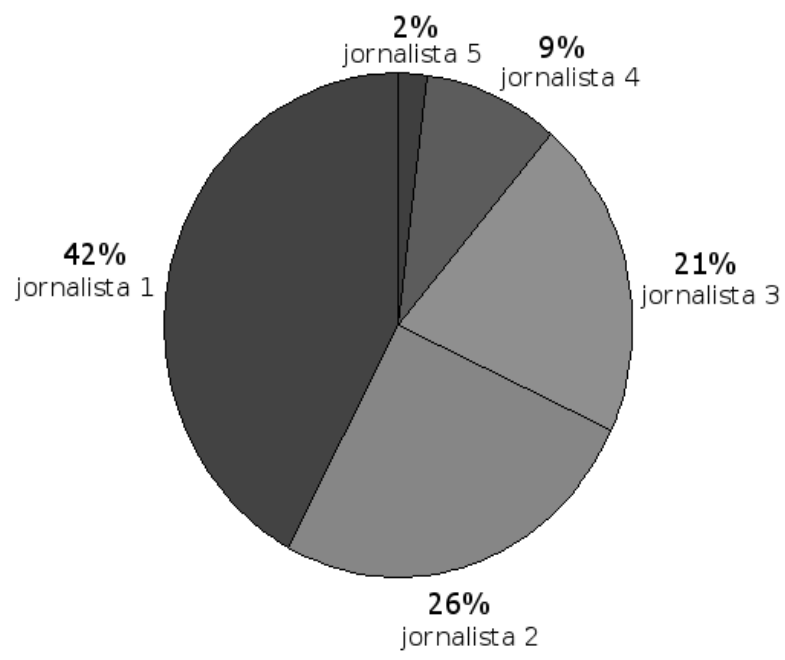

Figura 5.8: Concentração mensagens/usuário do bot publicar.noticia

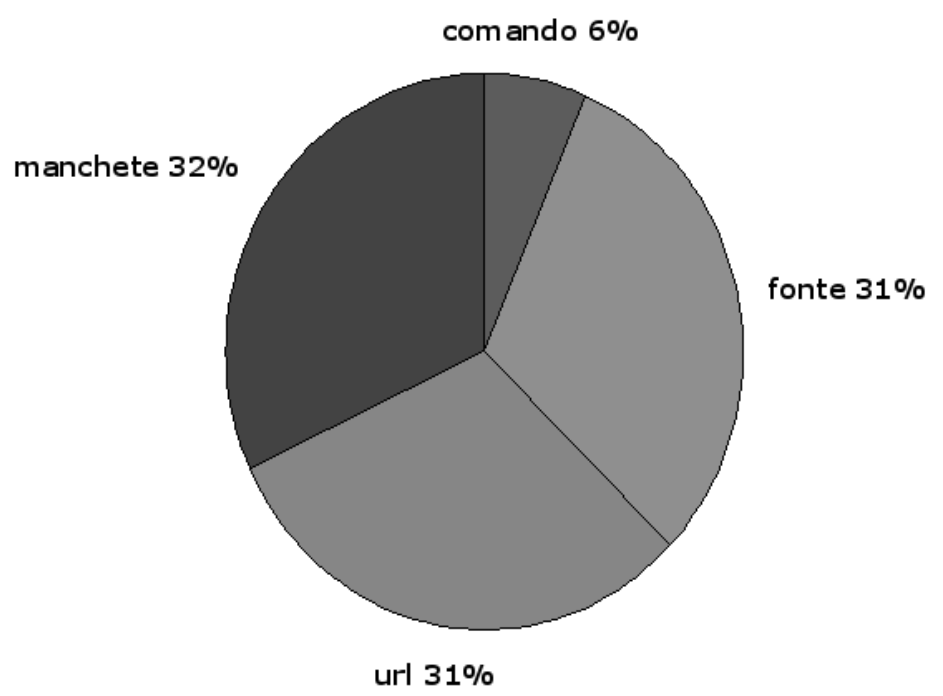

Figura 5.9: Tipos de mensagens enviadas ao bot publicar.noticia

necessários para publicação (envio de manchete, envio de url e envio de fonte), como apresenta a Figura 5.9. Assim, nota-se uma baixa quantidade de erros dos usuários durante a publicação, já que foram inseridas 65 notícias e apenas duas (3\%) foram canceladas durante o processo. Entretanto, a quantidade de erros após a publicação sobe para 21\%, já que 13 notícias foram apagadas logo após serem cadastradas. Somente $6 \%$ das mensagens recebidas pelo bot foram comandos, sendo que o único utilizado foi \# undo, para exclusão de notícias. O principal motivo (70\%) de exclusão de mensagens foi a melhoria da manchete, através da reordenação de palavras ou da diminuição do texto. Os comandos \#show e \#list, referentes a consulta de notícias não foram utilizados sequer uma vez, indicando que o bot foi utilizado apenas como bot de publicação. Curiosamente, o comando \#help também não foi utilizado, indicando que o comando \# undo foi de fá- 
cil memorização. É importante lembrar que a análise do log não contemplou a fase de aprendizado de utilização do bot, sendo verificado apenas o período final de utilização.

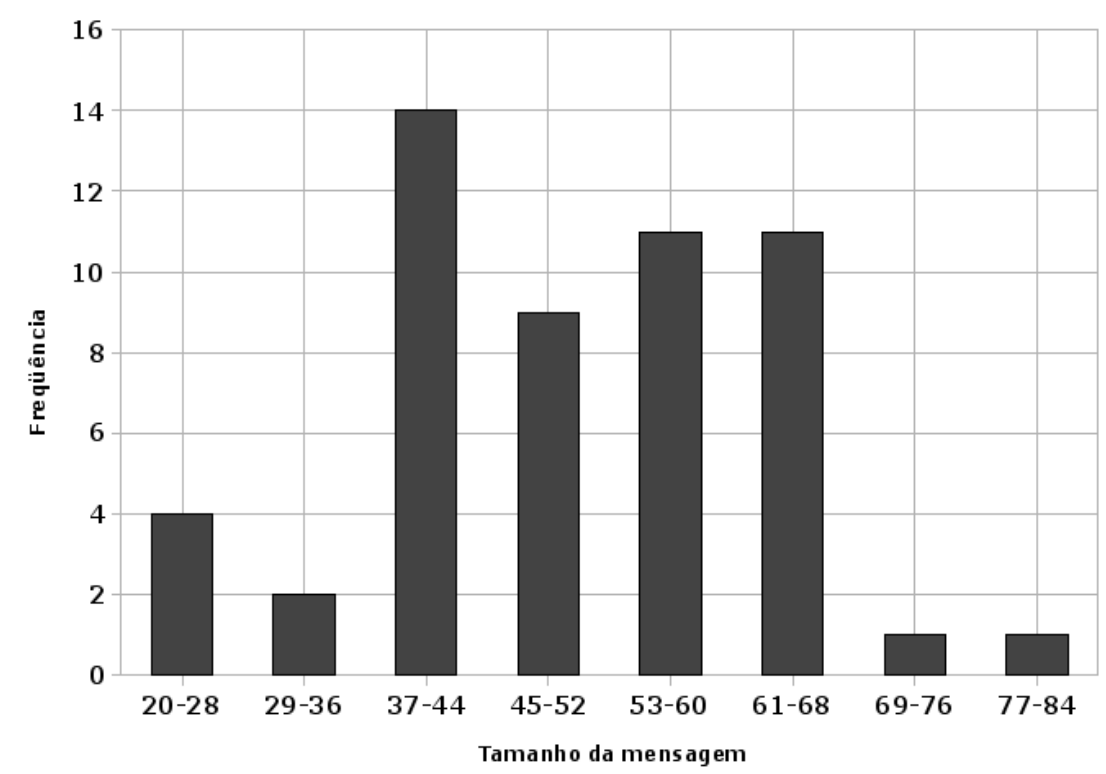

Figura 5.10: Histograma de freqüência das postagens no bot publicar.noticia

Com relação ao tamanho das manchetes de notícias enviadas para o bot, tiveram variação entre 20 e 78 caracteres, com média igual a 40,7, concentrando-se no intervalo de 37 a 68 caracteres, como mostra o histograma da Figura 5.10.

\subsection{Estudo de caso: Bot robot.wiki}

O bot robot.wiki foi utilizado por alunos e pesquisadores do grupo de pesquisa do Laboratório Intermídia do ICMC/USP durante o segundo semestre de 2007 e início de 2008, sendo a análise do log dos últimos quatro meses ${ }^{15}$ a forma de avaliação utilizada.

Após análise do registro das mensagens trocadas com o bot, foi constatado que 15 pessoas utilizaram o bot pelo menos uma vez, sendo recebidas 221 mensagens. Como mostra a Figura 5.11, apenas 3 usuários (20\%) são responsáveis por aproximadamente metade das mensagens enviadas, o que indica certa concentração de uso por parte desses usuários. Em média, os usuários enviaram 14,7 mensagens para o bot durante o período de avaliação.

Com relação aos aplicativos clientes utilizados para acessar o bot, foram registrados 8 programas diferentes: Gmail, Gtalk, Pidgin, Gaim, Adium, Meebo, TalkGadget e Kopete. O cliente mais utilizado (Gmail) foi origem de aproximadamente apenas $64 \%$ dos acessos,

\footnotetext{
${ }^{15}$ De $01 / 10 / 07$ a $01 / 02 / 08$
} 


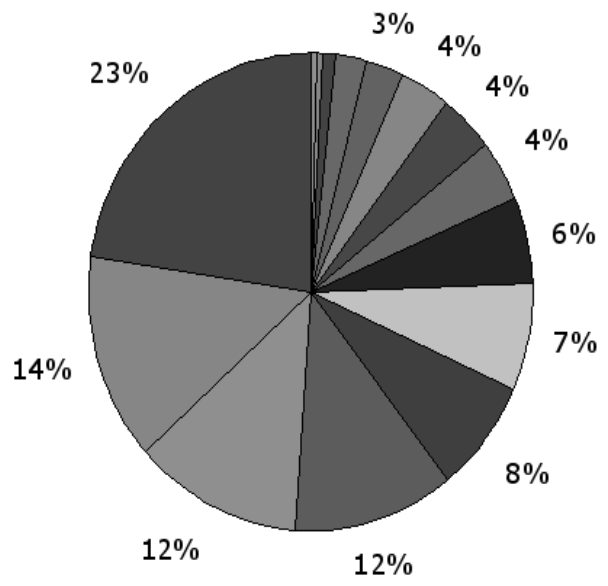

Figura 5.11: Concentração mensagens/usuário do bot robot.wiki

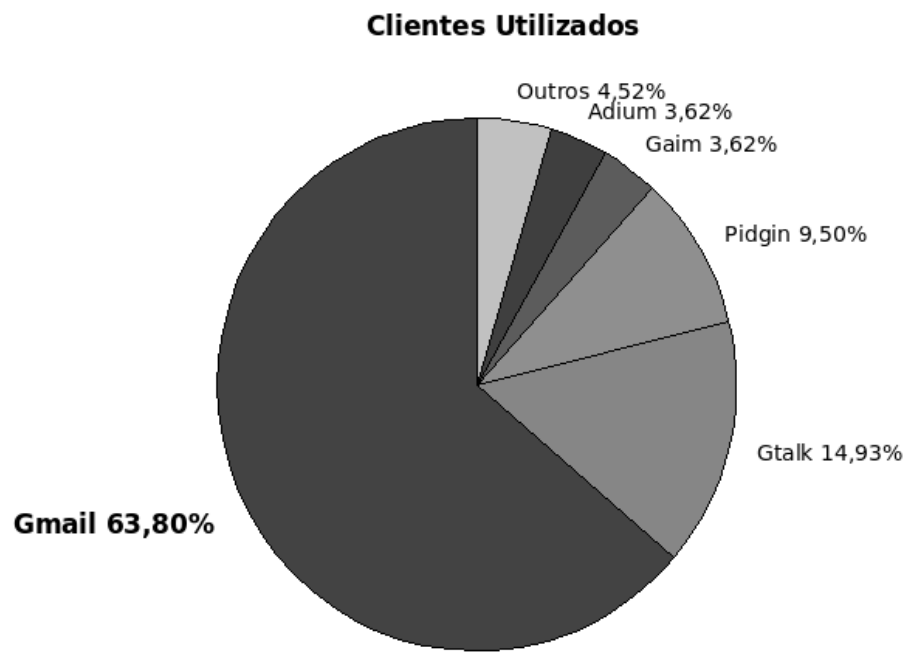

Figura 5.12: Clientes utilizados no bot robot.wiki

como mostra a Figura 5.12, indicando que construtores de bots devem estar cientes para a diversidade de clientes utilizados, como já citado na análise do bot assistente.universal.

As mensagens recebidas pelo bot foram agrupadas em quatro tipos: postagens, comandos, erros do usuário e erros do sistema. As postagens são mensagens que cumprem o objetivo final do bot, isto é, publicar mensagens no site e podemos ver na Figura 5.13 que cerca de metade das mensagens são desse tipo. Já as mensagens de comando servem principalmente para consulta ou manutenção das mensagens já enviadas e correspondem a $38 \%$ do total. As mensagens relacionadas a erro somam 13\%, sendo $6 \%$ bugs do sistema (recebimento de mensagens com conteúdo null $^{16}$ ) e $7 \%$ deslizes usuário (erros de digitação) ou enganos do usuário (envio de linguagem natural). É interessante notar que alguns usuários cometeram o deslize de enviar determinados comandos permitidos em apenas um dos bots para outro, ocasionando erro. Isso indica que é importante identificar

\footnotetext{
${ }^{16}$ Causa ainda não descoberta.
} 


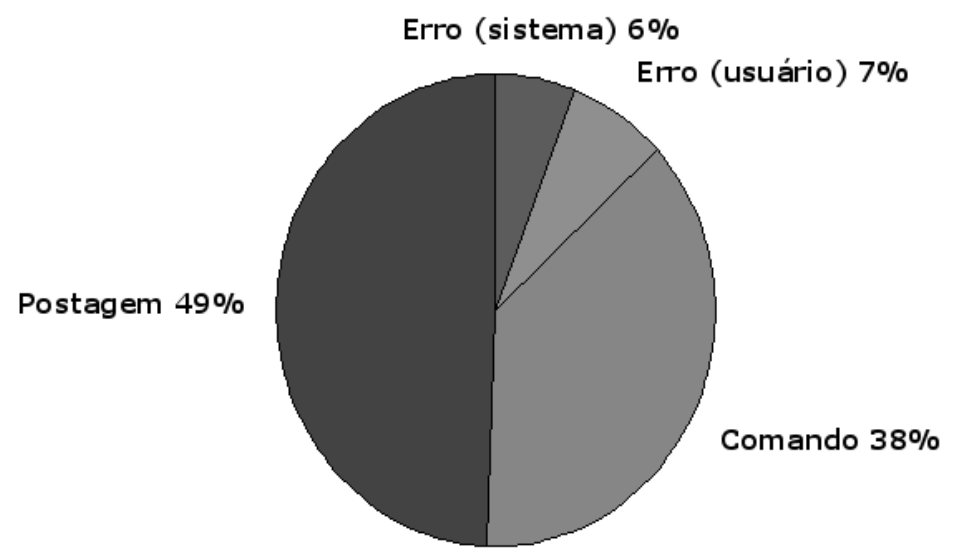

Figura 5.13: Tipos de mensagens enviadas ao bot robot.wiki

claramente qual a função de cada bot através de ícones relevantes e nomes sugestivos, que auxiliem o usuário a perceber e distinguir mais facilmente qual a função do bot. Como exemplo, temos que o nome publicar.noticia parece ser apropriado, ao passo que robot.wiki é desaconselhável por ser impreciso quanto a sua função.

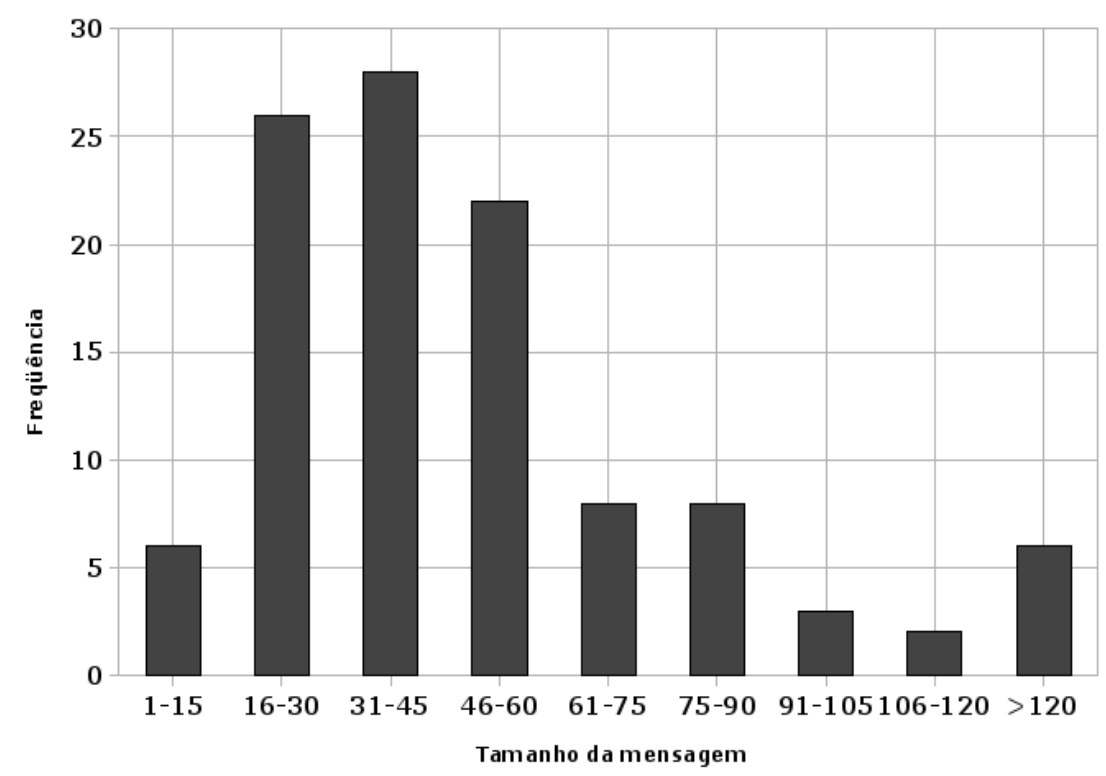

Figura 5.14: Histograma de freqüência das postagens no bot robot.wiki

O histograma da Figura 5.14 agrupa o tamanho das postagens enviadas ao bot em classes com amplitude de 15 caracteres. É possível notar que as postagens se concentram no intervalo entre 16 e 60 caracteres, indicando que o bot cumpriu sua função de publicar principalmente $\operatorname{curtas}^{17}$ mensagens de texto. Esse fato deve estar relacionado com a quantidade padrão de caracteres disponíveis para publicação no cliente gmail, o qual

\footnotetext{
${ }^{17}$ Como exemplo seguem duas mensagens, com 16 e 60 caracteres, respectivamente: "A rápida raposa!" e "A rápida raposa castanha salta por cima do cão lento agora!!"
} 
permite somente 74 caracteres. A menor e a maior postagens têm, respectivamente, 5 e 345 caracteres, sendo o tamanho médio das mensagens aproximadamente 88,5 caracteres, se distanciando do intervalo 16-60 por haverem algumas mensagens grandes isoladas, agrupadas principalmente na classe $>120$. As mensagens de maior tamanho são aquelas nas quais os usuários agruparam várias mensagens ao invés de mandar uma de cada vez.

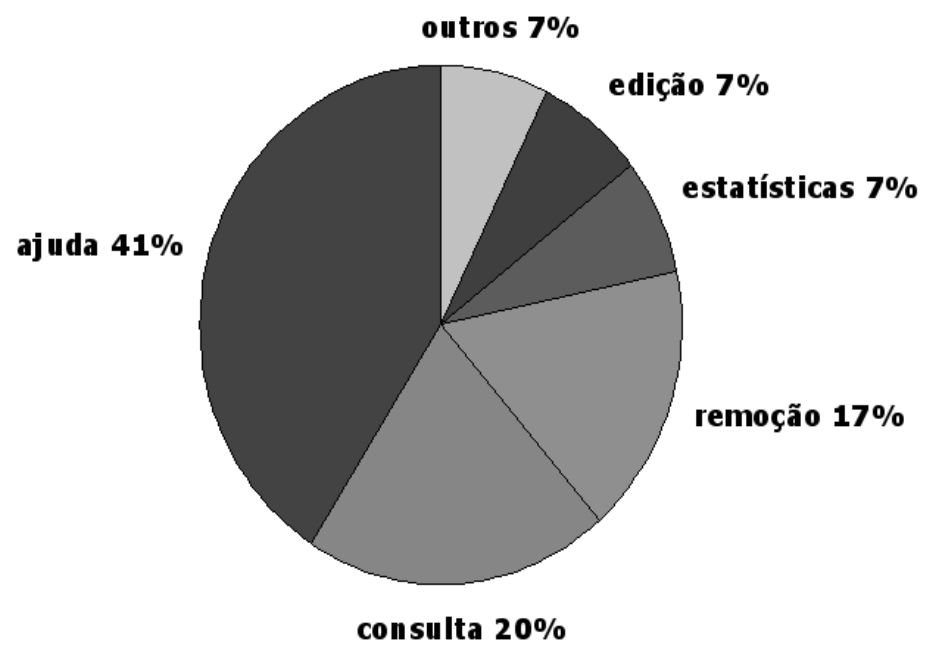

Figura 5.15: Tipos de comandos enviados ao bot robot.wiki

Na Figura 5.15, é apresentada a distribuição dos tipos de comandos enviados e, destes, $41 \%$ são de ajuda, o que indica, provavelmente, que os nomes escolhidos para os comandos não são de fácil memorização, já que os usuários consultaram com frequência a lista de comandos disponíveis. Os comandos para consulta de dados somam $20 \%$ dos comandos, sendo apenas $8 \%$ do total de mensagens trocadas, o que indica que o bot foi usado preferencialmente como bot de publicação do que como bot de consulta, ou seja, os usuários preferiam ir até a página web para acompanharem as postagens.

\subsection{Considerações Finais}

Com base nos estudos de caso realizados a partir dos bots desenvolvidos e análise dos trabalhos encontrados na literatura, observamos indícios de que a proposta de interação por meio dos bots para MI apresenta uma série vantagens e desvantagens, quando comparadas com ferramentas convencionais.

\section{Vantagens}

1. Tempo de interação reduzido: as respostas do questionário de avaliação do bot assistente.universal, contidas na subseção 5.2.1 e as conclusões do experimento 
relatado na subseção 5.2.2 fornecem indícios de que a interação por meio de bots requer menos tempo do que outras ferramentas que realizam a tarefa semelhante.

2. Aplicativo usado com frequência: uma pesquisa realizada por Shiu e Lenhart em 2004 mostrou que $42 \%$ dos usuários da Internet americana utilizam mensageiros instantâneos, sendo que 36\% destes o fazem diariamente [Shiu and Lenhart, 2004, p. I]. Dessa forma, é possível estimar que $15 \%$ dos usuários conectados estão com algum cliente de mensagem instantânea aberto. Assim, ganha-se agilidade, pois não é necessário abrir ou instalar outro programa para realizar a tarefa desejada. Vale notar que para ser diretamente acessado por esta proporção de usuários, o bot deve ser replicado entre os diversos mensageiros instantâneos, devido a incompatibilidade entre muitos sistemas.

3. Pré-autenticação: os mensageiros instantâneos convencionais requerem autenticação para serem utilizados e por este motivo os bots possuem as vantagens da autenticação. Herda-se, dessa forma, benefícios como o sigilo das mensagens e a garantia da origem dos dados (irrefutabilidade), citados por [Kurose and Ross, 2003, p. 442] como algumas das bases de uma comunicação segura. Assim, é possível desenvolver aplicativos que tenham restrição de acesso a informações sigilosas ou que permitam a publicação em páginas web de apenas usuários pré-definidos. Dessa forma, os bots possuem as vantagens de sistemas que requerem autenticação sem terem o custo da autenticação em si, pois esta já foi anteriormente realizada, aumentando a agilidade.

4. Aplicativo colaborativo, distribuído e móvel: os bots são ferramentas com grande potencial, pois herdam as características naturalmente colaborativas e distribuídas dos mensageiros instantâneos, já que todo bot pode ser acessado por sua lista de amigos (colaboratividade) e de qualquer ponto da Internet (distributividade) [Chan et al., 2005, p. 114]. Assim, uma tarefa pode ser iniciada por um usuário amigo do bot e ser encerrada por outro, como a edição de pequenos textos ou a publicação de notícias, por exemplo. Além disso, a comunicação pode ser iniciada e terminada pelo mesmo usuário em diferentes pontos de acesso, devido à possibilidade de acesso remoto. Os bots também possuem mobilidade, já que diversos dispositivos móveis, como laptops e celulares, incluem mensageiros instantâneos. Segundo pesquisa realizada por Shiu e Lenhart, 15\% dos americanos que utilizam mensageiros instantâneos o fazem por meio de dispositivos móveis [Shiu and Lenhart, 2004, p. $\mathrm{V}]$.

5. Vantagens da interação via texto: o fato dos bots possuírem uma interface totalmente baseada em texto faz com que estes herdem algumas das vantagens e 
desvantagens das interfaces por linha de comando. Como vantagem, podemos citar a possibilidade do uso de parâmetros e o acesso direto às funcionalidades do sistema (dependendo de como a interface via texto é projetada), em contraste com a navegação por meio de menus [Dix et al., 2003, p. 137]. Também há o aumento da agilidade que ocorre pelas características próprias da digitação, já que em teclados de computador as teclas são fixas, com posição absoluta, ao passo que em interações via mouse, os objetos a serem clicados podem estar em posição relativa, isto é, dependentes de contexto. Além disso, deve-se comparar o tempo gasto com o deslocamento do cursor do mouse pela tela com o tempo necessário para o deslocamento das teclas e a quantidade de informação que pode ser transmitida por estes métodos. Cálculos realizados por [Carroll, 2003, p. 401] mostram que a digitação é cerca de três vezes mais rápida do que a entrada de dados por meio de dispositivos apontadores, como o mouse. Vale notar que estas comparações analisam apenas as interações por mouse e teclado, descartando outras formas, como as que ocorrem por meio da voz ou por sensores.

6. Lembrança de tarefas: o fato dos bots serem incluídos na lista de contatos do usuário pode ajudá-lo a lembrar que determinada tarefa precisa ser realizada, conforme citado no experimento realizado por [Burke, 2004, p. 273]. Vale notar que os bots devem estar configurados para sempre aparecerem na lista de amigos e que este "lembrete" será mais eficaz caso o bot seja designado para uma tarefa específica.

7. Diminuição do tempo de aprendizado da interface: o esforço necessário para que um usuário comece a utilizar um bot é, provavelmente, menor do que em sistemas convencionais. Ao apresentarmos uma nova página web para um usuário, por exemplo, este precisa entender seus conceitos, como menus, botões, ações, etc. No caso dos mensageiros instantâneos, por serem ferramentas populares e usadas com frequência, isso não ocorre, pois o tempo de aprendizado foi realizado anteriormente. Em outras palavras, não é necessário aprender mais uma nova interface, apenas o novo diálogo.

\section{Desvantagens}

1. Limitação a textos pequenos: pelo fato de utilizarem interfaces projetadas para curtas conversas de texto, os bots para mensageiros instantâneos apresentam a desvantagem de receberem como entrada de dados pequenas ${ }^{18}$ strings. Essa característica pode ser um problema, dependendo da aplicação que é desenvolvida para o bot, como por exemplo, a publicação de conteúdo em páginas web: um usuário

\footnotetext{
${ }^{18}$ Apenas 1024 caracteres, por exemplo
} 
pode digitar o conteúdo previamente em um arquivo texto e, ao incluí-lo, deverá lidar com o problema da divisão da string em partes menores [Burke, 2004, p. 274]. Além disso, há o problema da atribuição de outra função à tecla enter em diversas implementações: ao invés de adicionar uma nova linha, o texto é enviado para o servidor, fazendo com que mensagens incompletas sejam enviadas [Burke, 2004, p. 274], diminuindo a usabilidade do sistema ao ferir o princípio da previsibilidade [Dix et al., 2003, p. 261]. Por fim, a limitação a pequenos textos também pode ser um desvantagem no caso da saída de dados, pois as mensagens deverão ser elaboradas de modo que possam ser lidas satisfatoriamente pelo usuário, mesmo em um espaço de poucas linhas.

2. Edição não WYSIWYG: no caso dos bots de publicação, a informação é enviada pelo bot mas é lida por meio de outra interface, como páginas web. Um problema que pode ocorrer é o usuário ficar inseguro por não ter um feedback imediato, isto é, ele precisará ler a mensagem fora do bot para ter certeza de que esta foi disponibilizada corretamente.

3. Desvantagens da interação via texto: desde que surgiram, em 1981, as interfaces baseadas em WIMP (Windows, Icons, Menus e Pointers) tornaram-se cada vez mais populares [Dix et al., 2003, p. 141], pois os usuários leigos estavam pouco acostumados a lidar com interfaces baseadas apenas em linha de comando. Por esse motivo, a interação via bots possui a desvantagem de ser incomum para usuários não-experientes. Além disso, mesmo que o usuário seja experiente, ele pode preferir realizar determinadas tarefas utilizando outras mídias além do texto [Burke, 2004, p. 273].

4. Forte dependência de terceiros: assim como as páginas web e os serviços de email, por exemplo, os bots também estão sujeitos ao funcionamento adequado de servidores e redes envolvidos na comunicação cliente-servidor. Os bots, porém, parecem ser mais sensíveis, já que a disponibilização do serviço pelo bot está sujeito à manutenção da sessão iniciada. Em outras palavras, para que o bot funcione é necessário que esteja logado no servidor de mensagens instantâneas. A dificuldade encontrada é que, muitas vezes, este servidor é externo ao desenvolvedor do bot, isto é, os mantenedores do bot não têm acesso aos servidores da empresa responsável pela gerência das mensagens. Dessa forma, o serviço disponibilizado pelo bot fica sujeito a variações externas, como desconexões inesperadas, queda geral do serviço ou alterações no protocolo utilizado. Burke, por exemplo, relata que, durante seu experimento, a AOL alterou o protocolo utilizado, para desencorajar as iniciativas de criação de vários clientes para o AIM (AOL Instant Messenger), tornando 
o bot indisponível diversas vezes [Burke, 2004, p. 273]. Outro problema é a possibilidade de bloqueio do bot por suspeita de SPIM por parte das empresas que gerenciam o tráfego das mensagens, já que a maioria dos SPIMs são enviados por bots [Paulson, 2004, p. 18].

5. Falta de padronização: atualmente não existe interoperabilidade entre os principais mensageiros instantâneos, fazendo com que os bots desenvolvidos para um determinado mensageiro não possam ser utilizados por outro [Chung and Nam, 2007, p. 213]. Isso sugere duas soluções para o problema: ou o bot deve ser replicado entre os diversos protocolos ou todos os usuários devem usar o mesmo mensageiro no qual o bot foi implementado. Vale notar que existem diversas iniciativas de padronização, sendo a criação do protocolo Jabber a de maior destaque, vindo a se tornar inclusive o padrão IETF $^{19}$, sob o nome de XMPP ${ }^{20}$. Entretanto, mesmo com a definição de um padrão, a maioria das implementações mais utilizadas ainda mantêm cada uma seu próprio sistema independente. Vale notar que existem exceções, como a utilização do protocolo XMPP pelo mensageiro Google Talk e a interoperabilidade entre os clientes ICQ-AIM, Yahoo!Mensseger-MSN e Gtalk-AIM. Um outro problema, relacionado com a falta de padronização, é a variedade de clientes de mensageiros que podem ser utilizados para acessar sistemas sob o mesmo protocolo. Em um dos experimentos realizados por Santos [dos Santos et al., 2009], foi constatado que as mensagens precisavam ser formatadas de acordo com o cliente utilizado, já que o mesmo bot, usando o mesmo protocolo, poderia ser acessado por clientes diferentes. Alguns clientes não permitiam a formatação do texto (adição de negrito e itálico) ao passo que outros o permitiam. Foi preciso condicionar a saída de dados do bot para o usuário, considerando a melhor forma de apresentação para o cliente utilizado.

6. Riscos à privacidade: como abordado na Seção 3.2, os mensageiros instantâneos muitas vezes induzem o envio de mensagens para o destinatário incorreto, pelo fato de várias conversas poderem ocorrer paralelamente [Chung and Nam, 2007, p. 213]. Assim, o mesmo problema pode ocorrer com os bots, no caso do usuário enviar trechos de uma conversa particular para ele, sendo este caso relatado no experimento realizado por [Burke, 2004, p. 273]. Isso pode ser crítico se o conteúdo da mensagem for uma conversa confidencial e esta for disponibilizada em uma página web pública. Será ainda mais crítico se o bot não possuir recursos para desfazer a ação assim que o usuário perceber o deslize que cometeu. Por esta razão, é de fundamental importância que os bots de publicação possuam mecanismos de recuperação em casos de erro (recoverability) [Dix et al., 2003, p. 272], para que a usabilidade do sistema

\footnotetext{
${ }^{19}$ Disponível em http://www.ietf.org nos RFCs 3920 e 3921

${ }^{20}$ Disponível em http://www.xmpp.org
} 
não fique comprometida. Vale notar que também pode ocorrer o inverso: uma mensagem que deveria ser enviada para o bot ser enviada para uma pessoa. Nesta situação não há como desfazer o envio da mensagem, pois em pouco tempo esta será lida pelo outro usuário e poderá se tornar um problema grave se o conteúdo da mensagem for confidencial. Como última ameaça à privacidade dos usuários, temos a possível utilização de bots para registrar alguns hábitos dos usuários por parte de pessoas ou empresas de má fé. Assim como nos vírus de computador, no qual até mesmo um programa útil é executado pelo usuário, mas tem a tarefa de introduzir um programa malicioso, um bot sadio pode ter funções danosas ao usuário. Ex: um bot poderia ser desenvolvido por uma grande empresa para ajudar as pessoas a consultarem quais filmes estão passando nos cinemas da cidade. Além dessa função, entretanto, o bot poderia gravar algumas informações dos usuários, como quantas horas por dia o usuário utiliza o mensageiro ou quais as principais mensagens de status que são utilizadas. Neste último caso, é possível obter a rotina da pessoa, caso ela liste de onde está acessando a Internet, escrevendo "em casa" ou "no trabalho". Enfim, é fácil perceber que, a combinação da utilização de bots duvidosos com a ingenuidade da disponibilização de informações valiosas pode ser perigosa ao usuário. Como possível solução a longo prazo, podemos citar a criação de sites que disponibilizem um banco de dados de bots confiáveis, assim como ocorre com sites de comércio eletrônico, por meio da Versign ${ }^{21}$, por exemplo.

7. Confusão do bot com humano: exceto nos casos em que o bot tenha como objetivo simular um humano, tentando enganar o usuário, os bots devem ser reconhecidos pelos usuários como máquinas. Dessa forma erros comuns podem ser evitados, como o envio de linguagem natural para um sistema que não consiga interpretá-la. Este deslizes dos usuários foram relatados por dos Santos, Fortes e Anacleto durante a fase de avaliação do bot assistente.universal [dos Santos et al., 2009].

Este capítulo apresentou os resultados obtidos com a avaliação dos bots implementados pelo autor deste trabalho. Analisando também os indícios obtidos da avaliação realizada com os resultados de experimentos relatados por outros pesquisadores na literatura disponível, foi possível identificar um conjunto de vantagens e desvantagens da utilização de bots em mensageiros instantâneos. Esse conjunto de vantagens e desvantagens proporciona uma orientação geral que pode servir de diretriz para desenvolvedores de bots para MIs mais evoluídos, ou seja, com funcionalidades mais complexas.

\footnotetext{
${ }^{21}$ http://www.verisign.com
} 
A crescente utilização da Internet nos últimos anos favoreceu o desenvolvimento de diversas ferramentas de comunicação via web. Especialmente as ferramentas que possibilitam a disponibilização online de conteúdos diversos, criados pelos próprios usuários, como as wikis. Nesse contexto, esta pesquisa se propôs a investigar o processo de edição em wikis com mensageiros instantâneos.

Motivada pela busca de um paradigma de interação que aumentasse ainda mais a agilidade durante a edição das páginas, foi projetado e implementado um sistema que combinou propriedades das duas ferramentas de comunicação distintas: mensageiros instantâneos (MI) e wikis.

Foram realizadas as seguintes atividades durante o desenvolvimento desta pesquisa :

Revisão Bibliográfica - um levantamento sobre as ferramentas de publicação na web foi descrito no Capitulo 2. Três taxonomias existentes foram estudadas e foi proposta uma nova taxonomia, atualizada - (Apêndice B). Ainda no Capítulo 2 foi destacado o conceito de wikis, bem como descritas suas características. Ao final, como trabalho relacionado, foi mencionado o sistema QwikWeb [Eto et al., 2005], cuja proposta de exploração de uma nova possibilidade de publicação na web (por meio do envio de emails) propiciou uma idealização promissora e serviu como ferramenta de referência, relevante para a presente pesquisa. No Capítulo 3 foram apresentadas as principais características dos mensageiros instantâneos, relatadas na literatura, além do seu histórico de utilização. Foram descritos também os bots 
para mensageiros instantâneos, foco desta pesquisa, e uma proposta de classificação, elaborada pelo autor deste trabalho, foi apresentada.

Projeto e Desenvolvimento - no Capítulo 4 foram apresentados os três bots que foram projetados e implementados (assistente.universal, publicar.noticia e robot.wiki). Eles serviram como prova de conceito para que a investigação sobre a forma de interação proposta fosse experimentada. Além disso, foi destacado o gerenciador de bots, que propicia uma generalização para a criação e gerenciamento de bots. Para cada bot foram descritas suas funcionalidades, comandos definidos e screenshots de utilização, visando ressaltar as características gerais e específicas dos três bots.

Avaliação da Proposta - no Capítulo 5 foram reportados os estudos de caso realizados a partir dos sistemas interativos de bots, como agentes nos mensageiros instantâneos disponibilizados. Foi possível a observação dos resultados da interação em wikis por meio de bots para mensageiros instantâneos, e os experimentos controlados foram úteis para uma avaliação da proposta em diferentes contextos de uso, com usuários reais.

Finalmente, a partir da experiência prática adquirida e dos estudos realizados, visando auxiliar melhorias no desenvolvimento de bots e sua implantação para real utilização, é proposto o seguinte conjunto de sugestões:

1. Incentivar o uso de mensageiros instantâneos para comunicação inter-pessoal, apresentando a ferramenta e seus benefícios aos usuários alvo;

2. Desenvolver aplicações relevantes, fazendo uso das características pré-existentes em mensageiros instantâneos, como a autenticação, colaboração, distributividade e mobilidade. Aplicações já consolidadas, que ocorrem atualmente por linha de comando, podem ser mais facilmente portadas para interação via bot;

3. Caso os bots estejam relacionados com alguma tarefa que o usuário precise realizar frequentemente, é melhor criar um bot para cada tarefa. Dessa forma, cada bot na lista de amigos do usuário será um lembrete do que deve ser feito;

4. Evitar mudar os clientes para mensageiros instantâneos utilizados pelos usuários em ambientes restritos, como empresariais ou acadêmicos. A alteração do software cliente será uma barreira a mais para a implantação dos bots, pois irá requerer maior tempo de aprendizagem.

5. Evitar desenvolver aplicações que tenham como entrada de dados grande quantidade de textos, pois muitos clientes possuem restrição no tamanho da entrada; No caso da 
exibição de dados para o usuário, deve-se pensar cuidadosamente em cada palavra apresentada, devido à restrição do tamanho da tela;

6. Desestimular o uso da tecla enter pois muitas mensagens poderão ser enviadas sem que o usuário deseje: nestes casos é preferível receber apenas um parágrafo por mensagem e depois unir os textos do lado do servidor;

7. Desenvolver algum método automático para verificar se o bot ainda está online e mantê-lo disponível, pois são grandes a chance de ficar desconectado;

8. Evitar construir bots que enviem muitas mensagens em um curto espaço de tempo ou que envie mensagens para muitos usuários simultaneamente, pois podem ser classificados como bots enviadores de SPIM e serem bloqueados pelas empresas mantenedoras do serviço. O uso de loops ${ }^{1}$ também é fortemente desaconselhável, pois é provável que existam algoritmos que tratem determinados padrões de comunicação implementados nos servidores destas empresas;

9. Tratar todas as mensagens que forem no sentido bot-usuário, para que estas sejam apresentadas adequadamente em todos os clientes de mensageiros utilizados;

10. Replicar o bot, para que seja acessado pelos principais mensageiros instantâneos. Dessa forma os usuários não precisam utilizar outro cliente;

11. Não registrar o histórico de utilização do mensageiro por parte dos usuários muito menos a string de status, para aumentar a privacidade;

12. Caso o bot não processe linguagem natural, explicar claramente para os usuários que ele é apenas um programa de computador que realiza determinadas tarefas e não uma pessoa;

Com a conclusão do presente trabalho, foram também identificadas algumas possibilidades de trabalhos futuros.

A taxonomia de ferramentas de comunicação pela web deve permanecer em constante atualização. Além disso, um estudo mais sistemático e aprofundado dessas ferramentas deve ser alvo de pesquisas científicas que contribuem com as tendências de inovações tecnológicas.

Uma possível evolução decorrente da presente pesquisa seria o desenvolvimento de um sistema que automatizasse a criação de bots, a partir da análise das atividades de um determinado usuário, relacionadas à comunicação, publicação e consultas.

\footnotetext{
${ }^{1}$ Ex. de loop de comunicação: suponha que um bot A envie uma mensagem para o bot B, para checar se ele está online. E suponha que o bot B faça o mesmo, para checar o A. Tem-se, dessa forma, um loop de comunicação A-B-A.
} 
Outro trabalho promissor seria o desenvolvimento de uma wiki que avisasse, por meio de notificações, os usuários sobre as atualizações de edição que ocorram.

Um trabalho futuro bastante desafiador se apresenta considerando-se outras formas de comunicação com a Web, em especial a multimodalidade. Ou seja, supondo que os bots recebam a interação via voz ou gestos. Nessa linha, a área de pesquisas em Computação Ubíqua pode se tornar muito profícua. 


\section{Referências Bibliográficas}

[Berners-Lee, 1989] Berners-Lee,

T. (1989).

Information Management: A Proposal.

CERN, Geneva.

Disponível em: $<$ www.w3.org/People/Berners-Lee/WorldWideWeb.html>. Acesso em: 30 ago. 2008.

[Berners-Lee and Cailliau, 1990] Berners-Lee, T. and Cailliau, R. (1990). WorldWideWeb: Proposal for a HyperText Project. CERN, Geneva. Disponível em: <www.w3.org/Proposal.html>. Acesso em: 31 ago. 2008.

[Bodine and Pignol, 2003] Bodine, K. and Pignol, M. (2003). Kinetic typography-based instant messaging. Conference on Human Factors in Computing Systems, pages 914-915.

[Burke, 2004] Burke, M. (2004). Instant Messaging and Course Diaries. Journal of Computing Sciences in Colleges, 19(5):270-274.

[Carroll, 2003] Carroll, J. M., editor (2003). HCI Models, Theories, and Frameworks: Toward a Multidisciplinary Science (Interactive Technologies). Morgan Kaufmann, 1 edition.

[Chan et al., 2005] Chan, S., Hill, B., and Yardi, S. (2005). Instant messaging bots: accountability and peripheral participation for textual user interfaces. Proceedings of the 2005 international ACM SIGGROUP conference on Supporting group work, pages 113-115.

[Chung and Nam, 2007] Chung, D. and Nam, C. (2007). An analysis of the variables predicting instant messenger use. New Media \& Society, 9(2):212. 
[Cosley et al., 2007] Cosley, D., Frankowski, D., Terveen, L., and Riedl, J. (2007). Suggestbot: using intelligent task routing to help people find work in wikipedia. In IUI '0\%: Proceedings of the 12th international conference on Intelligent user interfaces, pages 32-41, New York, NY, USA. ACM.

[Davies, 2004] Davies, J. (2004). Wiki Brainstorming and Problems with Wiki Based Collaboration. University of York Computer Science.

[Dix et al., 2003] Dix, A., Finlay, J. E., Abowd, G. D., and Beale, R. (2003). Human-Computer Interaction (3rd Edition). Prentice Hall, 3 edition.

[dos Santos and Fortes, 2006] dos Santos, R. P. and Fortes, R. P. M. (2006). Uso de Ontologias como Forma de Classificação de Textos. In Anais Estendidos - WebMedia'2006 (XII Simpósio Brasileiro de Sistemas Multimídia e Web), pages 19-22.

[dos Santos et al., 2009] dos Santos, R. P., Fortes, R. P. M., and Anacleto, J. C. (2009). Avaliação do Bot Assistente Universal. In Artigo em processo de revisão.

[Ebersbach et al., 2005] Ebersbach, A., Glaser, M., and Heigl, R. (2005). Wiki: Web Collaboration. Springer.

[Eto et al., 2005] Eto, K., Takabayashi, S., and Masui, T. (2005). QwikWeb: integrating mailing list and WikiWikiWeb for group communication. In WikiSym '05: Proceedings of the 2005 international symposium on Wikis, pages 17-23, New York, NY, USA. ACM Press.

[Flynn, 2004] Flynn, N. (2004). Instant Messaging Rules: A Business Guide to Managing Policies, Security, and Legal Issues for Safe IM Communication. AMACOM/American Management Association.

[Fortim, 2006] Fortim, I. (2006). Alice no país do espelho: o MUD - o jogo e a realidade virtual baseados em texto. Imaginario, 12(12):171-194.

[Fryer and Carpenter, 2006] Fryer, L. and Carpenter, R. (2006). Emerging technologies: Bots as language learning tools. Language Learning \& Technology, 10(3):8-14.

[Geer, 2005] Geer, D. (2005). Malicious bots threaten network security. Computer, $38(1): 18-20$.

[Giles, 2005] Giles, J. (2005). Internet encyclopaedias go head to head. In Nature 438, pages 900-901. 
[Golle and Ducheneaut, 2005] Golle, P. and Ducheneaut, N. (2005). Preventing bots from playing online games. Comput. Entertain., 3(3):3-3.

[Grinter and Palen, 2002] Grinter, R. and Palen, L. (2002). Instant messaging in teen life. Proceedings of the 2002 ACM conference on Computer supported cooperative work, pages $21-30$.

[Hannay, 1992] Hannay, D. G. (1992). Hypercard automata simulation: finite-state, pushdown and turing machines. SIGCSE Bull., 24(2):55-58.

[Hodgetts and Jones, 2007] Hodgetts, H. and Jones, D. (2007). Reminders, Alerts and Pop-ups: The Cost of Computer-Initiated Interruptions. Lecture Notes In Computer Science, 4550:818.

[Holz, 2005] Holz, T. (2005). A short visit to the bot zoo [malicious bots software]. Security \& Privacy Magazine, IEEE, 3(3):76-79.

[Isaacs et al., 2002] Isaacs, E., Walendowski, A., and Ranganthan, D. (2002). Hubbub: a sound-enhanced mobile instant messenger that supports awareness and opportunistic interactions. Proceedings of the SIGCHI conference on Human factors in computing systems: Changing our world, changing ourselves, pages 179-186.

[Jugel and Schmidt, 2006] Jugel, M. L. and Schmidt, S. J. (2006). The Radeox Wiki Render Engine. In WikiSym '06: Proceedings of the 2006 international symposium on Wikis, pages 33-36, New York, NY, USA. ACM Press.

[Koda, 2007] Koda, T. (2007). Cross-cultural Study of Avatars' Facial Expressions and Design Considerations within Asian Countries. IWIC.

[Kurose and Ross, 2003] Kurose, J. F. and Ross, K. W. (2003). Redes de Computadores e a Internet: Uma Nova Abordagem. Addison Wesley, 1 edition.

[Leuf and Cunningham, 2001] Leuf, B. and Cunningham, W. (2001). The Wiki Way: Quick Collaboration on the Web. Addison-Wesley Professional.

[Lih, 2004] Lih, A. (2004). Wikipedia as Participatory Journalism: Reliable Sources? Metrics for evaluating collaborative media as a news resource. In 5th International Symposium on Online Journalism (April 16-17, 2004).

[Lio et al., 2005] Lio, E. D., Fraboni, L., and Leo, T. (2005). Twiki-based facilitation in a newly formed academic community of practice. In WikiSym '05: Proceedings of the 2005 international symposium on Wikis, pages 85-111, New York, NY, USA. ACM Press. 
[Long and Baecker, 1997] Long, B. and Baecker, R. (1997). A taxonomy of Internet Communications Tools. In Proceedings of WebNet 97 - World Conference on the WWW, Internet $\&$ Intranet. AACE.

[Majchrzak et al., 2006] Majchrzak, A., Wagner, C., and Yates, D. (2006). Corporate wiki users: results of a survey. In WikiSym '06: Proceedings of the 2006 international symposium on Wikis, pages 99-104, New York, NY, USA. ACM Press.

[McFedries, 2007] McFedries, P. (2007). Technically speaking: All a-twitter. Spectrum, IEEE, 44(10):84-84.

[Millard and Ross, 2006] Millard, D. E. and Ross, M. (2006). Web 2.0: hypertext by any other name? In HYPERTEXT '06: Proceedings of the seventeenth conference on Hypertext and hypermedia, pages 27-30, New York, NY, USA. ACM.

[Muñoz-Avila and Fisher, 2004] Muñoz-Avila, H. and Fisher, T. (2004). Strategic planning for Unreal Tournament bots. Proceedings of AAAI-04 Workshop on Challenges on Game AI. AAAI Press.

[Murnan, 2006] Murnan, C. (2006). Expanding communication mechanisms: theyre not just e-mailing anymore. Proceedings of the 34th annual ACM SIGUCCS conference on User services, pages 267-272.

[of The American Heritage Dictionaries, 2006] of The American Heritage Dictionaries, E., editor (2006). The American Heritage Dictionary of the English Language, Fourth Edition. Houghton Mifflin, 4 edition.

[Pansanato and Fortes, 2005] Pansanato, L. T. E. and Fortes, R. P. M. (2005). Strategies for Filling Out LOM Metadata Fields in a Web-Based CSCL Tool. In LA-WEB '05: Proceedings of the Third Latin American Web Congress, page 187, Washington, DC, USA. IEEE Computer Society.

[Patil and Kobsa, 2005] Patil, S. and Kobsa, A. (2005). Privacy in Collaboration: Managing Impression. Proceedings of the First International Conference on Online Communities and Social Computing, Las Vegas, EUA.

[Paulson, 2004] Paulson, L. (2004). Spam hits Instant Messaging. Computer, 37(4).

[Raygan and Green, 2002] Raygan, R. E. and Green, D. G. (2002). Internet Collaboration: TWiki. In Proceedings of the IEEE SoutheastCon 2002, pages 137-141.

[Reid, 1991] Reid, E. M. (1991). Electropolis: Communication and Community on Internet Relay Chat. 
[Rittinghouse and Ransome, 2005] Rittinghouse, J. W. and Ransome, J. F. (2005). IM Instant Messaging Security. Digital Press.

[Shin et al., 2007] Shin, H., Lee, J., Park, J., Kim, Y., Oh, H., and Lee, T. (2007). A Tactile Emotional Interface for Instant Messenger Chat. Lecture Notes In Computer Science, 4558:166.

[Shiu and Lenhart, 2004] Shiu, E. and Lenhart, A. (2004). How Americans use Instant Messaging. Pew Internet and American Life Project.

[Silva, 2005] Silva, M. A. G. (2005). Uma ferramenta web colaborativa para apoiar a engenharia de requisitos em software livre. Master's thesis, Instituto de Ciências Matemáticas e de Computação - Universidade de São Paulo, São Carlos-SP.

[Snell et al., 2001] Snell, J., Tidwell, D., and Kulchenko, P. (2001). Programming Web Services with SOAP. O'Reilly Media, Inc., 1 edition.

[Sourin, 2004] Sourin, A. (2004). Nanyang technological university virtual campus [virtual reality project]. Computer Graphics and Applications, IEEE, 24(6):6-8.

[Team, 2002] Team, D. S. (2002). Instant Messaging Systems: Cracking the Code. Wiley.

[Tran et al., 2007] Tran, M. H., Yang, Y., and Raikundalia, G. K. (2007). Swim: an alternative interface for msn messenger. In AUIC '0\%: Proceedings of the eight Australasian conference on User interface, pages 55-62, Darlinghurst, Australia, Australia. Australian Computer Society, Inc.

[Viégas et al., 2004] Viégas, F., Wattenberg, M., and Dave, K. (2004). Studying Cooperation and Conflict between Authors with history flow Visualizations. In Proceedings of the Conference on Human Factors in Computing Systems (CHI 2004), pages 575-582.

[Voss, 2005] Voss, J. (2005). Measuring Wikipedia. In Proceedings of the ISSI 2005 (July 24-28,2005).

[Wallace, 2002] Wallace, R. (2002). The Anatomy of ALICE. Intl. LISP conference.

[Wams and van Steen, 2003] Wams, J. and van Steen, M. (2003). Pervasive messaging. Pervasive Computing and Communications, 2003.(PerCom 2003). Proceedings of the First IEEE International Conference on, pages 499-504.

[Wams and van Steen, 2004] Wams, J. and van Steen, M. (2004). Unifying user-to-user messaging systems. Internet Computing, IEEE, 8(2):76-82. 
[Weizenbaum, 1966] Weizenbaum, J. (1966). ELIZA - a computer program for the study of natural language communication between man and machine. Communications of the ACM, 9(1):36-45.

[Wright and Moore, 2003] Wright, W. and Moore, D. (2003). Jabber Developer's Handbook. Sams.

[Wyszynski et al., 2005] Wyszynski, B., Yamanaka, T., and Nakamoto, T. (2005). Recording and reproducing citrus flavors using odor recorder. Sensors and Actuators B, 106(1):388-393.

[Zambiasi and Rabelo, 2007] Zambiasi, S. P. and Rabelo, R. J. (2007). Virtualização de Colaboradores na Manufatura: Um Modelo Baseado em Agent Bots. In SBAI '0\%: Proceedings of the 8th Simpósio Brasileiro de Automação Inteligente. 


\section{Glossário}

CMS Content Management System (Sistema de Gerenciamento de Conteúdo) Software que simplifica a edição e a manutenção de um site, através do uso de templates e um SGBD, de forma transparente ao usuário.

Emoticon também conhecido com smiley, é um termo que se refere a utilização de uma combinação de caracteres para indicar o contexto emocional do autor em determinado texto ou para tentar eliminar ambiguidades na interpretação do texto. Os primeiros emoticons foram :-) feliz e :-( triste, criados em 1982.

IRC Internet Relay Chat (Bate-papo Transmitido pela Internet) é um protocolo de comunicação utilizado na Internet, basicamente para bate-papo e troca de arquivos, permitindo conversas em grupo ou privada, sendo o predecessor dos MIs atuais.

MI Mensageiro Instantâneo (Instant Messenger) é uma forma de comunicação em tempo real entre duas ou mais pessoas, baseada em texto. Ex: $\mathrm{MSN}^{2}, \mathrm{ICQ}^{3}$ e GoogleTalk ${ }^{4}$

RSS Padrão XML utilizado para indicar atualizações em conteúdos.

SGBD (Sistema Gerenciador de Banco de Dados) um conjunto de softwares responsáveis pelo gerenciamento de uma base de dados, normalmente através de comandos SQL.

SMS Short Message Service (Serviço de Mensagens Curtas) é um serviço disponível em telefones celulares digitais que permite o envio de mensagens curtas de texto entre estes equipamentos e entre outros dispositivos.

\footnotetext{
${ }^{2}$ http://get.live.com/messenger/overview

${ }^{3}$ http://www.icq.com/

${ }^{4}$ http://www.google.com/talk
} 
SPIM SPAM for Instant Messaging envio de mensagens indesejadas por meio de mensageiros instantâneos. São utilizados usuários fictícios que, conforme instruções recebidas, enviam milhares de mensagens para a lista de contatos do usuário.

SQL Structured Query Language (Linguagem de Questões Estruturadas) é uma sintaxe usada para a definição e manipulação de dados em um banco de dados relacional. Desenvolvido pela IBM em 1970, tornou-se um padrão industrial para linguagens de consulta na maioria dos SGBDs.

VoIP Voice over Internet Protocol (Voz sobre IP) também conhecido como Telefonia IP ou telefonia pela Internet, é o roteamento de conversas de voz através da Internet ou qualquer outra rede baseada no protocolo IP. Existem diversos aplicativos que permitem a utilização de VoIP, como Skype ${ }^{5}$, Gizmo Project ${ }^{6}$ e GoogleTalk ${ }^{7}$.

WYSIWYG What You See Is What You Get em português significa "O que você vê é o que você terá". Significa que os resultados gerados por um programa serão exatamente como o conteúdo que está sendo apresentado na tela.

\footnotetext{
${ }^{5}$ http://www.skype.com/

${ }^{6} \mathrm{http}: / /$ gizmoproject.com/

${ }^{7} \mathrm{http}: / /$ www.google.com/talk
} 


\section{Ferramentas de Publicação na Web: um estudo de caso}

Para a análise da popularização de determinadas ferramentas de publicação na web, são apresentados gráficos que foram gerados e contêm a quantidade relativa de buscas realizadas no buscador Google ${ }^{1}$, em um determinado período de tempo ${ }^{2}$. A ferramenta utilizada para a construção chama-se Google Trends $^{3}$, e deve-se levar em conta a imprecisão do método, pois além de ocorrem diversas aproximações, a ferramenta encontra-se em fase de desenvolvimento e contém dados de apenas um buscador.

Vale notar que são números relativos ao total de buscas realizadas, não sendo necessário, portanto, considerar o crescimento geral da Internet ou da utilização do buscador. Apenas para confirmar essa afirmação, o autor decidiu realizar uma busca por termos comuns, como "internet" ou "web", para que possa ser constatado que o aumento nas outras buscas não provém, provavelmente, de um aumento na utilização do buscador Google. Como pode-se notar na Figura A.1, o número de buscas tem pequena queda, o que indica que mesmo com o aumento de usuários na Internet e da utilização do buscador, a quantidade de buscas relativas por um determinado termo não precisa necessariamente aumentar.

\footnotetext{
${ }^{1}$ http://www.google.com

${ }^{2}$ Os dados coletados provém das buscas realizadas de janeiro/2004 a janeiro/2009

${ }^{3}$ http://www.google.com.br/trends
} 
APÊNDICE A. FERRAMENTAS DE PUBLICAÇÃO NA WEB: UM ESTUDO DE CASO

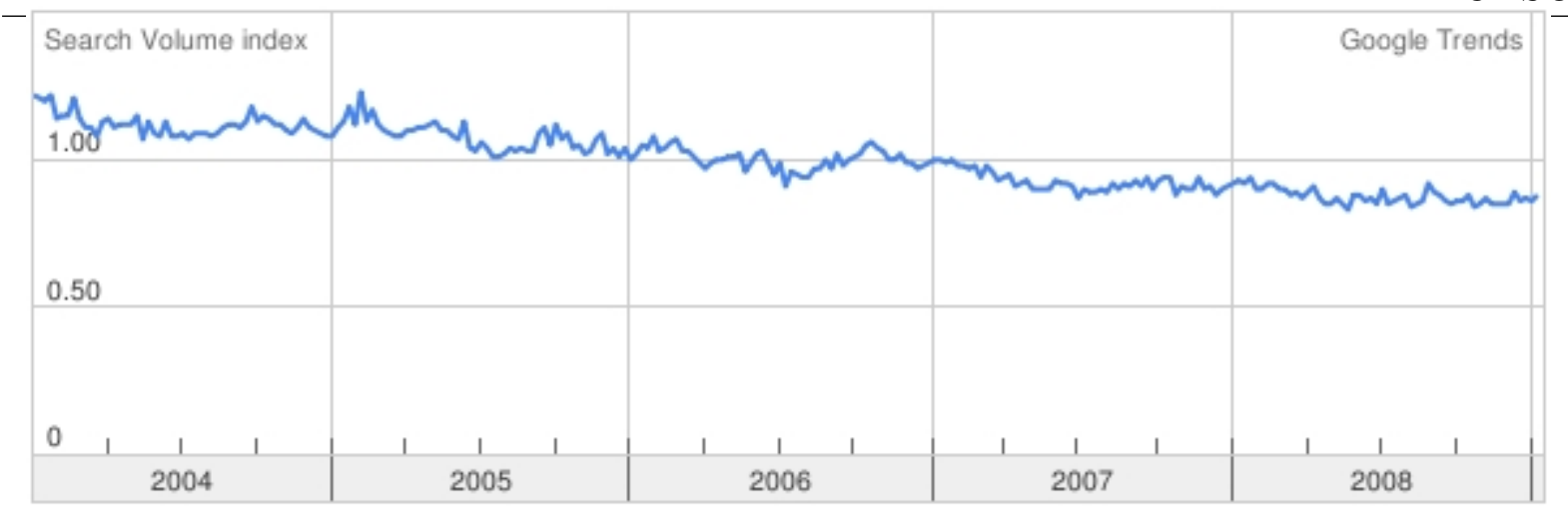

Figura A.1: Buscas pelo termos Internet ou web

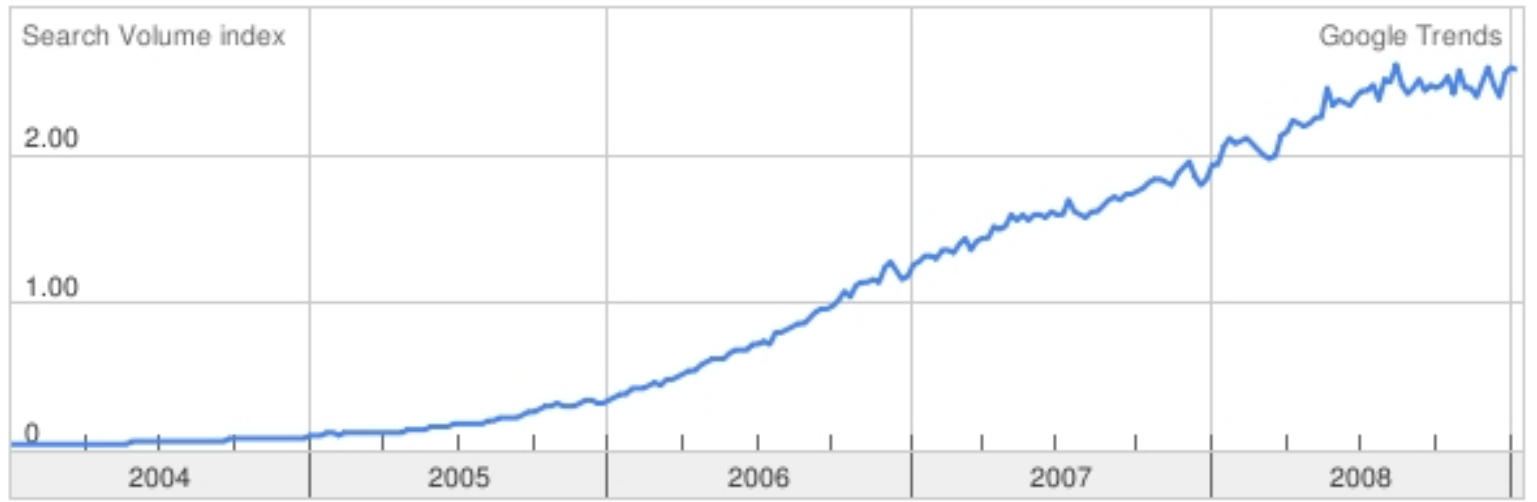

Figura A.2: Popularidade das wikis

Cada gráfico apresentado exibe no eixo $x$ o período em que foram realizadas as buscas, e o índice informado no eixo $y$ indica o volume de buscas realizadas, sendo atribuído o valor 1.0 à média de buscas do período pesquisado.

\section{- Wiki}

- Descrição da ferramenta: encontra-se na Seção 2.3.

- String de busca: (wikiwikiweb | wikiwikiwebs | wiki | wikis)

- Análise: pode-se notar um aumento contínuo e acentuado no número de buscas pelos termos referentes a wikis, conforme mostra a Figura A.2.

\section{- Blog}

- Descrição da ferramenta ${ }^{4}$ : uma página da Web, editada via browser, cuja estrutura permite a atualização rápida a partir da adição de trechos de conteúdo, conhecidos como artigos ou posts.

- String de busca: (blog | blogs | weblog | weblogs)

\footnotetext{
${ }^{4}$ http://pt.wikipedia.org/wiki/Weblog
} 
APÊNDICE A. FERRAMENTAS DE PUBLICAÇÃO NA WEB: UM ESTUDO DE

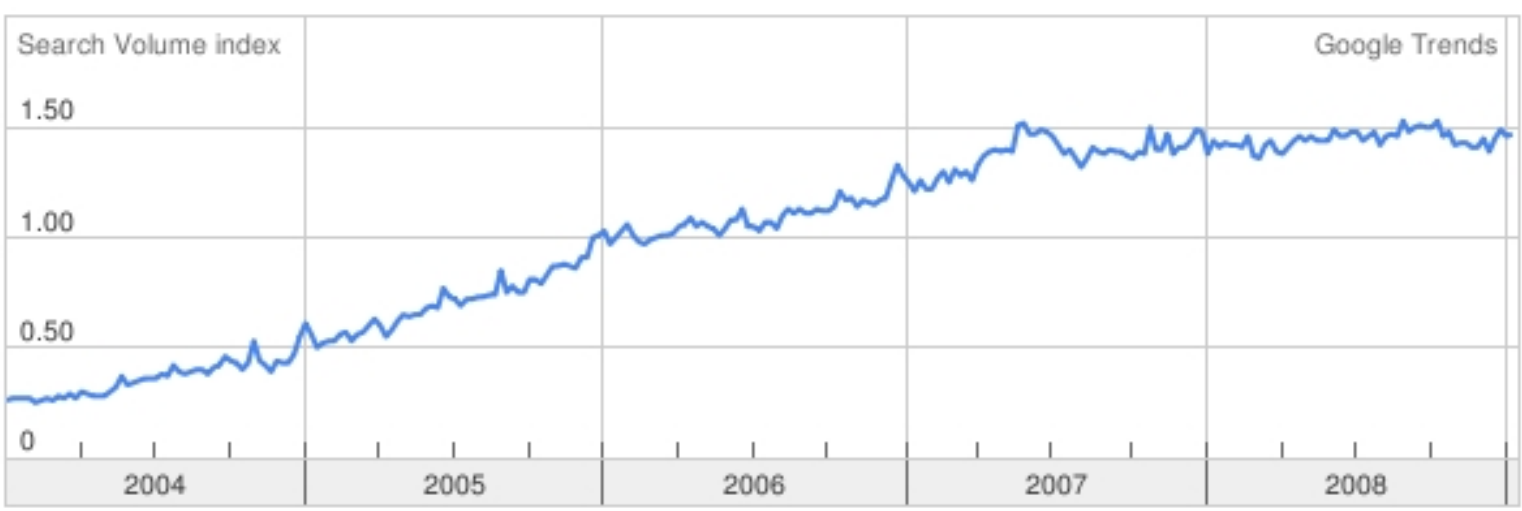

Figura A.3: Popularidade dos blogs

- Análise: as buscas relativas a blogs tiveram crescimento praticamente constante de 2004 a meados de 2007, mantendo-se estável até início de 2009, como mostra a Figura A.3.

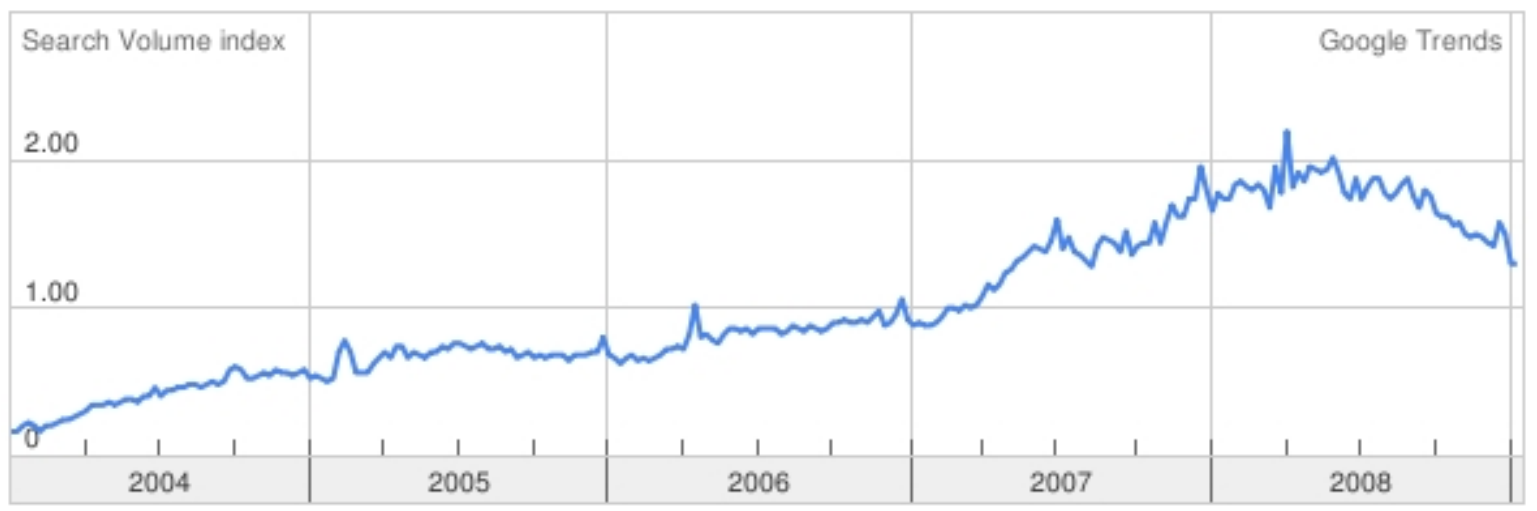

Figura A.4: Popularidade dos fotologs

\section{- Fotolog}

- Descrição da ferramenta ${ }^{5}$ : também conhecida como photoblog (em inglês), tem características semelhantes aos blogs, como a facilidade de disponibilização de conteúdo, embora tenha seu foco na publicação de imagens, ao invés de texto.

- String de busca: (photoblog | fotoblog | fotolog | fotologs)

- Análise: como mostra a Figura A.4, as buscas por fotolog tiveram um leve crescimento até o início de 2007, seguindo-se um crescimento mais acentuado até meados de 2008 e uma queda até o início de 2009.

- $\operatorname{Vlog}$

\footnotetext{
${ }^{5}$ Baseada em http://en.wikipedia.org/wiki/Photoblog
} 


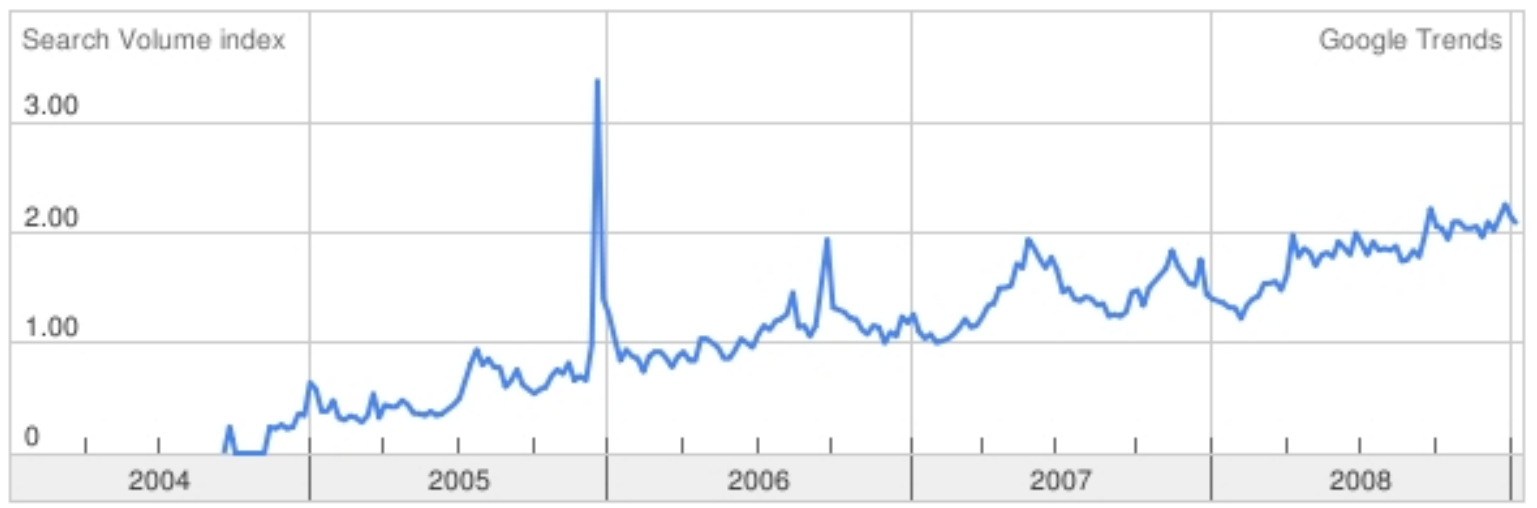

Figura A.5: Popularidade dos vlogs

- Descrição da ferramenta: serviço semelhante aos blogs, que tem como foco, entretanto, a disponibilização de vídeo.

- String de busca: (vlog | videolog | videoblog)

- Análise: como mostra a Figura A.5, o termo era praticamente desconhecido em 2004. As buscas referentes a vlog tiveram aumento acentuado e constante até início de 2009. O pico no final de 2005 refere-se a algum fato desconhecido pelo autor deste trabalho, ocorrido entre 10 e 25 de Dezembro de 2005.

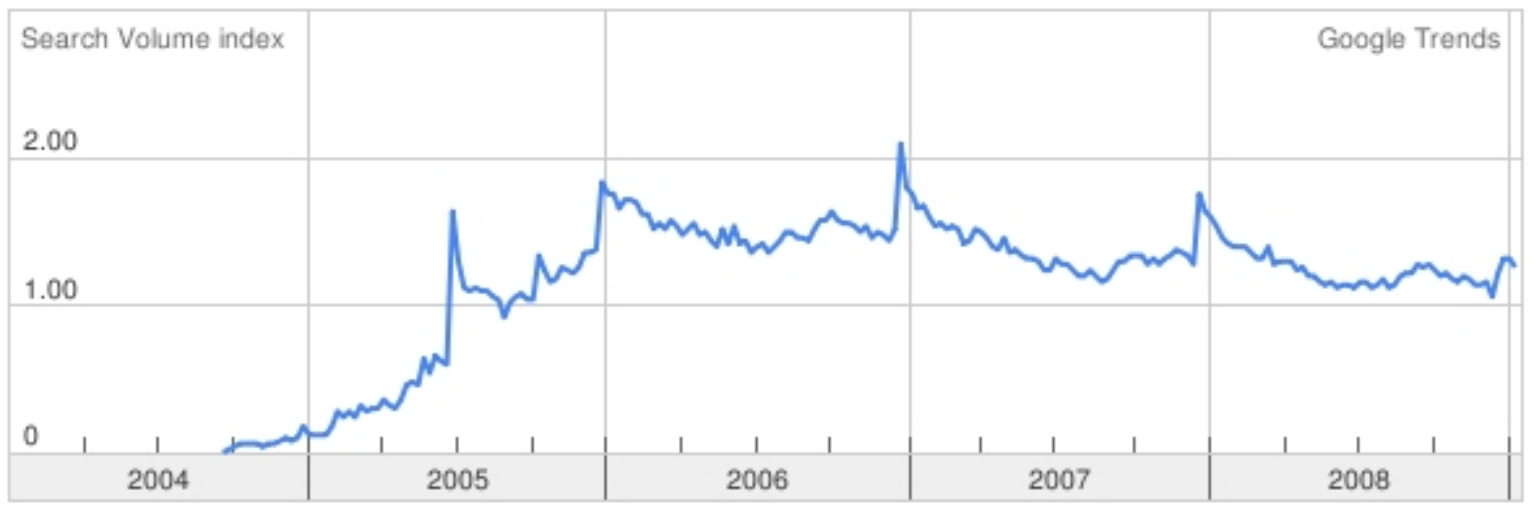

Figura A.6: Popularidade dos podcasts

\section{- Podcast}

- Descrição da ferramenta: serviço semelhante aos blogs, que tem como foco, entretanto, a disponibilização de áudio.

- String de busca: (podcast | podcasts)

- Análise: como nota-se na Figura A.6, o termo podcast, assim como no caso do termo vlog, era praticamente desconhecido em 2004. Durante 2005 obteve grande crescimento, caindo ligeiramente de 2006 ao início de 2009. 


\section{Comparação das ferramentas analisadas}

As cinco ferramentas ${ }^{6}$ analisadas anteriormente podem ser comparadas na Figura A.7. Pode-se observar que os termos relacionados a blogs e wikis obtiveram um volume visivelmente maior de buscas do que fotologs, vlogs e podcasts. Ainda é possível notar que a curva de popularização de wikis está em ascendência visivelmente maior do que as demais curvas.

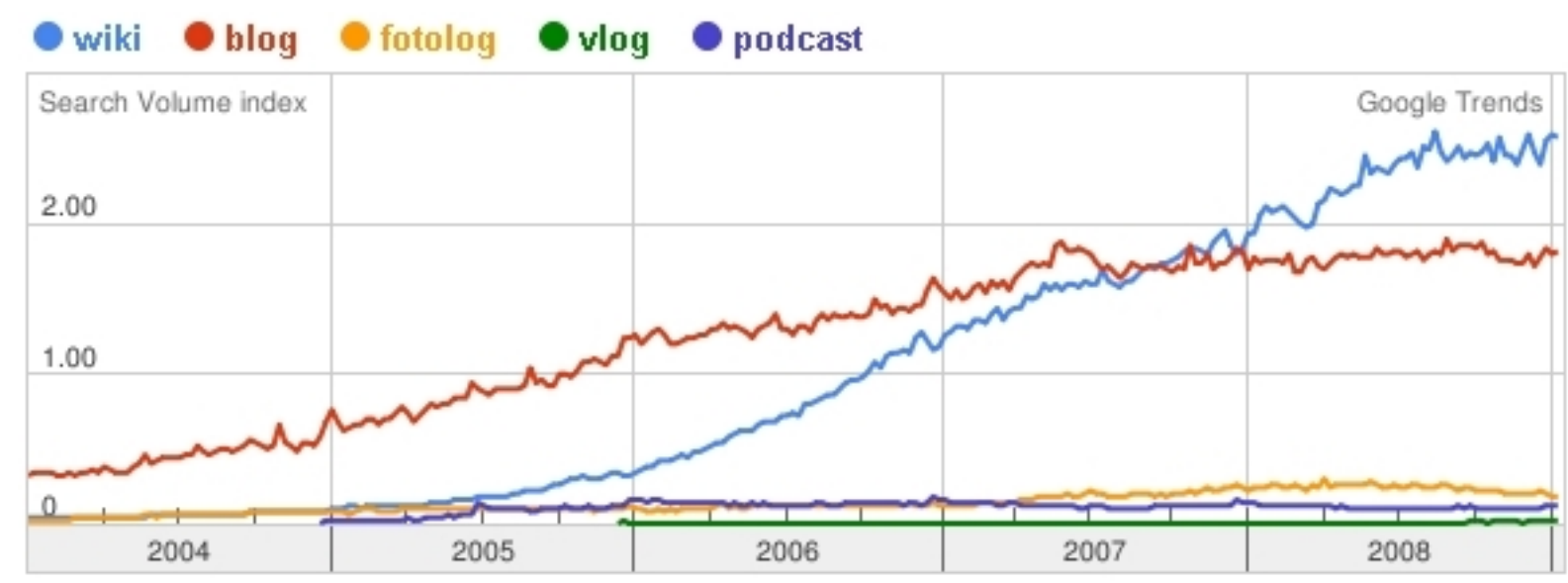

Figura A.7: Comparação das cinco ferramentas analisadas weblogs), (photoblog | fotoblog | fotolog | fotologs), (vlog | videolog | videoblog), (podcast | podcasts)". 



\section{Proposta de Taxonomia para}

\section{Ferramentas de Comunicação na Web}

Recentemente, observa-se que diversas ferramentas de comunicação pela Internet combinam funcionalidades entre si, para atender as crescentes demandas por parte dos usuários. Essas combinações sugerem questionamentos sobre a classificação e a comparação de tais ferramentas. Nesse contexto, uma proposta de taxonomia para as ferramentas de comunicação que ocorrem por meio da Internet é apresentada. A proposta é descrita tendo como referencial taxonomias pré-existentes, bem como a análise das ferramentas atuais para identificação das características relevantes.

\section{INTRODUÇÃO}

Pode-se perceber, principalmente nos últimos anos uma tendência de que diversas ferramentas de comunicação pela Internet mesclam características de ferramentas distintas. É possível notar diversas ferramentas populares que realizam combinação de conceitos, tais como: sistemas de email com características de mensageiros instantâneos (MIs), MIs com recursos VoIP e aplicativos VoIP com características de MIs, podendo ser citados Gmail ${ }^{1}$, $\mathrm{MSN}^{2}$ e Skype ${ }^{3}$, respectivamente.

\footnotetext{
${ }^{1}$ http://www.gmail.com

${ }^{2} \mathrm{http}: / /$ messenger.live.com

${ }^{3} \mathrm{http}: / /$ www.skype.com
} 
Nesse contexto, no qual ferramentas híbridas estão cada vez mais disseminadas, surgem, então, três questões relevantes: a) como definir o tipo de uma ferramenta, isto é, como descobrir a qual classe pertence determinada implementação? b) como comparar duas ferramentas, visando obter um valor objetivo que expresse o quanto são parecidas? c) como obter um índice que expresse o grau de inovação de determinada ferramenta?

A primeira questão é relevante pois a classificação das ferramentas nos ajuda a padronizar os termos e classes utilizados, além permitir o acompanhamento da evolução das ferramentas pertencentes a uma mesma classe, com o passar do tempo. A segunda questão é importante pois a comparação de ferramentas é útil para desenvolvedores que visão tornar sua implementação o mais próximo de outra existente, isto é, os requisitos poderem ser reutilizados a partir de um determinado software cujos requisitos já tenham sidos definidos. Por fim, a última questão está relacionada com um índice que expresse o quanto uma ferramenta é inovadora, isto é, o quanto seus recursos superam outra implementação pré-existente, fornecendo uma métrica importante em ambientes competitivos.

Este estudo apresenta uma proposta de taxonomia para as ferramentas de comunicação que ocorrem por meio da Internet e um método para sua utilização, considerando respostas para os questionamentos elicitados. A seguir, são descritos trabalhos relacionados com a elaboração de classificações para as ferramentas de comunicação, utilizados como base para este trabalho. Com base nesse levantamento dos trabalhos relacionados, ; é apresentado um aperfeiçoamento e respectiva atualização das classificações estudadas, acrescentando exemplos relevantes na forma de instâncias das classes definidas, demonstrando como a taxonomia proposta pode ser utilizada nos contextos de classificação, comparação e inovação; por fim, algumas considerações finais concluem a proposta de atualização de taxonomia apresentada.

\section{TRABALHOS RELACIONADOS}

A seguir são resumidos três trabalhos da literatura, relacionados com a criação de taxonomias para as formas de comunicação.

\section{Long e Baecker}

No trabalho de Long e Baecker [Long and Baecker, 1997] foram analisadas as principais ferramentas de comunicação utilizadas na Internet da época, 1997, e foi elaborada uma classificação das mesmas, expressa como uma taxonomia. Nesta taxonomia foram definidos seis atributos ${ }^{4}$, que estão listados na Tabela B.1.

\footnotetext{
${ }^{4}$ Os termos utilizados foram traduzidos e padronizados para facilitar a comparação entre as diversas taxonomias apresentadas
} 


\begin{tabular}{|l|l|}
\hline Atributo & Valores \\
\hline 1. Estilo & Unicast, Multicast, Broadcast \\
\hline 2. Audiência & Restrita, Global \\
\hline 3. Comunicação & Síncrona, Assíncrona \\
\hline 4. Mídias & Texto, Imagem, Áudio, Vídeo, Avatar \\
\hline 5. Inicialização & Endereço, Replicação, Servidor, URL, Máquina \\
\hline 6. Histórico & Sim, Não \\
\hline
\end{tabular}

Tabela B.1: Atributos da taxonomia de Long e Baecker

Essa taxonomia também estabelece 21 classes de ferramentas, sendo definidos os valores dos atributos para cada ferramenta. Entretanto, foram observadas propriedades que reduzem a expressividade da taxonomia:

Vinculada ao Período Corrente: fazem aproximadamente dez anos que a taxonomia foi definida e diversas outras formas de comunicação tornaram-se populares, como os blogs, que não foram contemplados pelo estudo da época. Além disso, os termos utilizados também poderiam ser atualizados, como é o caso de hipertexto colaborativo, que poderia ser renomeado para wiki. Também há ferramentas que estão em contínuo desuso, o que encoraja a

Definida sem distinção clara entre classes e instâncias: dos 21 tipos de ferramentas definidos pela taxonomia, três são instâncias, isto é, foi criada uma classe cujo nome é o mesmo de uma ferramenta. Essa característica tende a tornar a classificação obsoleta em pouco tempo, pois assim que uma ferramenta similar for desenvolvida, a taxonomia deverá ser atualizada. É o caso de PowWow, um dos primeiros clientes de MI: há uma classe com esse nome, mas nenhuma que se refira a um MI genérico.

\section{Wams e van Steen}

O trabalho de Wams e van Steen[Wams and van Steen, 2003][Wams and van Steen, 2004] também consistiu na criação de uma taxonomia, criada para organizar os Sistemas de Mensagens Eletrônicas (EMS). Foram definidos quatro atributos, que estão listados na Tabela B.2.

\begin{tabular}{|l|l|}
\hline Atributo & Valores \\
\hline 1. Estilo & Unicast, Multicast, Broadcast \\
\hline 2. Audiência & Restrita, Global \\
\hline 3. Tempo & Imediato, Impermanente, Permanente \\
\hline 4. Direção & Unidirecional, Bidirecional \\
\hline
\end{tabular}

Tabela B.2: Atributos da taxonomia de Wams e van Steen 
Essa taxonomia, entretanto, não tinha como objetivo classificar todas as formas de comunicação do escopo analisado, limitando-se apenas em citar cinco exemplos de classes: fax, newsgroup, email, IM e blog.

\section{Murnam}

O artigo de Murnam[Murnan, 2006] divide as formas de comunicação, digitais ou não, em três grandes grupos: de retorno esperado, de retorno não esperado e as formas que são uma combinação dos dois grupos anteriores. Como ferramentas de retorno esperado foram citadas: email, MI, chat, SMS, VoIP e celular (voz). Os exemplos de ferramentas de retorno não esperado foram páginas web, wikis e livros impressos. As formas de comunicação de uso combinado citadas foram os blogs e as redes de relacionamento, já que estes possuem formulários para posts como forma de resposta ao conteúdo disponibilizado. Além deste atributo, foram definidos outros dois, que estão listados na Tabela B.3.

\begin{tabular}{|l|l|}
\hline Atributo & Valores \\
\hline 1. Retorno Esperado & Sim, Não, Combinado \\
\hline 2. Recebimento da Informação & por imposição, por Solicitação \\
\hline 3. Tipo de Informação & Geral, Específica \\
\hline
\end{tabular}

Tabela B.3: Atributos da taxonomia de Murnam

O trabalho de Murnam é relevante pois é recente, de 2006, embora tenha focado a definição dos atributos na utilidade da forma de comunicação, isto é, a taxonomia foi criada baseando-se apenas nas características da informação trocada e não em questões relativas à interação. Esse fato faz com que a taxonomia torne-se bastante genérica e não suficiente para as necessidades deste trabalho, explicitadas nos questionamentos apresentados.

\section{PROPOSTA DE TAXONOMIA}

Este trabalho visa reduzir os pontos que enfraquecem as taxonomias citadas, unindo características positivas das três e atualizando os termos e instâncias das classes definidas.

A criação da taxonomia seguiu os seguintes critérios:

- Os termos utilizados devem ser correspondentes aos da UML, visando manter a consistência entre os conceitos já conhecidos na área de ciência da computação. Assim, o termo classe deve ser utilizado, ao invés de tipo, ferramenta ou categoria. O mesmo ocorre para atributo, em detrimento de propriedade ou característica. Por fim, cada implementação que corresponda a determinada classe será denominada instância ao invés de programa ou aplicativo, por exemplo. 
- O nome de uma classe não poderá ser igual ao nome de uma instância, mesmo que exista apenas uma instância daquela classe, visando reduzir as dificuldades encontradas na taxonomia de Long e Baecker [Long and Baecker, 1997].

- Deve ser definido o menor número possível de atributos, visando manter a taxonomia sem redundâncias. Por exemplo: não faz sentido acrescentar o atributo "possibilita comunicação remota" à taxonomia, já que o escopo das comunicações restringe-se apenas à web, e todas as classes teriam o valor "sim", isto é, todas podem ser remotas.

- As classes devem ser definidas de acordo com a popularidade das ferramentas, já que esta é uma classificação não exaustiva e que visa classificar apenas as ferramentas mais conhecidas.

Após a análise das três taxonomias apresentadas, foi construída uma nova proposta de taxonomia, considerando as características dos trabalhos estudados, resultando na definição de uma nova taxonomia, constituída de 7 atributos e 17 classes, que estão descritos a seguir.

\section{Atributos}

Os 7 atributos da taxonomia estão listados na Tabela B.4, bem como os possíveis valores para cada atributo. Nota-se que os valores não são necessariamente mutuamente excludentes, isto é, mais de um valor pode ser atribuído para um atributo. Por exemplo, uma determinada instância (implementação de ferramenta) pode permitir tanto a comunicação síncrona como assíncrona, tendo, dessa forma, ambos os valores.

\begin{tabular}{|l|l|}
\hline Atributo & Valores \\
\hline 1. Comunicação & Síncrona, Assíncrona \\
\hline 2. Estilo & Unicast, Multi., Broad., Colab. \\
\hline 3. Mídias & Text., Imag., Áud., Víd., Outras \\
\hline 4. Restrição & Envio, Recebimento \\
\hline 5. Retorno Esperado & Sim, Não \\
\hline 6. Recebimento Solicitado & Sim, Não \\
\hline 7. Editável & Sim, Não \\
\hline
\end{tabular}

Tabela B.4: Atributos da taxonomia proposta

Todos os atributos das taxonomias estudadas foram analisados, sendo mantidos apenas os que foram julgados relevantes pelo autor deste trabalho. Além disso, um atributo foi adicionado à taxonomia, mesmo não tendo sido encontrado em nenhuma das taxonomias anteriores, sendo este o editável, isto é, a possibilidade de uma mensagem ser alterada após seu envio. A Tabela B.5 contém a relação dos atributos considerados na presente proposta e qual a taxonomia de origem. 


\begin{tabular}{|l|c|c|c|}
\hline Atributo & Long & Wams & Murnam \\
\hline 1. Comunicação & $\mathrm{X}$ & & \\
\hline 2. Estilo & $\mathrm{X}$ & $\mathrm{X}$ & \\
\hline 3. Mídias & $\mathrm{X}$ & & \\
\hline 4. Restrição & $\mathrm{X}$ & $\mathrm{X}$ & \\
\hline 5. Retorno Esperado & & & $\mathrm{X}$ \\
\hline 6. Recebimento Solicitado & & & $\mathrm{X}$ \\
\hline 7. Editável & & & \\
\hline
\end{tabular}

Tabela B.5: Origem dos atributos

A justificativa de consideração de cada atributo e seus valores é apresentada a seguir:

- Comunicação - Síncrona (S): os participantes do diálogo precisam trocar mensagens durante o mesmo período de tempo, isto é, estar online simultaneamente. Ex: chat, MI, vídeo conferência. Assíncrona (A): não precisam estar online simultaneamente. Ex: email, página web.

- Estilo - Unicast (U): também conhecida como comunicação 1-1, destina-se ao diálogo privado entre apenas um emissor e um receptor. Ex: email, MI. Multicast (M): comunicação entre um emissor e vários receptores pré-definidos. Ex: lista de email, chat. Broadcast (B): também conhecida como 1-n, consiste na disponibilização de uma mensagem para qualquer receptor que queira recebê-la. Ex: página web, rádio online, wiki. Colaborativo (C): este valor indica se os estilos anteriores permitem a colaboração, isto é, permitem que cada mensagem seja composta por mais de um remetente. Assim, uma comunicação no estilo broadcast colaborativo consiste na disponibilização de uma mensagem composta por mais de uma pessoa para qualquer destinatário. Ex: wiki.

- Mídias - especifica quais mídias são utilizadas na forma de comunicação. Os valores podem ser texto (T) (email, chat), imagem (I) (página web, whiteboard), áudio (A) (aplicativo VoIP, rádio online), vídeo (V) (vídeo conferência) e outros ( $\mathbf{O})$.

- Restrição - Envio (E): informa se há algum tipo de controle sobre quem pode enviar/publicar mensagens, como: fazer parte de uma lista pré-definida, possuir login e senha, ser convidado para participar do diálogo, etc. Ex. com a restrição: $M I$, blog. Ex. sem a restrição: email, wiki. Recebimento (R): informa se há algum tipo de controle sobre quem pode receber/ler determinadas mensagens. Ex. com a restrição: email, aplicativo VoIP. Ex. sem a restrição: página web, rádio online.

- Retorno Esperado - Informa se o remetente da mensagem espera obter retorno de algum dos receptores, isto é, uma mensagem de resposta. Ex. de retorno esperado: email, MI. Ex. de retorno não esperado: rádio online, página web. 
- Recebimento Solicitado - Informa se, após ter iniciado o diálogo (estabelecimento de uma sessão), o participante precisa requisitar o recebimento de novas mensagens ou se estas já são automaticamente enviadas para ele. Ex. de recebimento solicitado: página web, blog. Ex. de recebimento não solicitado: email, $M I$.

- Editável - Este atributo informa se uma mensagem pode ser alterada após seu envio ou publicação. Foi o único atributo definido pelo autor deste trabalho e é relevante porque, ao tentar criarmos uma instância de uma classe com este atributo definido como "falso", experimentamos formas de comunicação pouco convencionais. Por exemplo: o trabalho de Eto et al. [Eto et al., 2005] consistiu na criação de uma lista de emails que permite a edição de mensagens já enviadas, expondo vantagens e desvantagens obtidas com a alteração deste atributo, já que as listas convencionais não permitem a edição das mensagens. Ex. de editáveis: página web, blog. Ex. de não editáveis: chat, email.

Vale notar que algumas alterações foram realizadas nos atributos provenientes das taxonomias estudadas. Foi adicionado o valor colaborativo ao atributo estilo, devido ao modo peculiar de funcionamento das wikis. O valor avatar $^{5}$ foi renomeado para outros, no atributo mídias, para agrupar qualquer outro tipo de mídia, inclusive as pouco convencionais, como as relacionadas com o olfato [Wyszynski et al., 2005]. O atributo audiência (restrita ou global) foi redefinido para permitir especificar se a restrição encontra-se do lado do remetente ou do destinatário da mensagem.

É importante notar que alguns atributos foram descartados porque estão fortemente relacionados com características da implementação de determinadas ferramentas ou simplesmente não são relevantes do ponto de vista do usuário. Este é o caso dos atributos inicialização, histórico, tempo, direção e tipo de informação.

\section{Classes}

Após a definição dos atributos da taxonomia, o autor deste trabalho passou para a etapa de definição das classes, visando englobar as ferramentas de comunicação mais populares disponíveis na Internet atual. Para cada classe, foram definidos os valores dos atributos, com base no mínimo que uma instância (implementação) precise ter para que seja considerada desta classe. Por exemplo: um cliente de email pode ou não permitir a utilização de imagens, mas deve permitir a utilização de texto. Dessa forma, o atributo mídia, da classe email, recebe o valor texto ao invés de texto e imagem.

Ao término desta etapa foram definidas 17 classes e os valores de seus atributos, dispostos na Figura B.1.

\footnotetext{
${ }^{5}$ Representação de um participante em um diálogo, em ambientes virtuais
} 


\begin{tabular}{|c|c|c|c|c|c|c|c|c|c|c|c|c|c|}
\hline \multirow{2}{*}{$\mathbf{N}$} & \multirow{2}{*}{ Classe } & \multicolumn{2}{|c|}{ Comun. } & \multicolumn{3}{|c|}{ Estilo } & \multicolumn{2}{|r|}{ Mídias } & \multicolumn{2}{|c|}{ Restrição } & \multirow{2}{*}{$\begin{array}{l}\text { Ret. } \\
\text { Esp. }\end{array}$} & \multirow{2}{*}{$\begin{array}{c}\text { Rec. } \\
\text { Sol. }\end{array}$} & \multirow{2}{*}{ Edit. } \\
\hline & & $\mathrm{S}$ & $A$ & $\mathrm{U}$ & $M$ & B C & & $=1 \mathrm{AVO}$ & $E$ & $\mathrm{R}$ & & & \\
\hline 1 & Email & & $x$ & $\mathrm{x}$ & & & $x$ & & & $x$ & $x$ & & \\
\hline 2 & Lista de Email & & $x$ & & $x$ & & $x$ & & & $x$ & $x$ & & \\
\hline 3 & Página Web & & $x$ & & & $x$ & $x$ & & $\mathrm{x}$ & & & $\mathrm{x}$ & $x$ \\
\hline 4 & Fórum & & $x$ & & & $x$ & $x$ & & $\mathrm{x}$ & & $x$ & $\mathrm{x}$ & \\
\hline 5 & Blog & & $x$ & & & $x$ & $x$ & & $\mathrm{x}$ & & & $x$ & $x$ \\
\hline 6 & Fotolog & & $x$ & & & $x$ & & $x$ & $x$ & & & $x$ & $x$ \\
\hline 7 & Podcast & & $x$ & & & $x$ & & $x$ & $x$ & & & & $x$ \\
\hline 8 & Videolog & & $\mathrm{x}$ & & & $x$ & & $x$ & $x$ & & & & $x$ \\
\hline 9 & Wiki & & $x$ & & & $x \quad x$ & $x$ & & & & & $x$ & $x$ \\
\hline 10 & MI & $x$ & & $x$ & & & $x$ & & $x$ & $x$ & $x$ & & \\
\hline 11 & Whiteboard & $\mathrm{x}$ & & $\mathrm{x}$ & & & & $x$ & $x$ & $x$ & $x$ & & $x$ \\
\hline 12 & VolP & $x$ & & $x$ & & & & $x$ & $x$ & $x$ & $x$ & & \\
\hline 13 & Video. Conf. & $x$ & & $x$ & & & & $x$ & $x$ & $x$ & $x$ & & \\
\hline 14 & Chat & $\mathrm{x}$ & & & $x$ & & $x$ & & $x$ & $\mathrm{x}$ & $x$ & & \\
\hline 15 & Amb. Virtual & $\mathrm{x}$ & & & $x$ & & $x$ & $\mathbf{x}$ & $x$ & $x$ & $x$ & & \\
\hline 16 & Rádio Online & $x$ & & & & $x$ & & $x$ & $\mathrm{x}$ & & & & \\
\hline 17 & TV Online & $x$ & & & & $x$ & & $x$ & $x$ & & & & \\
\hline
\end{tabular}

Figura B.1: Taxonomia definida

\section{Instâncias}

Os atributos da classe têm a função de indicar se determinada instância possui o mínimo de características necessárias para ser classificada como tal. Como exemplo, temos a instância $M S N$, um cliente de MI. É fácil perceber que cumpre todos os requisitos que um MI deve ter: permite a comunicação sincronizada e unicast via texto, possui restrição de envio e recebimento e tem retorno esperado. Um outro exemplo é a instância Wikipédia ${ }^{6}$ : cumpre os requisitos para que seja instância da classe wiki, pois permite a comunicação assíncrona por broadcast colaborativo de texto, tendo recebimento solicitado, e é editável.

A seguir, são listados exemplos de instâncias para as classes definidas: Email Yahoo!Mail, Hotmail; Lista de Email - Yahoo!Grupos, Google Grupos; Página Web qualquer página web; Fórum - Yahoo! Respostas, Google Answers; Blog - Wordpress, Blogspot; Fotolog - Flickr, Picasaweb; Podcast - Podcast.com, Podcast.net; Videolog - YouTube, Google Vídeo; Wiki - Wikipédia, Pbwiki; MI - MSN Messenger, Gtalk; Whiteboard - Microsoft NetMeeting, PaintChat; Aplicativo VoIP - Skype, MSN Messenger; Vídeo conferência - Skype, MSN Messenger; Chat - Bate-papo UOL, Terra Chat; Ambiente virtual - Second Life, World of Warcraft; Rádio online - Rádio USP, Antena 1; TV online - Joost, ChannelChooser.

\footnotetext{
${ }^{6}$ http://pt.wikipedia.com
} 


\section{Utilização da Taxonomia}

Pode-se utilizar a taxonomia proposta para realizar a classificação de ferramentas, isto é, definir de que tipo é determinada ferramenta, além de verificar se têm o mínimo de recursos necessários para que faça parte de determinada classe. Para realizar a classificação, basta comparar os valores dos atributos da classe com a ferramenta analisada. A classe que obtiver o maior número de valores de atributos iguais aos da implementação será o resultado da classificação. Dessa forma, pode-se classificar ferramentas confrontando-se com padrões, mesmo que sejam implementações híbridas, isto é, que misturem características de classes distintas.

Além disso, é possível realizar comparações do tipo instância-classe, que retornará o quão próxima uma ferramenta está de determinada classe. Assim, é útil ao desenvolvedor do software, pois informa quais requisitos já foram cumpridos e quais ainda devem ser atendidos. Uma outra forma de comparação é a instância-instância, que irá indicar o quanto duas ferramentas são semelhantes. Assim, pode ser útil para desenvolvedores que têm por objetivo "clonar" outra implementação pré-existente, apropriando-se de seus requisitos de software.

Por fim, a taxonomia também pode ser utilizada para a análise do grau de inovação de determinada ferramenta. Sabemos que uma instância de uma classe possui todos os valores dos atributos iguais aos da classe que pertence. A inovação ocorrerá quando tiver recursos a mais, isto é, quando a implementação superar a própria classe a que pertence. Este índice tem relevância principalmente na indústria de software, pois é uma maneira objetiva de verificar se um produto está ou não cumprindo metas relacionadas com inovação.

\section{CONCLUSÃO}

A taxonomia proposta visa ser utilizada para a obtenção de respostas para os questionamentos apresentados. Para a definição do tipo de uma ferramenta, isto é, para classificar determinada implementação, basta comparar os atributos da ferramenta com os atributos de cada classe. Além disso, a taxonomia proposta permite as comparações instância-classe e instância-instância, isto é, avaliar o quanto uma implementação está próxima de determinado padrão e o quanto duas implementações são parecidas. Por fim, a taxonomia também pode ser utilizada para a obtenção de um índice que expresse o quanto uma ferramenta é inovadora em relação a um padrão.

Neste trabalho, foram apresentadas três taxonomias existentes na literatura e sugestões de como se pode derivar nova taxonomia a partir de pré-existentes. Além disso, foi 
disponibilizada a taxonomia proposta. Por fim, este trabalho também apresentou um modo de utilização de taxonomias em três contextos, em resposta aos questionamentos previamente elicitados: classificação, comparação e grau de inovação.

Em relação a trabalhos futuros, podemos citar a avaliação da relevância da inclusão dos seguintes atributos à taxonomia: mensagem criptografada, múltiplos idiomas, ciência de presença dos destinatários e lista de receptores. Além disso, o escopo da taxonomia poderia ser aumentado de forma sistemática, isto é, um estudo sistematizado das implementações existentes possibilitaria a criação de uma taxonomia que contemplasse todos os tipos de ferramentas atuais. 